\title{
MULTI-SCALE FACTORS RELATED TO ABUNDANCE OF BATS AND INSECT PREY IN SAVANNAS, WOODLANDS, AND FORESTS IN THE OZARK HIGHLANDS, USA
}

\section{A Dissertation}

Presented to

The Faculty of the Graduate School

At the University of Missouri-Columbia

In Partial Fulfillment

Of the Requirements for the Degree

Doctor of Philosophy

by

KATHRYN MARIE WOMACK

Dr. Frank R. Thompson III, Dissertation Supervisor

MAY 2017 
The undersigned, appointed by the dean of the Graduate School, have examined the dissertation entitled

MULTI-SCALE FACTORS RELATED TO ABUNDANCE OF BATS AND INSECT PREY IN SAVANNAS, WOODLANDS, AND FORESTS IN THE OZARK HIGHLANDS, USA

Presented by Kathryn Marie Womack

a candidate for the degree of Doctor of Philosophy

and hereby certify that, in their opinion, it is worthy of acceptance.

Professor Frank R. Thompson III

Professor Matthew Gompper

Dr. Sybill K. Amelon

Professor Lori Eggert

Professor Rose-Marie Muzika 
This would have not been possible without the love and support from my village. Special thanks to Niki, Ed, Jaymi, and Cara. 


\section{ACKNOWLEDGEMENTS}

I would like to thank the many individuals without whose efforts this study would not have been possible. First, I would like to thank my advisor, Frank Thompson for all his support, advice, and patience throughout the years. I would also like to extend a special thanks to Sybill Amelon for taking a chance on me over a decade ago, and who brought me to Missouri. I would like to my dissertation committee: Matt Gompper, Sybill Amelon, Lori Eggert, and Rose-Marie Muzika. I would not have completed as many sites without the help and willingness to run trap at sites for 3 nights from Sarah Bradley, Nettie Sittingup, Linda Mills, Megan York-Harris, Clarissa Starbuck, Risa Wright, and Sybill Amelon. In addition, I could not have completed this project without the ArcGIS and statistical assistance from Bill Dijak and Jaymi LeBrun. Tom Bonnot and Julianna Jenkins supported me tremendously in helping me trouble shoot errors in R code, and provided an environment for me to increase my confidence in my statistical analysis skills. I would like to thank my other lab mates: Liz Matseur and Melissa Roach for being a support system, and providing encouragement during the final hours of the degree. I could not have finished with as much grace without their encouragement. Lastly, I would like to thank my family, both born with and chosen, for taking my 4 a.m. phone calls, and believing in me when I did not believe in myself. I love you and I hope you feel that this degree is shared among us. This research was funded by the USDA Forest Service Northern Research Station. 


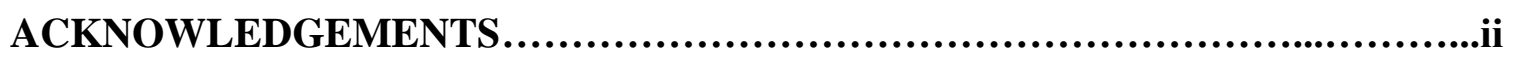

LIST OF ILLUSTRATIONS.......................................................ii

DESCRIPTION OF CHAPTERS..................................................

DISSERTATION ABSTRACT .....................................................

CHAPTER 1: INTRODUCTION....................................................

LITERATURE CITED ......................................................... 6

CHAPTER 2: PERFORMANCE OF HIERARCHICAL ABUNDANCE MODELS

ON SIMULATED BAT CAPTURE DATA........................................8

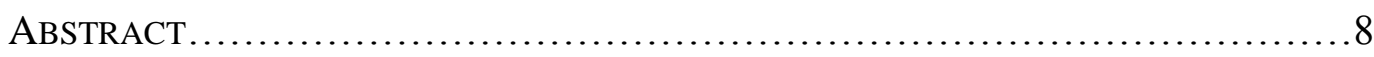

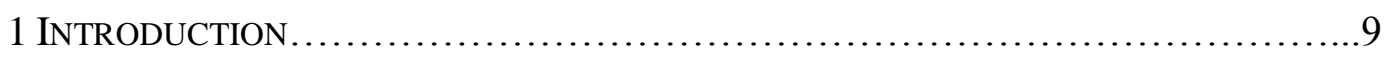

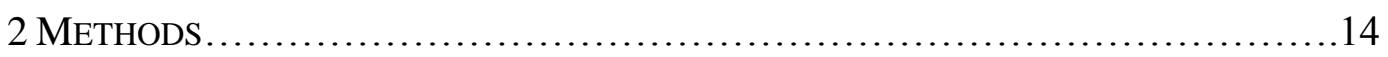

2.1 Model descriptions and assumptions...................................14

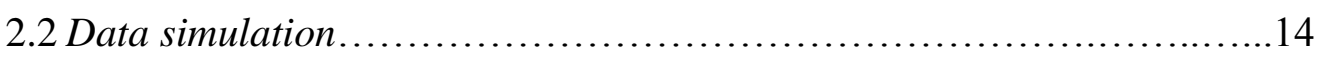

2.3 Model performance .................................................. 17

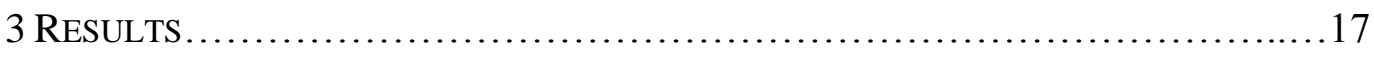

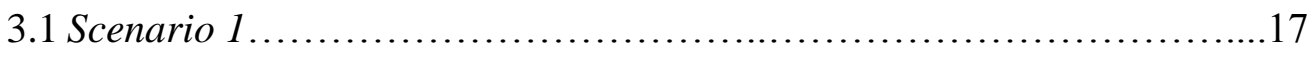

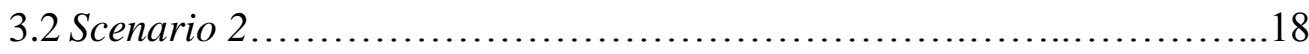


4 Discussion

LITERATURE CITED .23

\section{CHAPTER 3: RESTORATION AND HABITAT FACTORS RELATED TO INSECT ABUNDANCE ACROSS A GRADIENT OF SAVANNAS, WOODLANDS, AND NON-MANAGED FORESTS IN THE OZARK HIGHLANDS, USA..........38}

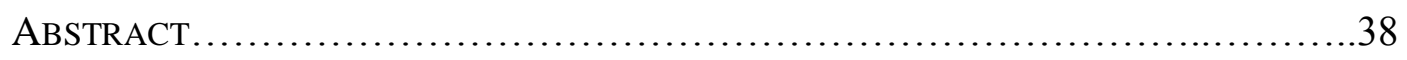

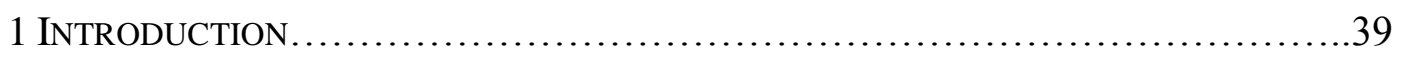

2 Methods............................................................ 45

2.1 Study areas..................................................45

2.2 Study design .............................................46

2.3 Insect surveys .........................................47

2.4 Insect processing protocol..................................48

2.5 Vegetation surveys and covariates.............................49

2.6 Environmental, management, and temporal covariates..............49

2.7 Data analysis............................................50

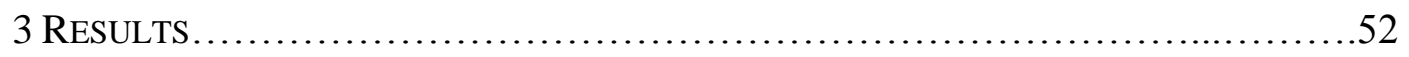


4 DISCUSSION

LITERATURE CITED.

\section{CHAPTER 4: BAT ABUNDANCE IN RELATIONSHIP TO HABITAT FACTORS AT MULTIPLE SCALES ACROSS SAVANNAS, WOODLANDS, AND FORESTS IN THE MISSOURI OZARKS.....................................................92}

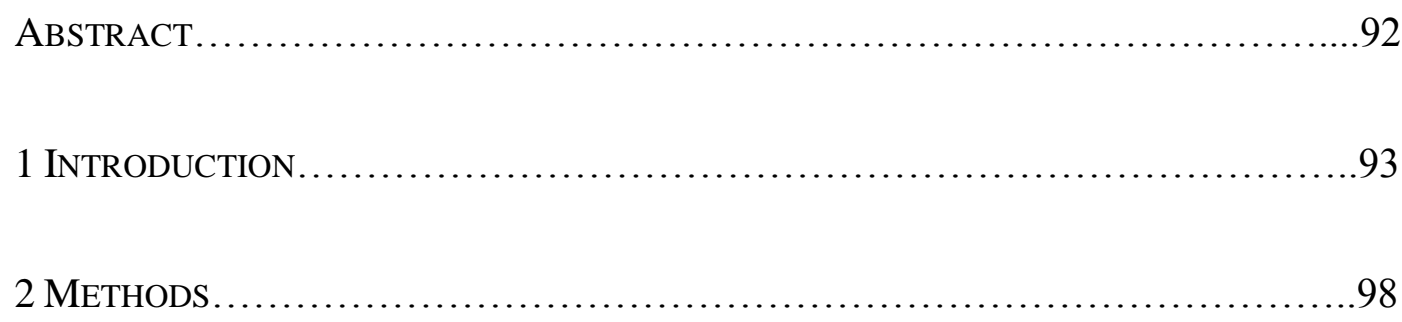

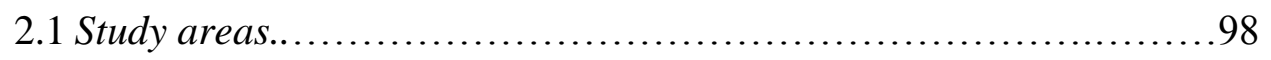

2.2 Experimental design .......................................99

2.3 Mist net survey and bat capture protocol.......................100

2.4 Site scale measurements and covariates........................101

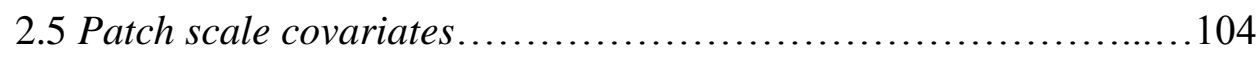

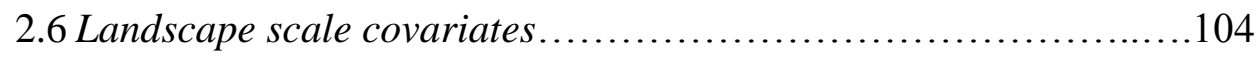

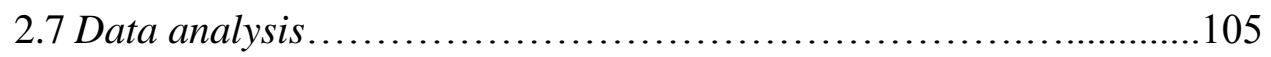




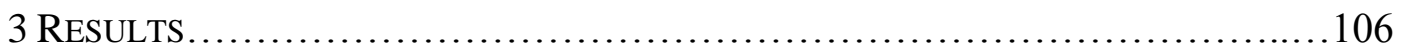

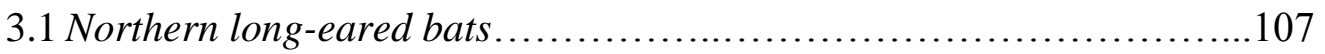

3.2 Tri-colored bats .................................................. 108

3.3 Evening bats................................................ 109

3.4 Eastern red bats...............................................110

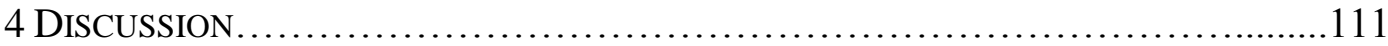

5 MANAGEMENT IMPLICATIONS.............................................. 117

LITERATURE CITED.................................................... 119

CHAPTER 5: CONCLUSION.....................................................152

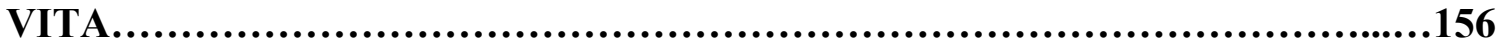




\section{List of Illustrations}

\section{LIST OF TABLES}

Chapter 2 Tables

Page

1. Model scenarios and parameters used to generate simulated datasets to evaluate the performance of n-mixture and removal models fit in the UNMARKED package. We varied the number of sites, number of visits to a site, the known population size $(\hat{N})$ and the probability of detection (p) to create four scenarios.

2. Mean estimated abundance $(\mathrm{N})$, standard error (SE), relative bias (RB), mean absolute error (MAE) and mean absolute percent error (MA\%E) in abundance estimates by the n-mixture and removal model from simulated data for different numbers of sites and $\mathbf{N}=70, p=0.5$, and 3 visits to a site...................29

3. Mean estimated abundance $(\mathrm{N})$, standard error (SE), relative bias (RB), mean absolute error (MAE) and mean absolute percent error (MA\%E) in abundance estimates by the n-mixture and removal model from simulated data for different numbers of visits and $\mathrm{N}=70, p=0.5$, and 80 sites......................... 30

4. Mean estimated abundance $(\mathrm{N})$, standard error ( $\mathrm{SE})$, relative bias (RB), mean absolute error (MAE) and mean absolute percent error (MA\%E) in abundance estimates by the n-mixture and removal model from simulated data for different known population sizes and detection probabilities and 3 visits to a site.

5. Mean estimated abundance $(\mathrm{N})$, standard error ( $\mathrm{SE})$, relative bias (RB), mean absolute error (MAE) and mean absolute percent error (MA\%E) in abundance estimates by the n-mixture and removal model from simulated when detection probability changed from 0.5 to 0.1 after individuals first capture $\left(\mathrm{p}, \mathrm{p}_{1}\right)$ and known population $=70$, number of sites $=80$, and 3 visits to a site

\section{Chapter 3 Tables}

1. Hypotheses and candidate models used for effects on insect response variables based on passive and active plot surveys across a gradient of savannas, woodlands, and non-managed forests in the Ozarks of Missouri, 2014-2016. Site 
was used as a random effect and year (YR) and Julian date (JUL) were included as fixed effects in all models

2. Descriptions of model covariates used in generalized linear mixed models with a negative binomial distribution to predict abundances of insects across a gradient of actively managed savanna-woodlands and non-managed forests in the Ozark Highlands of Missouri, 2014-2016.

3. Response variables used in generalized linear mixed models with a negative binomial distribution examining the effects of restoration management, habitat, and climate covariates on insect abundance across a gradient of savanna, woodland, and forests in the Ozarks of Missouri, 2014-2016. Response variables represent the mean captures at plots over the 3 survey days. We combined malaise and panel trap yields for each plot for analysis. .70

4. Descriptive statistics for covariates measured at plots where active methods were used to sample insects in a study of relationships between insect abundances and savanna woodland restoration in the Ozarks of Missouri, 2014-2016.

5. Descriptive statistics for covariates measured at plots where passive methods were used to sample insects in a study of relationships between insect abundances and savanna woodland restoration in the Ozarks of Missouri, 2014-2016

6. Support for generalized linear mixed models of different insect responses including the number of model parameters (k), log likelihood (LogLik), Akaike's Information Criterion for small sample size (AICc), delta AICc ( $\triangle \mathrm{AICc}$ ), and AICc weight $\left(w_{\mathrm{i}}\right)$. Models were fit to data from 179 active plots collected across a gradient of savanna, woodland, and forest in the Missouri Ozarks in summers, 2014-2016. .......................................................... 73

7. Support for post hoc and a priori candidate generalized linear mixed models for mean Tricopteran response variable including the number of model parameters (k), log likelihood (LogLik), Akaike's Information Criterion for small sample size (AICc), delta AICc ( $\triangle \mathrm{AICc})$, and AICc weight $\left(w_{\mathrm{i}}\right)$. Models were fit to data from 179 active plots collected across a gradient of savanna, woodland, and forest in the Missouri Ozarks in summers, 2014-2016 
8. Parameter estimates $(\beta)$, standard errors (SE), and 95\% confidence limits (LCL, UCL) for parameters in our top model for mean total insects, Coleopterans, and Tricopterans captured at 179 active plots during bat mist-net surveys at 89 sites across a gradient of savanna, woodland, and forest in the Ozark Highlands of Missouri, 2014-2016. Reference covariates are YR1 (2014). We did not include mean Lepidopterans, as the NULL model was the top model for this response variable...

9. Support for generalized linear mixed models of different insect responses variable including the number of model parameters (k), log likelihood (LogLik), Akaike's Information Criterion for small sample size (AICc), delta AICc ( $\triangle \mathrm{AICc}$ ), and AICc weight $\left(w_{\mathrm{i}}\right)$. Models were fit to data from 174 passive plots collected across a gradient of savanna, woodland, and forest in the Missouri Ozarks in summers, 2014-2016.

10. Support for post hoc and a priori candidate generalized linear mixed models of different mean total insect response variable including the number of model parameters (k), log likelihood (LogLik), Akaike's Information Criterion for small sample size (AICc), delta AICc ( $\triangle \mathrm{AICc})$, and AICc weight $\left(w_{\mathrm{i}}\right)$. Models were fit to data from 174 passive plots collected across a gradient of savanna, woodland, and forest in the Missouri Ozarks in summers, 2014-2016.

11. Parameter estimates $(\beta)$, standard errors (SE), and 95\% confidence limits (LCL, UCL) for parameters in our top model for mean total insect captured at 174 passive plots during bat mist-net surveys at 89 sites across a gradient of savanna, woodland, and forest in the Ozark Highlands of Missouri, 2014-2016. Reference covariates are YR1 (2014). We did not include mean Coleopterans or Dipterans as the NULL model was the top model.

\section{Chapter 4 Tables}

1. Habitat covariates at four spatial scales used in hierarchical abundance models for four bat species across a gradient of savanna, woodland, and forest in the Ozark Highlands of Missouri

2. Covariates evaluated for relationships with detection probabilities of four bat species in hierarchical abundance models based on mist-net surveys s across a 
gradient of savanna, woodland, and forest in the Ozark of Missouri, 2014-

2016

3. Candidate detection models used to estimate detection probabilities of four bat species in hierarchical abundance models based on mist-net surveys across a gradient of savanna, woodland, and forest in the Ozark Highlands of Missouri, 2014-2016

4. Candidate abundance models used for four bat species based on mist-net surveys across a gradient of savanna, woodland, and forest in the Ozark Highlands of Missouri, 2014-2016. We used the general multinomial-Poisson model for removal sampling in the UNMARKED package. Year was included as a fixed effect in all abundance models

5. Descriptive statistics for detection and abundance covariates measured at mist net sites for a study of relationships between bat detection probability and abundance and savanna woodland restoration in the Ozarks of Missouri, 2014-2016. 130

6. Support for detection probability (O) models based on the number of model parameters (k), Akaike Information Criterion (AIC), delta AIC ( $\triangle \mathrm{AIC}$ ), and AIC weight $\left(w_{\mathrm{i}}\right)$ for four bat species based on mist-net surveys $\mathrm{s}$ across a gradient of savanna, woodland, and forest in the Ozark Highlands of Missouri, 20142016

7. Parameter estimates $(\beta)$, standard errors (SE), and 95\% confidence limits (LCL, UCL) for parameters in our top detection models for four bat species based on hierarchical abundance models and mist-net surveys at 89 sites across a gradient of savanna, woodland, and forest in the Ozark Highlands of Missouri, 20142016 134

8. Support for abundance $(\chi)$ models for the northern long-eared bat (Myotis septentrionalis) including the number of model parameters (k), Akaike's Information Criterion (AIC), delta AICc ( $\triangle \mathrm{AICc})$, and AICc weight $\left(w_{\mathrm{i}}\right)$. Models were fit with the general multinomial Poisson model for removal sampling using the UNMARKED package and data from mist-net surveys at 89 sites across a gradient of savanna, woodland, and forest in the Ozark Highlands of Missouri, 2014-2016. All models include the top ranked detection model O(minTEMP + WIND + PRESSURE + LUNAR + JUL + YR) 
9. Parameter estimates $(\beta)$, standard errors (SE), and 95\% confidence limits (LCL, UCL) for parameters in our top hierarchical abundance model for northern longeared bat (Myotis septentrionalis) captured during mist-net surveys at 89 sites across a gradient of savanna, woodland, and forest in the Ozark Highlands of Missouri, 2014-2016. Reference covariates are YR1 (2014) and $\%$ NON1km

10. Support for abundance $(\chi)$ models for the tri-colored bat (Perimyotis subflavus) including the number of model parameters (k), Akaike's Information Criterion (AIC), delta AICc $(\triangle \mathrm{AICc})$, and AICc weight $\left(w_{\mathrm{i}}\right)$. Models were fit with the general multinomial Poisson model for removal sampling using the UNMARKED package and data from mist-net surveys at 89 sites across a gradient of savanna, woodland, and forest in the Ozark Highlands of Missouri, 2014-2016. All models include the top ranked detection model O(PRESSURE).

11. Parameter estimates $(\beta)$, standard errors (SE), and $95 \%$ confidence limits (LCL, UCL) for parameters in our top hierarchical abundance model for tri-colored bats (Perimyotis subflavus) captured during mist-net surveys at 89 sites across a gradient of savanna, woodland, and forest in the Ozark Highlands of Missouri, 2014-2016. Reference covariates are YR1 (2014), YRburned $=0$ or non-

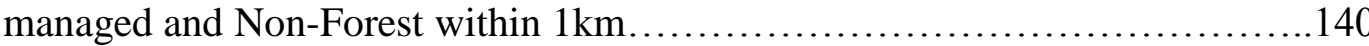

12. Support for abundance $(\chi)$ models for evening bats (Nycticeius humeralis) including the number of model parameters (k), Akaike's Information Criterion (AIC), delta AICc $(\triangle \mathrm{AICc})$, and AICc weight $\left(w_{\mathrm{i}}\right)$. Models were fit with the general multinomial Poisson model for removal sampling using the UNMARKED package and data from mist-net surveys at 89 sites across a gradient of savanna, woodland, and forest in the Ozark Highlands of Missouri, 2014-2016. All models include the top ranked detection model O(PRESSURE).

13. Parameter estimates ( $\beta$ ), standard errors (SE), and 95\% confidence limits (LCL, UCL) for parameters in our top hierarchical abundance model for evening bats (Nycticeius humeralis) captured during mist-net surveys at 89 sites across a gradient of savanna, woodland, and forest in the Ozark Highlands of Missouri, 2014-2016. Reference covariates are YR1 (2014) and YRburned1 $=+10$ years or non-managed.

14. Support for abundance $(\chi)$ models for eastern red bats (Lasiurus borealis) including the number of model parameters (k), Akaike's Information Criterion 
(AIC), delta AICc ( $\triangle \mathrm{AICc})$, and AICc weight $\left(w_{\mathrm{i}}\right)$. Models were fit with the general multinomial Poisson model for removal sampling using the UNMARKED package and data from mist-net surveys at 89 sites across a gradient of savanna, woodland, and forest in the Ozark Highlands of Missouri, 2014-2016. All models include the top ranked detection model O(mnTEMP + LUNAR + PRESSURE). 144

15. Parameter estimates ( $\beta$ ), standard errors (SE), and $95 \%$ confidence limits (LCL, UCL) for parameters in our top hierarchical abundance model for eastern red bats (Lasiurus borealis) captured during mist-net surveys at 89 sites across a gradient of savanna, woodland, and forest in the Ozark Highlands of Missouri, 2014-2016. Reference covariates are YR1 (2014), \%NON1km, and Other16km. .146

\section{LIST OF FIGURES}

Chapter 2 Figures

1. Abundance estimates by the removal and the n-mixture models fit in the package UNMARKED based on simulated count data and different numbers of sites and a

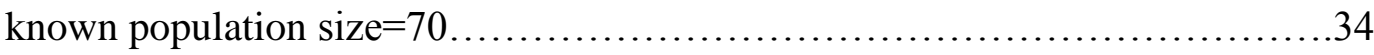

2. Abundance estimates by the removal and n-mixture models fit in the package UNMARKED with simulated data for 3, 4, or 5 visits to a site and known

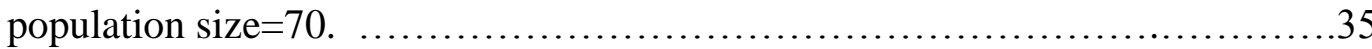

3. Abundance estimates by the removal and n-mixture models fit in the package UNMARKED for various $p$ and Ń. Models were fit to simulated count data for a population sizes indicated within each graph of $\hat{N}=35,70,110$, and $150 \ldots \ldots \ldots 36$

4. Abundance estimates by the removal and n-mixture models fit in the package UNMARKED for the removal model and n-mixture model with constant detection probability (baseline) and with detection probability changing from 0.5 to 0.1 after an individual's first capture to simulate net avoidance behavior and known population size $=70$. Results do not change for the removal model since it only uses an individual's first capture.

\section{Chapter 3 Figures}

1. Mist-net site locations (dark magenta circles) with either 8 insect plots (2014) or 4 insect plots (2015-2016) surveyed within $250 \mathrm{~m}$ of sites across a gradient of 
savanna, woodlands, and non-managed forests on state and federal lands within the Ozarks of Missouri between May $15^{\text {th }}$-August $15^{\text {th }}, 2014-2016$....

2. Frequency of captures expressed as mean total, Lepidopteran, Tricopterans, Coleopterans insects captured per active trap $(\mathrm{N}=179)$ across a gradient of savanna, woodlands, and non-managed forests in the Ozarks of Missouri, 2014-

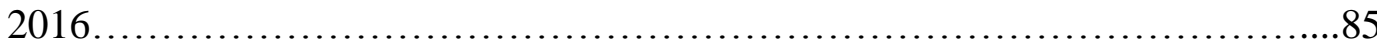

3. Frequency of captures expressed as mean total, Dipterans, Coleopterans insects captured per passive trap $(\mathrm{N}=174)$ across a gradient of savanna, woodlands, and non-managed forests in the Ozarks of Missouri, 2014-2016...................86

4. Frequency of captures expressed as mean total insects captured in pitfall traps at 174 passive plots across a gradient of savanna, woodlands, and non-managed forests in the Ozarks of Missouri, 2014-2016.

5. Predicted abundance and $95 \%$ confidence limits for mean total insects at active plots across ranges of supported restoration, habitat, and environmental covariates in the Ozarks of Missouri, 2014-2016.

6. Predicted abundance and $95 \%$ confidence limits for mean Coleopterans captured at active plots across ranges of supported restoration, habitat, and environmental covariates in the Ozarks of Missouri, 2014-2016.

7. Predicted abundance and $95 \%$ confidence limits for mean Trichopterans captured at active plots across ranges of supported restoration, habitat, and environmental covariates in the Ozarks of Missouri, 2014-2016. Non-managed are sites either never burned or sites not burned within the last 10 years.....................90

8. Predicted abundance and $95 \%$ confidence limits for mean total insects captured at passive plots across ranges of supported restoration, habitat, and environmental covariates in the Ozarks of Missouri, 2014-2016. Non-managed are sites either never burned or sites not burned within the last 10 years......................91

\section{Chapter 4 Figures}

1. Bat mist-net capture site locations (dark magenta circles) surveyed across a gradient of savanna, woodlands, and non-managed forests on state and federal lands within the Ozarks of Missouri between May $15^{\text {th }}$-August $15^{\text {th }}, 2014-$ 2016 
2. Predicted abundance and $95 \%$ confidence limits for northern long-eared bats (Myotis septentrionalis) from model supported site, patch, and landscape factors in the Ozarks of Missouri, 2014-2016................................................148

3. Predicted abundance and 95\% confidence limits for tri-colored bats (Perimyotis subflavus) from model supported site, patch, and landscape factors in the Ozarks of Missouri, 2014-2016. Non-managed are sites either never burned or sites not

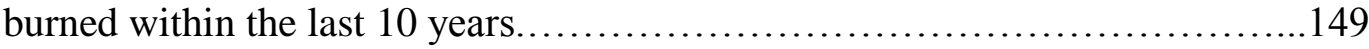

4. Predicted abundance and $95 \%$ confidence limits for evening bats (Nycticeius humeralis) from model supported site, patch, and landscape factors in the Ozarks of Missouri, 2014-2016. Non-managed are sites either never burned or sites not burned within the last 10 years........................................... 150

5. Predicted abundance and $95 \%$ confidence limits for eastern red bats (Lasiurus borealis) from model supported site, patch, and landscape factors in the Ozarks of

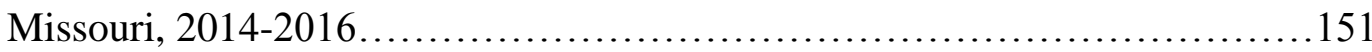




\section{DESCRIPTION OF CHAPTERS}

The second, third, and forth chapter of this dissertation were written as independent manuscripts with the intent to submit to peer-reviewed journals. For the dissertation, I included a general introduction (Chapter 1) and conclusion (Chapter 5) to tie elements of the chapters together into a more complete narrative. Because chapters 2, 3, and 4 were written as independent manuscripts, there is some overlap in the information conveyed in the introductions as well as the methods and references. Intended co-authors of the manuscripts were listed after each chapter title, and the dissertation was written using plural nouns to include co-authors. 


\section{DISSERTATION ABSTRACT}

Restoration of savanna and woodland ecosystems are high priorities for state and federal agencies in the Midwest and prescribed fire and mechanical tree thinning are the main tools used to restore these communities. Information on how bat species and their insect prey respond to restoration is needed to guide management decisions for species of conservation concern. There is a heightened urgency to collect demographic data during the summer maternity season due to white-nose syndrome (WNS) and other threats to bat populations. Our objectives were to: 1) evaluate the performance of the n-mixture model for repeated count data and the general multinomial-Poisson model for removal sampling (n-mixture model and removal model, respectively) for estimating bat abundance from simulated mist-net capture data, 2) determine the relationships between prescribed fire, vegetation structure, and site characteristics on insect abundance, and 3) determine the effect of restoration, vegetation structure, and landscape factors on bat species abundances across a gradient of savannas, woodlands, and non-managed forest in the Ozark Highlands of Missouri.

We fit the n-mixture and removal models in the UNMARKED package in $\mathrm{R}$, and simulated datasets that examined how both models would perform based on potential study design constraints, various probabilities of detection, and population sizes. We simulated 4 scenarios each based on 85 iterations on 1000 randomly generated datasets. We calculated relative bias (RB), mean absolute error (MAE), and mean absolute percent error (MA\%E) from model predictions to evaluate model performance. Relative bias, MAE, and MA\%E decreased as detection probability and bat abundance increased. 
Model fit was acceptably low when bat abundance was $\geq 70$, and detection probability was $>0.5$ for n-mixture models. The removal model outperformed the n-mixture model in all scenarios except when detection probability was 0.05 . The removal model correctly estimated bat abundance for $50 \%$ of simulated scenarios versus the n-mixture model's 3 out of 43. Utilization of the removal model using data from repeated mist-net surveys may allow resource managers and conservationists to better quantify how resource management and landscape composition affect bat species abundance and overall populations. We provide managers with evidence of the utility of the removal model to estimate bat abundances from repeated mist-net survey data while incorporating meaningful habitat, management, and landscape covariates. Furthermore, documenting changes in populations sizes during the summer maternity season will enable improved conservation practices for species management.

We sampled insects at 8 plots in 2014, and 4 plots in 2015 and 2016 within $250 \mathrm{~m}$ of each mist-net sites. We fit generalized linear mixed effects models to evaluate a priori hypotheses on the effects of savanna woodland restoration on insect abundances. Prescribed fire did affect insect abundances at plots surrounding each mist-net site. Insect plots burned 2 or 3 times within the last ten years had higher insect abundances for some insect response groups compared to non-managed plot. Year since a plot burned also affected insect abundances, with sites burned more recently within 3 years had lower insect abundances for some insect response groups and in others - we found no relationship. We only evaluated insect Orders and did not examine specific families or species richness to understand how management affects diversity of insects. 
Temperature was the best predictor of insect abundances at plots for most response variables, and we found support for site aspect, and tree density by size classes. Managers should be mindful that different insect groups had different responses to prescribed fire, therefore a diversity of practices in the landscape will provide for more diverse insect prey Overall, restoration practices did not have a lasting negative effect on insect abundances, and some positive effects.

We conducted mist-net surveys at 89 sites across the Ozark region of Missouri from 2014-2016, and collected demographic data on 4 bat species captured: northern longeared bat (Myotis septentrionalis), tri-colored bat (Perimyotis subflavus), evening bat (Nycticeius humeralis), and eastern red bat (Lasiurus borealis). We fit the removal model to evaluate multi-scale a priori hypotheses on the effects of restoration, landscape factors, and prey availability at sites that potentially affect either the detection or abundance of bats at sites. Top models for all four bat species highlighted the importance of evaluating multiple spatial scales in ecological studies. Overall, we found no evidence that restoration negatively affected any of the bat species investigated; although, northern long-eared bats abundance presented stronger positive relationship to percent forest and increased tree densities than to percent savanna-woodlands within $1 \mathrm{~km}$. Our study was the first to predict abundances from repeated count data from mist-net surveys during the summer maternity season and accounting for varying detection probabilities. We did not find support for relationships between potential insect prey and bat abundances. Eastern red bats, tricolored, and evening bat abundances were positively related to prescribed fire and negatively to tree densities or percent canopy and therefore should respond positively 
to savanna and woodland restoration. Northern long-eared bat had higher abundances at sites with higher tree densities of pole and saw timber and eastern red bat and northern long-eared bat abundances was positively related to sites with higher percentage of forest and savanna-woodland habitat within $1 \mathrm{~km}$ of mist-net sites. Evening bat abundances was the greatest at sites that had higher fire frequencies within $1 \mathrm{~km}$ of a mist-net site. We suggest managers consider the tradeoffs among species in these abundance relationships when planning management and that restoration of savanna and woodlands, when part of a larger management goal to create heterogeneity of forest types, will likely promote higher abundances of all four bat species. 


\section{Chapter 1: Introduction}

Hierarchical, multi-scale, habitat selection by animals influences ecological processes like dispersal, reproduction, and migration (Hildens 1965, Cushman and McGarigal 2004). Knowledge of local (small scale) structural and habitat features only answers part of the question of what influences habitat selection since species rarely respond to habitat at only one spatial scale (Hilden 1965, Hutto 1985, Lawler and Edwards 2006). Understanding the spatial scales that influence habitat selection is critical to identifying the necessary structural, habitat, and landscape features that affect a species survival (Wiens 1989, Saab 1999, Hayes and Loeb 2007). I address multi-scale, hierarchical, habitat selection by directly comparing support for relationships between bat abundance and environmental features at local, patch, and landscape scales, and by assessing which scales most greatly affect species' abundances.

Identifying proximate and ultimate factors affecting habitat selection is a central theme in ecology. Proximate factors are directly linked to site selection by a species. Typically, these landscape or habitat measures stimulate the use of a site by an individual due to one or more important features (e.g. open versus forested landscape, proximity to water, proximity to conspecific individuals; Hilden 1965). Ultimate factors that determine habitat selection are the driving cause behind selection; however, these ultimate factors are often masked by proximate factors. Typical ultimate factors are food, shelter, and species-specific constraints of behavior as well as locomotion strategies. Few studies have examined simultaneously proximate and ultimate factors affecting habitat selection (Johnson and Sherry 2001, Orians and Wittenberger 1991). My study is unique in that it addresses multi-scale habitat attributes as well as proximate and ultimate factors. I 
directly address the relative importance of food, an ultimate factor, and proximate habitat factors - specifically, vegetation structure, landscape composition, and prescribed fireby comparing evidence for relationships between these factors and bat abundance.

Indices of abundance or estimates of site occupancy can be used to address many ecological questions for wildlife. However, many conservation questions require knowledge of the actual numbers of animals such as those concerning species status or viability. Furthermore, indices are often misused because users assume detection probability is constant when it is often not (Rosenstock et al. 2000). Occupancy modeling provides information on the relative use or importance of sites, but does not directly indicate the number of individuals using sites (MacKenzie 2006). Rather, it is a coarse metric for examining population variation among habitats. Knowledge of true abundance is needed to evaluate species status. Traditional methods to estimate detection-corrected abundance are mark-recapture, removal, and distance sampling (Buckland et al. 2001, Williams et al. 2002). These methods are labor intensive, and are often unfeasible for bats. Most bat survey techniques use presence only data or raw counts (O'Shea and Bogan 2003). Newly developed models can use count data to estimate detection probability and abundance while incorporating meaningful site, habitat, and landscape covariates that influence detection probability and abundance (Royle et al. 2004a, Royle et al. 2004b). I investigated the application of n-mixture models for repeated count data, and general multinomial-Poisson models using removal sampling, to estimate bat abundance at capture sites - something hereto has not been attempted. 
I investigated broader ecological issues (e.g. multi-scale habitat selection, proximate and ultimate factor effects on abundance, and estimate true abundance) while addressing two contemporary conservation issues: the restoration of savanna and woodlands and bat conservation. Savanna woodland restoration is taking place across the Midwest.

Prescribed fire removes understory vegetation and small trees creating a more open forest understory, and preventing recruitment to the overstory at savanna woodland restoration sites. Examining how prescribed fire influences the use of sites by wildlife species can provide additional information on drivers of habitat selection. By working across a gradient of savanna, woodland, and non-managed forest in the Missouri Ozarks, I address concerns about management effects on wildlife while using the variation in structure and composition to address broader ecological questions.

Many animals, including bats, eat insects. A potential value of savannas and woodlands for bats and other wildlife is increased abundance of insect prey. By evaluating how fire frequency, years since burn, vegetation structure and composition changes predict insect abundance at sites, I was able to make inferences on how savanna woodland restoration influences insect abundance, and therefore, potential site use of wildlife based on increased food supply.

I focused on bats not only because they are of great conservation concern, but also because they are a good study species to investigate broader ecological principles such as important spatial scales, and proximate versus ultimate factors in habitat selection. Due to their mobility and the capacity to move between areas that provide adequate resources to 
meet energetic, shelter, and water requirements, bats serve as a good model to examine habitat selection at multiple spatial scales to identify important environmental drivers of selection (Hayes and Loeb 2007).

\section{Dissertation Objectives}

In my second chapter, I evaluated the performance of two abundance models for bat capture data. I used n-mixture models for repeated count data and general multinomialPoisson models using removal sampling to estimate bat abundance from simulated data. The goal of this chapter is to validate the performance and sensitivity of these models for populations. In my third chapter, I examined the effects of savanna woodland restoration by evaluating support for relationships between insect abundance, vegetation structure, and prescribed fire in managed savannas and woodlands and non-managed forests. I used my results from chapters 2 and 3 to evaluate local, patch, and landscape factors affecting bat abundance across a savanna, woodland, and forest gradient in my fourth chapter. I utilized an information theoretic approach to examine the relationship between abundance of northern long-eared bat (Myotis septentrionalis), tri-colored bat (Perimyotis subflavus), evening bat (Nycticeius humeralis), and eastern red bats (Lasiurus borealis) to changes in food abundance, prescribed fire, vegetation structure, and landscape composition and pattern.

\section{Impacts}

My research has substantial management and conservation implications. The ability to estimate the true number of bats using a site based on captures over several nights is a 
meaningful contribution for bat research and monitoring. The use of both simulated data and field data should provide a robust evaluation of the applicability of these models for estimating bat abundance. Information on bat abundance will allow for resource managers and conservationists to evaluate management impacts on bats, and the applicability of these models for other wildlife species.

By determining how restoration management affects insect abundance, I provide important information on the general impacts of fire on insect abundance. I also provide insight on how an ultimate factor, insect prey abundance, may affect habitat selection for wildlife species based on changes in food availability caused by restoration management.

More generally, understanding how bats respond to multi-scale proximate and ultimate factors is essential because bats are of high conservation concern. Besides increasing our knowledge of habitat selection for wildlife, my dissertation will improve our (scientists, management agencies, and other shareholders) ability to plan conservation management strategies at scales most influential to bat populations. My dissertation provides abundance estimates that can be extrapolated over spatial and temporal scales, and used to create population estimates for species to assess the status, population trends, and viability (Thogmartin et al. 2007, Amar et al. 2010). This is especially necessary in light of recent population declines of bat species related to landscape conversion, wind energy developments, and WNS. 


\section{LITERATURE CITED}

Amar, A., S. Redpath, I. Sim, and G. Buchanan. 2010. Spatial and temporal associations between recovering populations of common raven Corvus corax and British upland wader populations. Journal of Applied Ecology 47(2): 253-262.

Buckland, S. T., D.R. Anderson, K.P. Burnham, J.L. Laake, D.L. Borchers, and L. Thomas. 2001. Introduction to distance sampling estimating abundance of biological populations. Oxford University Press, Oxford, U.K.

Cushman, S.A. and K. McGarigal. 2004. Hierarchial analysis of forest bird speciesenvironment relationships in the Oregon cost range. Ecological Applications 14(4): 1090-1105.

Hayes, J. P. and S.C. Loeb. 2007. The influences of forest management on bats in North America. Pp. 207-235 in Bats in forests: conservation and management (Lacki M.J., J.P. Hayes, and A. Kurta, eds.). Johns Hopkins University Press, Baltimore, MD. 329pp.

Hilden, O. 1965. Habitat selection in birds: a review. Annales Zoologici Fennici 2: $53-$ 75 .

Hutto, R.L. 1985. Habitat selection by nonbreeding, migratory land birds. Pp 455-476 in Habitat selection in birds. (M.L. Cody, ed.). Academic Press, New York, NY. 558 pp.

Johnson, M.D. and T.W. Sherry. 2001. Effects of food availability on the distribution of migratory warblers among habitats in Jamaica. Journal of Animal Ecology 70: 546560.

Lawler, J.J. and T.C. Edwards Jr. 2006. A variance-decomposition approach to investigating multiscale habitat associations. The Condor 108: 47-58.

Orians, G.H. and J.F. Wittenberger. 1991. Spatial and temporal scales in habitat selection. The American Naturalist 137: S29-S49.

O’Shea TJ, Bogan MA (eds) (2003) Monitoring trends in bat populations of the United States and territories: problems and prospects. US Geological Survey, Biological Resources Division, Information and Technology Report, USGS/BRD/ITR-2003-003, Washington, DC. 281 pp.

Rosenstock, S. S., D. R. Anderson, K. M. Giesen, T. Leukering, and M. F.Carter. 2002. Landbird counting techniques: current practices and an alternative. Auk 119: 46-53.

Royle, J.A. 2004a. Generalized estimators of avian abundance from count survey data. Animal Biodiversity and Conservation 27(1): 375-386. 
Royle, J.A. 2004b. N-mixture models for estimating population size from spatially replicated counts. Biometrics 60(1): 108-115.Royle, J.A., and J.D. Nichols. 2003. Estimating abundance from repeated presence-absence data or point counts. Ecology 84(3): 777-790.

Saab, V.A. 1999. Importance of spatial scale to habitat use by breeding birds in riparian forests: a hierarchical analysis. Ecological Applications 9(1): 135-151.

Thogmartin, W.E., B.R. Gray, M. Gallagher, N. Young, J.J. Rohweder, and M.G. Knutson. 2007. Power to detect trend in short-term time series of bird abundance. The Condor 109(4): 943-948.

Williams, B.K., J.D. Nichols, and M.J. Conroy. 2002. Analysis and management of animal populations: modeling, estimation, and decision making. Academic Press.San Diego, CA. 817 pp. 


\title{
CHAPTER 2: Performance of hierarchical abundance models on simulated bat
}

\section{capture data}

\author{
Kathryn M. Womack ${ }^{1,3}$, Sybill K. Amelon ${ }^{2}$, Frank R. Thompson III ${ }^{2}$, and Jaymi J. \\ LeBrun $^{3}$ \\ ${ }^{1}$ School of Natural Resources, 302 Natural Resource Building, University of Missouri, \\ Columbia, MO 65211, USA \\ ${ }^{2}$ Northern Research Station, U.S.D.A. Forest Service, 202 Natural Resource Building, \\ Columbia MO 65211, USA \\ ${ }^{3}$ Region 3 Regional Office, U.S. Fish and Wildlife Service, Suite 990, 5600 American \\ Boulevard, Bloomington, MN 55437, USA \\ ${ }^{4}$ Corresponding author: E-mail: kmwhr5@mail.missouri.edu
}

\begin{abstract}
The ability to accurately estimate bat abundance is crucial to ecologists, conservationists, and area managers to provide insight on species status, population trends, and viability. Acoustic detection and occupancy modeling can provide an understanding of resource use, but these methods do not estimate how many bats are in an area, or how these numbers change over time. In light of white-nose syndrome (WNS) and other threats to bat populations, there is a heightened need to estimate bat abundance and trends. We evaluated the performance of the n-mixture model for repeated count data, and the general multinomial-Poisson model for removal sampling (n-mixture model and removal model, respectively) to estimate bat abundance from simulated mist-net capture data. We evaluated the performance of both abundance models under varying numbers of sites and visits, detection probability, and population size. We simulated 4 scenarios each based on 85 iterations on 1000 randomly generated datasets. We used the UNMARKED package in $\mathrm{R}$ to fit the n-mixture model and removal model. We calculated relative bias (RB), mean absolute error (MAE), and mean absolute percent error (MA\%E) from model
\end{abstract}


predictions to evaluate model performance. Relative bias, MAE, and MA\%E decreased as detection probability and bat abundance increased. Model fit was acceptably low when bat abundance was $\geq 70$, and detection probability was $>0.5$ for n-mixture models. The removal model outperformed the n-mixture model in all scenarios except when detection probability was 0.05 . The removal model correctly estimated bat abundance for $50 \%$ of simulated scenarios versus the n-mixture model's 3 out of 43 . Utilization of the removal model using data from repeated mist-net surveys may allow resource managers and conservationists to better quantify how resource management and landscape composition affect bat species abundance and overall populations.

\section{INTRODUCTION}

Wildlife management often requires estimates of animal abundance. Indices of abundance or estimates of site occupancy can be used to address ecological questions for wildlife. However, many conservation questions require knowledge of the actual number of animals such as those concerning species status. Species of conservation concern (SCC), or those federally listed as threatened or endangered, are often the focus of studies to estimate abundance because of the need to understand factors driving their population numbers. Studies often seek to understand relationships between species abundance and specific habitat or landscape characteristics (Royle 2004a), so they can inform

conservation and management. Abundance estimates collected over time can be used to determine if species abundance is decreasing, increasing or stable. 
Analysis methods used to analyze count data can either generate indices of abundance or estimate abundance by correcting for incomplete and variable detectability (Buckland et al. 2001, Williams et al. 2002, Johnson 2008, Rosenstock et al. 2002). Analyses of relationships between abundance and environmental features can be confounded if detection probability varies with the features being considered (Ruiz-Gutiérrez et al. 2010). Mark-recapture, removal, and distance-sampling methods are common approaches for estimating detection probability and abundance (Buckland et al. 2001, Williams et al. 2002, Farnsworth et al. 2002). Correctly estimating abundance is challenging for rare species, species with low detectability, and species that are trap shy or avoid capture even if they are common on the landscape and especially if detection probabilities are variable or change spatially and temporally. Several methods exist for estimating abundance and detectability without individuals being marked or removed from the population, or measurements of distance (Kéry et al. 2005). These abundance models have been developed to account for rare species by allowing for low numbers of detections per site while incorporating meaningful site, habitat, and landscape covariates that influence detection probability and abundance (Royle et al. 2004a, Kery et al. 2005, Royle et al. 2004b). These models have potential utility in bat conservation and management because bat detection varies between sites based on habitat and landscape variability as well as patchy abundance within populations.

Recent threats to bat populations in the eastern United States (e.g., white-nose syndrome, wind turbine fatalities, habitat destruction, etc.) provide heightened demand for methodologies that can estimate abundance at sites (Kunz et al. 2007, Walters et al. 2013, 
Puechmaille et al. 2011, Turner et al. 2011). Bats are difficult to count due to their cryptic behavior. Mark-recapture or distance sampling methods are largely not-feasible for bats because of low recapture probabilities and it is difficult or impossible to measure distances to detections (Kunz and Kurta 1988, Karr 1981, Marques et al. 2013). For these reasons and others, bat studies usually have not attempted to measure abundance, and focus instead on site occupancy (MacKenzie et al. 2002, Amelon 2007). Bat occupancy studies often use acoustic detectors to actively or passively record echolocation calls to determine the presence or non-detection of a species at a survey location (Marques et al. 2013, Amelon 2007, Starbuck et al. 2015, Yates and Muzika 2006, Walters et al. 2013). Even though abundance and occupancy are often related, bat occupancy studies based on acoustic detection can distinguish between species but not individuals within a species using a site.

Abundance models that use repeated counts or removal sampling approaches to estimate detection probabilities are potentially useful for estimating abundance of bats, but have not been tested for this application. Models available in the UNMARKED package in $\mathrm{R}$ use count data to estimate detection probability and abundance while incorporating meaningful site, habitat, and landscape covariates that affect detection probabilities and density/ abundance estimates (Royle et al. 2004a, Royle et al. 2004b). Many bird studies have used this package to analyze point count data, and were able to predict ecologicallyrealistic abundance and density estimates (e.g., Roach 2016, Rigby 2016, Reidy et al. 2014). We sought to use several of these models to determine their utility in bat ecology. 
The n-mixture model for repeated counts and general multinomial Poisson model for removal sampling (hereafter n-mixture model and removal model, respectively) are potentially suitable for estimating abundance of bats from repeated mist-net surveys, and do not require distance measurements or mark-recapture to estimate abundance. The nmixture model assumes a closed population between repeated visits at a site, and that species detectability across visits is independent. The removal model assumes that the population is closed, but that each repeated visit is dependent on previous visits. The removal function is a common survey protocol when estimating abundances in a closed population (Williams et al. 2002, Dorazio and Royle 2003). Removal sampling requires that an individual must be removed from all subsequent visits at a site, either by physical removal from the population, marking captured individuals to remove from data, or by accounting for the reduction in trap-ability due to net avoidance behavior after initial capture (Dorazio and Royle 2005, Williams et al. 2002, Royle 2004b, Rigby 2016). The assumption that a population is closed between repeated visits should hold true in summer bat studies (Menzel et al. 2005, Veilleux and Veilleux 2004), especially if visits occur over consecutive nights during the maternity season. The assumption by the nmixture model of independence between visits may be violated because bats exhibit net avoidance behavior after capture (Larson et al. 2007, Kunz and Anthony 1977, Berry et al. 2004). The removal model is not affected by individuals that exhibit avoidance behavior because only the first capture is used to estimate abundance.

Study design constraints (e.g., numbers of visits versus number of sites) and differences among species (e.g., rare versus common; high versus low detection probabilities) could 
also affect the performance of n-mixture and removal models. Summer bat studies are often limited to three months (May $15^{\text {th }}$ - August $15^{\text {th }}$ ) which restricts number of sites and/or visits, or increases personnel, and labor expenditures. The evaluation of models with simulated data is common in the literature as justification and validation of new analytical techniques for different taxa (Royle 2004a, McCaffery et al. 2016, Yamaura et al. 2016, Rigby 2016). Our goal is to determine the utility of these two abundance models so that future studies might collect population demographic information beyond only occupancy data to address the heightened need for population demographic data over time to evaluate changes in population size.

We evaluated the application of n-mixture (Royle 2004a) and removal models (Royle $2004 b$ ) to estimate bat abundance from capture data. We simulated data to represent bat captures from repeated mist-net surveys with known population sizes $(\hat{N})$ to determine how accurately these models would estimate abundance. We evaluated the sensitivity of abundance estimates to the number of sites (Scenario 1), number of visits (Scenario 2), various population sizes (Ń) and probabilities of detection (Scenario 3), and the effect of net avoidance behavior as represented by decreasing detection probability at a site over time (Scenario 4). We designed scenarios to cover the range of values we expected for each simulation parameter from a literature review and previous field studies. 


\section{METHODS}

\subsection{Model descriptions and assumptions}

We fit $\mathrm{n}$-mixture models and removal models in the UNMARKED package in $\mathrm{R}$ using the pcount and multinomPois procedures, respectively (version 3.2; Fiske and Chandler 2011). We did not include any detection or abundance covariates but rather focused on elements study design and model assumptions. Both models required repeated visits or sampling events at a site, and assume closed population during the time between visits. N-mixture models treat each sampling visit as independent events, and use a Poisson distribution (Fiske and Chandler 2011). The removal model assumes that repeated visits at a site are dependent on previous counts. The removal function within the model requires that all individuals captured at a site during previous visit(s) be removed from all subsequent sampling events at a site (Fiske and Chandler 2011). This can be done physically, or by ignoring recaptures of marked animals. The removal model uses a Poisson distribution which is often appropriate for count data with a high frequency of zeros (Fiske and Chandler 2011).

\subsection{Data simulation}

We created four scenarios within which we varied the number of sites, the number of visits, the number of bats and detection probability, or detection probabilities based on capture history to simulate net avoidance behavior. We manipulated these parameters across a realistic range of expected values for bat species. We generated 1000 random data sets for each level of a parameter within a scenario, and fit models to the data. 
Baseline values of parameters were sites $=80$, visits $=3, \hat{N}=70$, and detection probability (p) $=0.5$.

We simulated counts of captures for a given visit at a site using a binomial distribution ( $1=$ captured or $0=$ not captured $)$ for each individual based on $N$ and probability of detection. Captured individuals were totaled by visit for the n-mixture model, but only the first capture of an individual at a site was counted for the removal model. We used a for loop function in $\mathrm{R}$ to repeat this process to generate count data for each visit at a site and for all sites, and imported counts into a count matrix. We created an UNMARKED data frame from the count matrix, fit the model, and output a matrix that contained the model's abundance estimate and standard error for the simulated data. We used another for loop function in $\mathrm{R}$ to repeat this process 999 times, resulting in 1000 estimates for each level of a parameter in the scenario.

We simulated 50, 60, 80, 90, and 120 sites, and held other parameters at baseline values in scenario 1 (Table 1). Previous experience suggested the potential for suitable weather on 60 nights from May $15^{\text {th }}$ - August $15^{\text {th }}$, and we assumed a minimum of 3 visits which means one team of field researcher could survey 20 sites per year. Another constraint is the number of federally permitted biologists available to conduct surveys; however, studies can occur over multiple years to offset this constraint. Given these constraints, we thought 50 to 120 sites was a reasonable range of sites to consider for a multiple year study. 
We simulated surveys based on 3,4 , and 5 visits to a site with other parameters at baseline values in scenario 2 (Table 1). Since there is a tradeoff between the number of visits and the number of sites that can be visited for a given level of effort, we thought 35 visits was a realistic and relevant number of visits to consider.

We varied $p$ 0.05-0.90 and Ń 35-150 in scenario 3 (Table 1). We chose values of $p$ and $\mathrm{N}$ based on literature on $p$ and maternity colony size estimates from emergence counts at roost locations within our study region (Careres and Barclay 2000, Schwartz and Schwartz 2001, Amelon 2007, Starbuck et al. 2015). We chose Ń to represent rare $(\hat{N}=35)$ to very abundant species ( $\hat{N}=150$; Table 1$)$. Maternity roosts for northern longeared bats generally have $<60$ individuals (Careres and Barclay 2000). Tri-colored bats maternity colonies range from 24-50 individuals (Schwartz and Schwartz 2001). Males for all species are either solitary or form small bachelor colonies during summer (Schwartz and Schwartz 2001, Careres and Barclay 2000). We chose 150 as our largest $\mathbf{N}$ because several maternity colonies could utilize the same mist net site for foraging or a water source.

We simulated learned net avoidance behavior in scenario 4 by using $p=0.5$ for an individual until it was captured, and then $p=0.1$ for all subsequent visits at a site. This scenario violated the assumption for the n-mixture model that repeated counts were independent at a site. We compared these results to results with constant $p=0.5$ and $\mathrm{N}=70$. 


\subsection{Model performance}

We evaluated model performance by calculating mean relative bias (RB), mean absolute error (MAE), and mean absolute percent error (MA\%E) across the 1,000 simulated data sets for each parameter level within a scenario as:

$$
\begin{array}{ll}
\mathrm{RB}=\mathrm{N} / \mathrm{N}-1 & (\text { Formula } 1) \\
\mathrm{MAE}=\left(\sum\left|\mathrm{y}_{\mathrm{i}}-\grave{y}_{\mathrm{i}}\right|\right) / \mathrm{n} & (\text { Formula } 2) \\
\left.\mathrm{MA} \% \mathrm{E}=100\left[\sum\left|\mathrm{y}_{\mathrm{i}}-\grave{y}_{\mathrm{i}}\right| / \mathrm{y}_{\mathrm{i}}\right) / \mathrm{n}\right] & (\text { Formula } 3)
\end{array}
$$

(Legates and McCabe 1999, Mayer and Butler 1993, Efford and Dawson 2009). Relative bias is a measure of variation between the predicted value and the expected value (Efford and Dawson 2009). Mean relative biases that differ from zero indicated a bias in the model estimate. Low values of MAE and MA\%E indicate model predications have low deviance from the true value, and are a better model in estimating abundance.

\section{RESULTS}

We generated 85,000 simulated datasets to evaluate both models. The removal model performed consistently better than the n-mixture model for all four scenarios except when probability of detection was low $(p=0.05)$. The removal model outperformed the $\mathrm{n}$ mixture model in estimating abundances with generally low RB and high accuracy in all scenarios.

\subsection{Scenario 1}

The n-mixture model over estimated abundance $(\mathrm{N}=70)$ for the range of site numbers simulated (Table 2 and Figure 1). The lowest number of sites (50) resulted in the 
abundance estimate closest to the true abundance $\left(\mathrm{N}_{50}=100.12\right.$; Table 2). Relative bias ranged from 0.43 - 0.51, MAE ranged from 31.26 - 35.69, and MA\%E ranged from 44.65 - 50.09 (Table 2). The removal model, on average, estimated abundance correctly (Ń =70) across all sample sizes with approximately zero relative bias $(-0.0005-0.0005)$ for all levels of sample size (Figure 1 and Table 2).

\subsection{Scenario 2}

The n-mixture model overestimated abundance for all number of visits simulated (Figure 2 and Table 3). Sites simulated as visited 5 times had the closest abundance estimate to N (Figure 2 and Table 3). For the n-mixture model, the relative bias decreased by $6 \%$ between 3 and 4 visits, and further decreased by $10 \%$ between 4 and 5 visits (Table 3 ). The removal model, on average, correctly estimated site abundance ( $\mathrm{N}=70$; Figure 2$)$ for 3 and 5 visits per site with relative bias 0.0039 and -0.0007 ; respectively (Table 3 ). The results for 4 visits per site underestimated the abundance, on average, by 2 individuals ( $\mathrm{N}$ =68; Figure 2 and Table 3), and had a relative bias of -0.169 (Table 3).

\subsection{Scenario 3}

N-mixture models for $\mathrm{N}=35, \hat{N}=70$, and $\mathrm{N}=110$ showed low $\mathrm{RB}, \mathrm{MAE}$, and MA\%E when probabilities of detection were high, $p=0.75$ and 0.9 (Figure 3 and Table 4). The n-mixture model correctly estimated abundance, on average, when $p=0.9$ when $\mathrm{N}=35$, 70, 110 (Table 4). When $\mathbf{N}=150$, the n-mixture model estimated population abundance with the lowest RB, MAE, and MA\%E when $p$ was $40 \%$ (Figure 3 and Table 4). The nmixture model did not converge to generate abundance estimates when the known 
population was 150 and $p=0.9$. The removal model did not converge when the probability of detection was 0.05 for all levels of Ń (Figure 3 and Table 4); however, this model correctly estimated abundance, on average, for $\hat{N}=35$ and $\hat{N}=150$ when $p$ was $\geq$ 0.25 (Figure 3 and Table 4). When $\mathrm{N}=70$, the removal model correctly estimated abundance, on average, when $p \geq 0.2$ (Figure 3 and Table 4). The removal model correctly estimated abundances, on average, when $p \geq 0.4$ when $\mathrm{N}=150$ (Figure 3 and Table 4).

\subsection{Scenario 4}

The n-mixture model produced more accurate abundance estimates $(\mathrm{N}=74)$ when $p$ changed from 0.5 to 0.1 after the first visit than it did for the baseline scenario with constant $p(\mathrm{~N}=104$; Figure 4 and Table 5). Never-the-less the removal model outperformed both n-mixture models results and correctly estimated abundance, on average, (N=70; Figure 4 and Table 5).

\section{DISCUSSION}

Recent population threats to bats have resulted in renewed interest in developing and validating methodologies to estimate abundances, and relating them to environmental factors (Kunz et al. 2007, Puechmaille et al. 2011, Turner et al. 2011). We evaluated two hierarchical abundance models that account for species detectability and allow habitat and landscape covariates to be incorporated in both the detection and abundance portion of the model (Friske and Chandler 2011). We provided evidence to evaluate the effectiveness of the n-mixture model and removal model to estimate abundance correctly 
(or without bias) from simulated count data. The ability to estimate abundance is a fundamental attribute of populations that provides insight into species status, habitat use, population trends, and viability. Other common approaches, such as acoustic detection and occupancy models, provide insight into resource use, but cannot be utilized to estimate how many bats use an area, or how numbers change over time. In light of WNS, wind energy, and anthropogenic changes to the landscape, we sought to provide guidance in examining the performance of new analytical tools for bat studies seeking to estimate species abundance.

The n-mixture model over-estimated abundance for most simulated scenarios. Our results were consistent with Rigby (2016) who examined the n-mixture model in the UNMARKED package for utility in estimating black throated blue warblers in Minnesota. Rigby (2016) found n-mixture model results were highly inflated for most simulation years, and were not correlated to true densities. The n-mixture model only correctly estimated abundances when $p=0.9$. In bat ecology, a $p$ of $90 \%$ for an individual is unlikely from mist net captures. Our results are consistent with other studies indicating that when $p$ is high the n-mixture model can correctly estimate abundance (Yamaura et al. 2016, McIntyre et al. 2012, Yamaura 2013, Rigby 2016). Bats are cryptic species, and are not likely to have counts close to the actual population abundance or $p=$ 0.9 due to net avoidance behavior (Larson et al. 2007, Berry et al. 2004, Kunz and Kurta 1988). Yamaura et al. (2016) suggests modifying the study design for species with low $p$ by increasing sampling locations or otherwise increase the chance of detecting individuals (e.g., increase sampling time at a site) which should improve the n-mixture 
model performance (Drapeau et al. 1999). Our results contradict this suggestion as we had the lowest bias when the number of sites was the lowest (50). We found that the nmixture model performed better when we violated the assumption of independence and $p$ declined between repeated visits, which is consistent with the idea that the model was underestimating $p$ and overestimating $N$ to begin with. We do not recommend use of the the n-mixture model for field studies of bats that are similar to the conditions we simulated given its low accuracy and high bias for most conditions simulated.

In contrast to the n-mixture model, the removal model had small errors and biases in all scenarios. Rigby (2016) similarly found that the removal model produced better estimates than the n-mixture model and the multinomial Poisson model for double observer sampling when applied to simulated bird point counts. Another study estimating abundances for a darter species found the removal model correctly estimated abundances by testing model performance on simulated data that fit the ecology of this species (Dorazio and Royle 2005). The removal model correctly estimated abundances, on average, for all numbers of sites suggesting that unless sample size is extremely small, it does not affect abundance estimates for this model. The removal model correctly estimated abundance even with as few as 3 visits to a site. Fewer visits allows more sites to be sampled within the summer maternity season thus increasing sample size. Our findings were consistent with Rigby's (2016) suggestion that high numbers of repeated visits to a site are less critical when using the removal sampling method to adjust count data. We found that the removal model estimated abundances correctly, on average, and with low relative bias for all $p$ except for $p=0.05$. The removal model failed to converge 
for any variation of $N^{\prime}$ when $p=0.05$. Our results are consistent with Rigby (2016) who found this model had difficultly when $p$ was low; but otherwise, this model outperformed the n-mixture model.

We suggest the use of the removal model in bat ecology as probabilities of detection for individuals is likely $\leq 0.75$. We caution the use of this model for bat species with extremely low $p(0.05)$ as this model will likely fail to converge. The model performed well with moderate sample size (50) and with only 3 repeated visits. The removal model's assumption of dependence between visits is consistent with bat behavior and known net avoidance by individuals that have been previously captured (Larson et al. 2007, Kunz and Anthony 1977, Berry et al. 2004). We suggest that researcher should be thoughtful in ensuring that the removal models assumption of a closed population is fulfilled between visits to a site. This can be accomplished by conducting surveys during the maternity season when site fidelity is high and keeping visits close together in time. We agree with Rigby's (2016) recommendation when designing a study to try to reduce forms of potential biases in count data that should increase confidence in abundance estimates, and any relationship found between habitat or landscape covariates. 


\section{LITERATURE CITED}

Amelon, S. K. 2007. Multi-scale factors influencing detection, site occupancy and resource use by foraging bats in the Ozark Highlands of Missouri. PhD Dissertation. University of Missouri, Columbia, MO. Xiv + 223 pp.

Berry, N., W. O'connor, M.W. Holderied, and G. Jones. 2004. Detection and avoidance of harp traps by echolocating bats. Acta Chiropterologica 6(2): 335-346.

Buckland, S. T., D.R. Anderson, K.P. Burnham, J.L. Laake, D.L. Borchers, and L. Thomas. 2001. Introduction to distance sampling estimating abundance of biological populations. Oxford University Press, Oxford, U.K.

Caceres, M. C. and R. M. R Barclay. 2000. Myotis septentrionalis. Mammalian Species 634: $1-4$.

Dorazio R.M. and J.A. Royle. 2005. Estimating size and composition of biological communities by modeling the occurrence of species. Journal of American Statistical Association 100: 389-398.

Dorazio, R.M. and J.A. Royle. 2003. Mixture models for estimating the size of a closed population when capture rates vary among individuals. Biometrics 59: 351-364.

Drapeau P., A Leduc, and R. McNeil. 1999. Refining the use of point counts at the scale of individual points in studies of bird-habitat relationships. Journal of Avian Biology 30: 367-382.

Efford, M. G. and D.K. Dawson. 2009. Effect of distance-related heterogeneity on population size estimates from point counts. The Auk 126(1): 100-111.

Farnsworth, K.D., O. Lyashevska, and T. Fung. 2012. Functional complexity: the source of value in biodiversity. Ecological Complexity 11: 46-52.

Fiske, I.J. and R.B. Chandler. 2011. Unmarked: an R package for fitting hierarchical models of wildlife occurrence and abundance. Journal of Statistical Software 43(10): $1-23$.

Johnson, D.H. 2008. In defense of indices: the case of bird surveys. The Journal of Wildlife Management 72(4): 857-868.

Kéry, M., J.A. Royle, and H. Schmid. 2005. Modeling avian abundance from replicated counts using binomial mixture models. Ecological Applications. 15(4): 1450-1461.

Kunz, T.H. and E.L. Anthony, 1977. On the efficiency of the Tuttle bat trap. Journal of Mammalogy 58(3): 309-315. 
Kunz, T.H., E.B. Arnett, W.P. Erickson, A.R. Hoar, G.D. Johnson, R.P. Larkin, M.D. Strickland, R.W. Thresher, and M.D. Tuttle. 2007. Ecological impacts of wind energy development on bats: questions, research needs, and hypotheses. Frontiers in Ecology and the Environment 5(6): 315-324.

Kunz, T.H. and A. Kurta. 1988. Capture methods and holding devices. Pp 1-29. In: Ecological and Behavioral Methods for the Study of Bats, T.H. Kunz, ed. Smithsonian Institution Press. Washington, D.C. 533 pp.

Larsen, R.J., Boegler, K.A., Genoways, H.H., Masefield, W.P., Kirsch, R.A., and Pedersen, S.C. 2007. Mist netting bias, species accumulation curves, and the rediscovery of two bats on Montserrat (Lesser Antilles). Acta Chiropterologica 9(2): 423-435.

Legates, D.R. and G.J. McCabe, Jr. 1999. Evaluating the use of 'goodness-of-fit" measures in hydrologic and hydroclimatic model validation. Water Resources Research 35(1): 233-241.

Marques J.T., M.J. Ramos Pereira, T.A. Marques, C.D. Santos, J. Santana, et al. 2013. Optimizing Sampling Design to Deal with Mist-Net Avoidance in Amazonian Birds and Bats. PLoS ONE 8(9): e74505.

Mayer, D. G. and D.G. Butler. 1993. Statistical validation. Ecological Modelling 68(12): $21-32$.

McCaffery, R., J. J. Nowak, and P. M. Lukacs. 2016. Improved analysis of lek count data using N-mixture models. Journal of Wildlife Management 80:1011-1021.

McIntyre A.P., J.E. Jones, E.M. Lund, F.T. Waterstrat, J.N. Giovanini, S.D. Duke, M.P. Hayes, T. Quinn, and A.J. Kroll. 2012. Empirical and simulation evaluations of an abundance estimator using unmarked individuals of cryptic forest-dwelling taxa. Forest Ecology and Management 286:129-136.

McKenzie, D.I., J.D. Nichols, G.B. Lachman, S. Droege, A.J. Royle, and C.A. Langtimm. 2002. Estimating site occupancy rates when detection probabilities are less than one. Ecology 83(8): 2248-2255.

Menzel, J. M., W. M. Ford, M. A. Menzel, T. C. Carter, J. E. Gardner, J. D. Garner, and J. E. Hofmann. 2005. Summer habitat use and home-range analysis of the endangered Indiana bat. Journal of Wildlife Management 69: 430-436.

Puechmaille, S.J., G. Wibbelt, V. Korn, H. Fuller, F. Forget, K. Mühldorfer, A. Kurth, W. Bogdanowicz, C. Borel, T. Bosch, T. Cherezy, M. Drebet, T. Görföl, A. Haarrsma, F. Herhaus, G. Hallart, M. Hammer, C. Jungmann, Y. Le Bris, L. Lutsar, M. Masing, B. Mulkens, K. Passior, M. Starrach, A. Wojtaszewski, U. Zöphel, E. Teeling. 2011. 
Pan-European distribution of white-nose syndrome fungus (Geomyces destructans) not associated with mass mortality. PLoS ONE 6(4): e19167.

Schwartz, C.W. and E.R. Schwartz. 2001. The Wild Mammals of Missouri. University of Missouri Press. Columbia, MO. 368 pp.

Starbuck, C.A., S.K. Amelon, and F.R. Thompson. 2015. Relationships between bat occupancy and habitat and landscape structure along a savanna, woodland, forest gradient in the Missouri Ozarks. Wildlife Society Bulletin 39(1): 20-30.

Reidy, J.L., F.R. Thompson, and S.W. Kendrick. 2014. Breeding bird response to habitat and landscape factors across a gradient of savanna, woodland, and forest in the Missouri Ozarks. Forest Ecology and Management 313: 34-46.

Rigby, E.A. 2016. Simulating effects of imperfect detectability in bird surveys. $\mathrm{PhD}$ Dissertation. University of Minnesota. Minneapolis, MN. X + 324 pp.

Roach, M.C. 2016. Breeding bird response to pine-savanna and woodland restoration in the Ozark-Ouachita Interior Highlands. Master's Thesis. University of Missouri, Columbia, MO. Ix $+126 \mathrm{pp}$.

Rosenstock, S. S., D. R. Anderson, K. M. Giesen, T. Leukering, and M. F. Carter. 2002. Landbird counting techniques: current practices and an alternative. The Auk 119: 4653.

Royle, J.A. 2004a. Generalized estimators of avian abundance from count survey data. Animal Biodiversity and Conservation 27(1): 375-386.

Royle, J.A. 2004b. N-mixture models for estimating population size from spatially replicated counts. Biometrics 60(1): 108-115.

Royle, J.A., and J.D. Nichols. 2003. Estimating abundance from repeated presenceabsence data or point counts. Ecology 84(3): 777-790.

Ruiz-Gutierrez, V., E. F. Zipkin, and A. A. Dhondt. 2010. Occupancy dynamics in a tropical bird community: Unexpectedly high forest use by birds classified as nonforest species. Journal of Applied Ecology 47: 621-630.

Turner, G.G., D.M. Reeder, J.T.H. Coleman. 2011. A five-year assessment of mortality and geographic spread of white-nose syndrome in North American bats and a look to the future. Bat Research News 52(2): 13-27.

Veilleux, J.P. and S.L.Veilleux, 2004. Intra-annual and interannual fidelity to summer roost areas by female eastern pipistrelles, Pipistrellus subflavus. The American Midland Naturalist 152(1): 196-200. 
Walters, C., A. Collen, T. Lucas, K. Mroz, C. Sayer, and K. E. Jones. 2013. Challenges of using bioacoustics to globally monitor bats. Pp. 479-500 in Bat evolution, ecology, and conservation (R. A. Adams and S. C. Pedersen, eds.). Springer, New York. 547 pp.

Williams, B.K., J.D. Nichols, and M.J. Conroy. 2002. Analysis and management of animal populations: modeling, estimation, and decision making. Academic Press. San Diego, CA. 817 pp.

Yamaura, Y. 2013.Confronting imperfect detection: behavior of binomial mixture models under varying circumstances of visits, sampling sites, detectability, and abundance, in small-sample situations. Ornithological Science 12: 73-88.

Yamaura, Y., M. Kery, and J.A. Royle. 2016. Study of biological communities' subject to imperfect detection: bias and precision of community N-mixture abundance models in small-sample situations. Ecological Research 31(3): 289-305.

Yates, M. D. and R. M. Muzika. 2006. Effect of forest structure and fragmentation on site occupancy of bat species in Missouri Ozark forests. Journal of Wildlife Management 70: $1238-1248$. 
Table 1. Model scenarios and parameters used to generate simulated datasets to evaluate the performance of n-mixture and removal models fit in the UNMARKED package. We varied the number of sites, number of visits to a site, the known population size (Ń) and the probability of detection $(p)$ to create four scenarios

\begin{tabular}{|c|c|c|c|c|}
\hline Model Scenarios & Sites & Visits & Ń & $p$ \\
\hline 0 - Baseline Values & 80 & 3 & 70 & 0.50 \\
\hline \multirow[t]{5}{*}{1 - Manipulation of Site Number } & 50 & 3 & 70 & 0.50 \\
\hline & 60 & 3 & 70 & 0.5 \\
\hline & 80 & 3 & 70 & 0.5 \\
\hline & 90 & 3 & 70 & 0.5 \\
\hline & 120 & 3 & 70 & 0.5 \\
\hline \multirow[t]{3}{*}{2 - Manipulation of Visit Number } & 80 & 3 & 70 & 0.50 \\
\hline & 80 & 4 & 70 & 0.50 \\
\hline & 80 & 5 & 70 & 0.50 \\
\hline \multirow[t]{13}{*}{3 - Manipulation of $\mathrm{N}$ and $P$} & 80 & 3 & 35 & 0.05 \\
\hline & 80 & 3 & 35 & 0.1 \\
\hline & 80 & 3 & 35 & 0.15 \\
\hline & 80 & 3 & 35 & 0.2 \\
\hline & 80 & 3 & 35 & 0.25 \\
\hline & 80 & 3 & 35 & 0.4 \\
\hline & 80 & 3 & 35 & 0.5 \\
\hline & 80 & 3 & 35 & 0.75 \\
\hline & 80 & 3 & 35 & 0.9 \\
\hline & 80 & 3 & 70 & 0.05 \\
\hline & 80 & 3 & 70 & 0.1 \\
\hline & 80 & 3 & 70 & 0.15 \\
\hline & 80 & 3 & 70 & 0.2 \\
\hline
\end{tabular}




\begin{tabular}{|c|c|c|c|c|}
\hline Model Scenarios & Sites & Visits & Ń & $p$ \\
\hline & 80 & 3 & 70 & 0.25 \\
\hline & 80 & 3 & 70 & 0.4 \\
\hline & 80 & 3 & 70 & 0.5 \\
\hline & 80 & 3 & 70 & 0.75 \\
\hline & 80 & 3 & 70 & 0.9 \\
\hline & 80 & 3 & 110 & 0.05 \\
\hline & 80 & 3 & 110 & 0.1 \\
\hline & 80 & 3 & 110 & 0.15 \\
\hline & 80 & 3 & 110 & 0.2 \\
\hline & 80 & 3 & 110 & 0.25 \\
\hline & 80 & 3 & 110 & 0.4 \\
\hline & 80 & 3 & 110 & 0.5 \\
\hline & 80 & 3 & 110 & 0.75 \\
\hline & 80 & 3 & 110 & 0.9 \\
\hline & 80 & 3 & 150 & 0.05 \\
\hline & 80 & 3 & 150 & 0.1 \\
\hline & 80 & 3 & 150 & 0.15 \\
\hline & 80 & 3 & 150 & 0.2 \\
\hline & 80 & 3 & 150 & 0.25 \\
\hline & 80 & 3 & 150 & 0.4 \\
\hline & 80 & 3 & 150 & 0.5 \\
\hline & 80 & 3 & 150 & 0.75 \\
\hline & 80 & 3 & 150 & 0.9 \\
\hline $\begin{array}{l}4 \text { - Variation in capture } P \text { once } \\
\text { captured }^{3}\end{array}$ & 80 & 3 & 70 & $0.5,0.1$ \\
\hline
\end{tabular}


Table 2. Mean estimated abundance $(\mathrm{N})$, standard error (SE), relative bias (RB), mean absolute error (MAE) and mean absolute percent error (MA\%E) in abundance estimates by the n-mixture and removal model from simulated data for different numbers of sites and known population $=70$, detection probability $=0.5$, and 3 visits to a site.

\begin{tabular}{lcccccc}
\hline Model & Sites & $\mathrm{N}$ & $\mathrm{SE}$ & $\mathrm{RB}$ & MAE & MA\%E \\
\hline N-mixture & 50 & 100 & 20.46 & 0.43 & 31.26 & 44.65 \\
& 60 & 102 & 19.45 & 0.46 & 32.91 & 47.02 \\
& 80 & 104 & 17.85 & 0.49 & 34.57 & 49.39 \\
& 90 & 103 & 17.48 & 0.48 & 33.56 & 47.94 \\
& 120 & 106 & 16.17 & 0.51 & 35.69 & 50.99 \\
& 50 & 70 & 1.47 & -0.0005 & 0.70 & 1.00 \\
& 60 & 70 & 1.34 & 0.0001 & 0.64 & 0.91 \\
& 80 & 70 & 1.16 & 0.0004 & 0.54 & 0.78 \\
& 90 & 70 & 1.10 & 0.0005 & 0.51 & 0.72 \\
& 120 & 70 & 0.95 & 0.0005 & 0.44 & 0.63 \\
\hline
\end{tabular}


Table 3. Mean estimated abundance $(\mathrm{N})$, standard error $(\mathrm{SE})$, relative bias (RB), mean absolute error (MAE) and mean absolute percent error (MA\%E) in abundance estimates by the n-mixture and removal model from simulated data for different numbers of visits and known population $=70$, detection probability $=0.5$, and 80 sites.

\begin{tabular}{lcccccc}
\hline Model & Visits & $\mathrm{N}$ & $\mathrm{SE}$ & $\mathrm{RB}$ & MAE & MA\%E \\
\hline N-Mixture & 3 & 104 & 17.85 & 0.49 & 34.57 & 49.39 \\
& 4 & 100 & 17.04 & 0.43 & 30.25 & 43.21 \\
Removal & 5 & 93 & 14.64 & 0.33 & 23.37 & 33.38 \\
& 3 & 70 & 1.16 & 0.0004 & 0.54 & 0.78 \\
& 4 & 68 & 0.87 & -0.1690 & 0.22 & 1.99 \\
& 5 & 70 & 0.96 & -0.0001 & 0.17 & 1.24 \\
\hline
\end{tabular}


Table 4. Mean estimated abundance (N), standard error (SE), relative bias (RB), mean absolute error (MAE) and mean absolute percent error (MA\%E) in abundance estimates by the n-mixture and removal model from simulated data for different known population sizes and detection probabilities and 3 visits to a site.

\begin{tabular}{|c|c|c|c|c|c|c|c|c|c|c|c|}
\hline \multirow[b]{2}{*}{$\mathrm{N}^{1}$} & \multirow[b]{2}{*}{$p^{2}$} & \multirow[b]{2}{*}{$\mathrm{N}$} & \multirow[b]{2}{*}{ SE } & \multicolumn{3}{|c|}{ N-Mixture } & \multicolumn{5}{|c|}{ Removal } \\
\hline & & & & $\mathrm{RB}$ & MAE & MA\%E & $\mathrm{N}$ & SE & $\mathrm{RB}$ & MAE & $\mathrm{MA} \% \mathrm{E}$ \\
\hline \multirow[t]{9}{*}{35} & 0.05 & 59 & 35.1 & 0.7 & 29.6 & 84.7 & - & - & - & - & - \\
\hline & 0.1 & 68 & 26.8 & 0.9 & 34.3 & 98.1 & 43 & 22.6 & 0.2 & 7.0 & 12.0 \\
\hline & 0.15 & 74 & 21.3 & 1.1 & 39.7 & 113.5 & 37 & 7.7 & 0.0 & 5.6 & 16.1 \\
\hline & 0.2 & 78 & 20.5 & 1.2 & 43.0 & 123.0 & 35 & 4.2 & 0.0 & 3.2 & 9.3 \\
\hline & 0.25 & 81 & 18.1 & 1.3 & 45.9 & 131.3 & 35 & 2.6 & 0.0 & 2.0 & 5.6 \\
\hline & 0.4 & 81 & 20.6 & 1.3 & 45.8 & 130.8 & 35 & 1.1 & 0.0 & 0.7 & 2.0 \\
\hline & 0.5 & 68 & 19.8 & 0.9 & 33.0 & 94.4 & 35 & 0.8 & 0.0 & 0.4 & 1.1 \\
\hline & 0.75 & 36 & 1.9 & 0.0 & 1.8 & 5.1 & 35 & 0.7 & 0.0 & 0.1 & 0.2 \\
\hline & 0.9 & 35 & 0.8 & 0.0 & 0.4 & 1.0 & 35 & 0.7 & 0.0 & 0.0 & 0.0 \\
\hline \multirow[t]{12}{*}{70} & 0.05 & 68 & 25.7 & 0.0 & 12.5 & 17.9 & - & - & - & - & - \\
\hline & 0.10 & 81 & 16.9 & 0.2 & 13.9 & 19.9 & 77 & 24.7 & 0.1 & 6.6 & 11.6 \\
\hline & 0.15 & 88 & 13.3 & 0.3 & 19.0 & 27.1 & 71 & 9.7 & 0.0 & 6.2 & 10.1 \\
\hline & 0.20 & 93 & 11.7 & 0.3 & 23.8 & 33.9 & 70 & 5.5 & 0.0 & 4.2 & 6.0 \\
\hline & 0.25 & 98 & 10.9 & 0.4 & 28.6 & 40.8 & 70 & 3.7 & 0.0 & 2.8 & 4.0 \\
\hline & 0.40 & 107 & 13.7 & 0.5 & 36.9 & 52.7 & 70 & 1.6 & 0.0 & 1.0 & 1.4 \\
\hline & 0.50 & 104 & 18.3 & 0.5 & 34.4 & 49.2 & 70 & 1.2 & 0.0 & 0.5 & 0.8 \\
\hline & 0.75 & 73 & 3.7 & 0.0 & 3.4 & 4.8 & 70 & 0.9 & 0.0 & 0.1 & 0.2 \\
\hline & 0.90 & 70 & 1.3 & 0.0 & 0.7 & 1.1 & 70 & 0.9 & 0.0 & 0.0 & 0.0 \\
\hline & 0.05 & 77 & 19.5 & -0.3 & 33.1 & 30.1 & - & - & - & - & - \\
\hline & 0.10 & 90 & 11.7 & -0.2 & 20.1 & 18.3 & 117 & 28.0 & 0.1 & 5.1 & 9.6 \\
\hline & 0.15 & 99 & 9.4 & -0.1 & 11.4 & 10.4 & 112 & 12.0 & 0.0 & 9.3 & 8.4 \\
\hline
\end{tabular}




\begin{tabular}{|c|c|c|c|c|c|c|c|c|c|c|c|}
\hline \multirow[b]{2}{*}{$\mathrm{N}^{1}$} & \multirow[b]{2}{*}{$p^{2}$} & \multirow[b]{2}{*}{$\mathrm{N}$} & \multirow[b]{2}{*}{ SE } & \multicolumn{3}{|c|}{ N-Mixture } & \multicolumn{5}{|c|}{ Removal } \\
\hline & & & & $\mathrm{RB}$ & MAE & MA\%E & $\mathrm{N}$ & SE & $\mathrm{RB}$ & MAE & $\mathrm{MA} \% \mathrm{E}$ \\
\hline \multirow{15}{*}{150} & 0.20 & 106 & 8.5 & 0.0 & 4.1 & 3.7 & 111 & 6.9 & 0.0 & 5.4 & 4.9 \\
\hline & 0.25 & 113 & 8.2 & 0.0 & 3.6 & 3.2 & 110 & 4.6 & 0.0 & 1.5 & 1.6 \\
\hline & 0.40 & 130 & 9.3 & 0.2 & 20.6 & 18.7 & 110 & 2.0 & 0.0 & 1.3 & 1.2 \\
\hline & 0.50 & 137 & 12.8 & 0.2 & 27.1 & 24.7 & 110 & 1.5 & 0.0 & 0.7 & 0.6 \\
\hline & 0.75 & 114 & 5.8 & 0.0 & 5.4 & 4.9 & 110 & 1.2 & 0.0 & 0.1 & 0.1 \\
\hline & 0.90 & 110 & 1.9 & 0.0 & 1.2 & 1.1 & 110 & 1.2 & 0.0 & 0.0 & 0.0 \\
\hline & 0.05 & 83 & 15.6 & -0.4 & 67.2 & 44.8 & - & - & - & - & - \\
\hline & 0.1 & 97 & 9.6 & -0.4 & 53.3 & 35.6 & 158 & 31.2 & 0.2 & 7.0 & 12.1 \\
\hline & 0.15 & 108 & 7.6 & -0.3 & 42.4 & 28.3 & 152 & 13.7 & 0.0 & 10.6 & .0 \\
\hline & 0.2 & 117 & 6.9 & -0.2 & 32.8 & 21.9 & 151 & 8.0 & 0.0 & 6.4 & 4.3 \\
\hline & 0.25 & 126 & 6.6 & -0.2 & 23.9 & 15.9 & 150 & 5.3 & 0.0 & 1.3 & 1.2 \\
\hline & 0.4 & 151 & 6.9 & 0.0 & 2.5 & 1.7 & 150 & 2.3 & 0.0 & 1.4 & 0.9 \\
\hline & 0.5 & 163 & 9.2 & 0.1 & 14.6 & 9.7 & 150 & 1.7 & 0.0 & 0.1 & 0.7 \\
\hline & 0.75 & 156 & 7.8 & 0.0 & 7.2 & 4.8 & 150 & 1.4 & 0.0 & 0.2 & 0.1 \\
\hline & 0.9 & - & - & - & - & - & 150 & 1.4 & 0.0 & 0.0 & 0.0 \\
\hline
\end{tabular}


Table 5. Mean estimated abundance (N), standard error (SE), relative bias (RB), mean absolute error (MAE) and mean absolute percent error (MA\%E) in abundance estimates by the n-mixture and removal model from simulated when detection probability changed from 0.5 to 0.1 after individuals first capture $\left(\mathrm{p}, \mathrm{p}_{1}\right)$ and known population $=70$, number of sites $=80$, and 3 visits to a site.

\begin{tabular}{lccccccc}
\hline Model & $\mathrm{N}$ & $\mathrm{SE}$ & $p$ & $p_{1}$ & $\mathrm{RB}$ & $\mathrm{MAE}$ & $\mathrm{MA} \% \mathrm{E}$ \\
\hline N-mixture & 104 & 17.85 & 0.5 & - & 0.49 & 34.57 & 49.39 \\
& 73.98 & 10.03 & 0.5 & 0.1 & 0.06 & 36.86 & 52.66 \\
Removal & 70 & 1.16 & 0.5 & - & 0.0004 & 0.54 & 0.78 \\
\hline
\end{tabular}




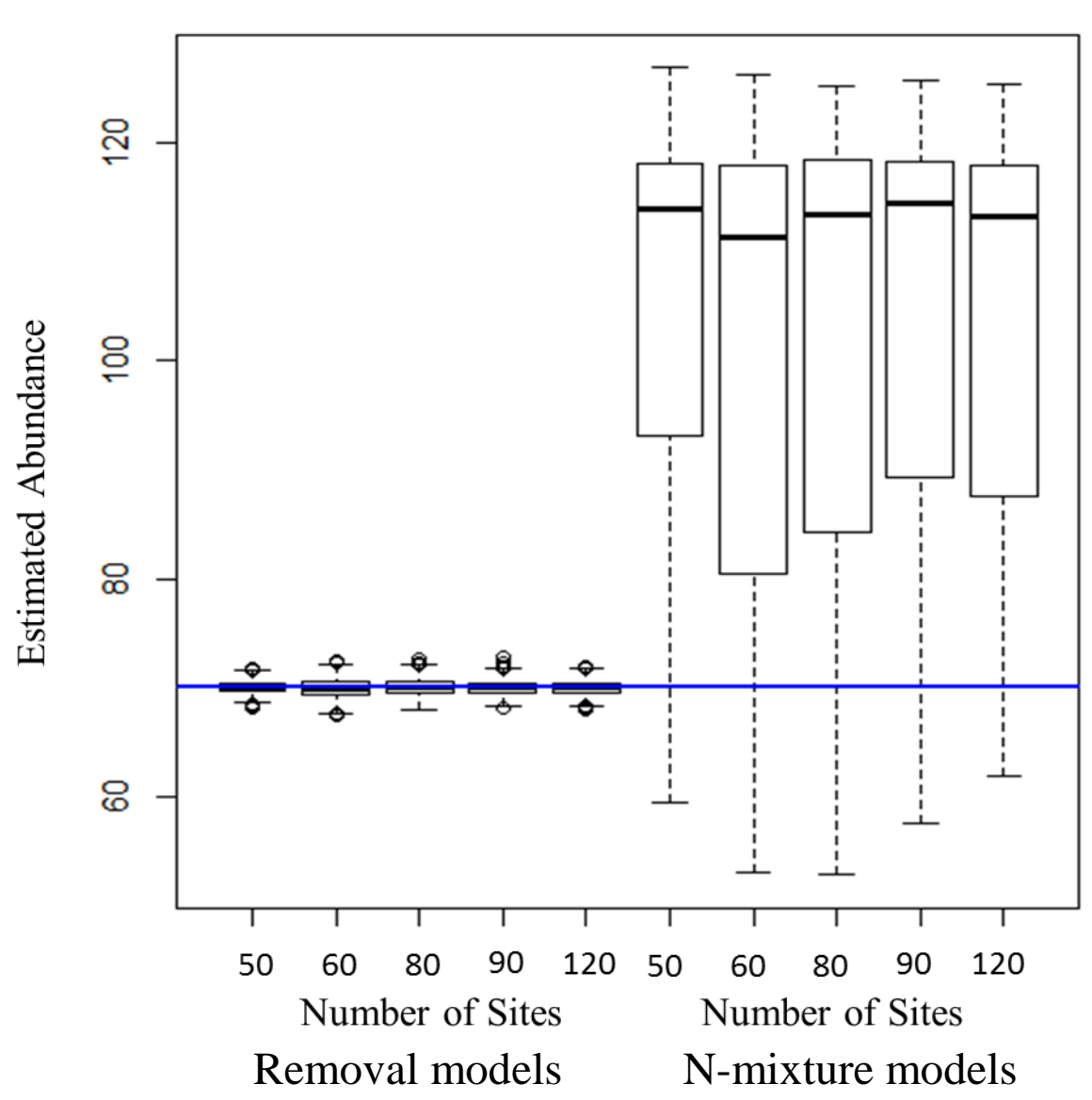

Figure 1. Abundance estimates by the removal and the n-mixture models fit in the package UNMARKED based on simulated count data and different numbers of sites and a known population size $=70$. 


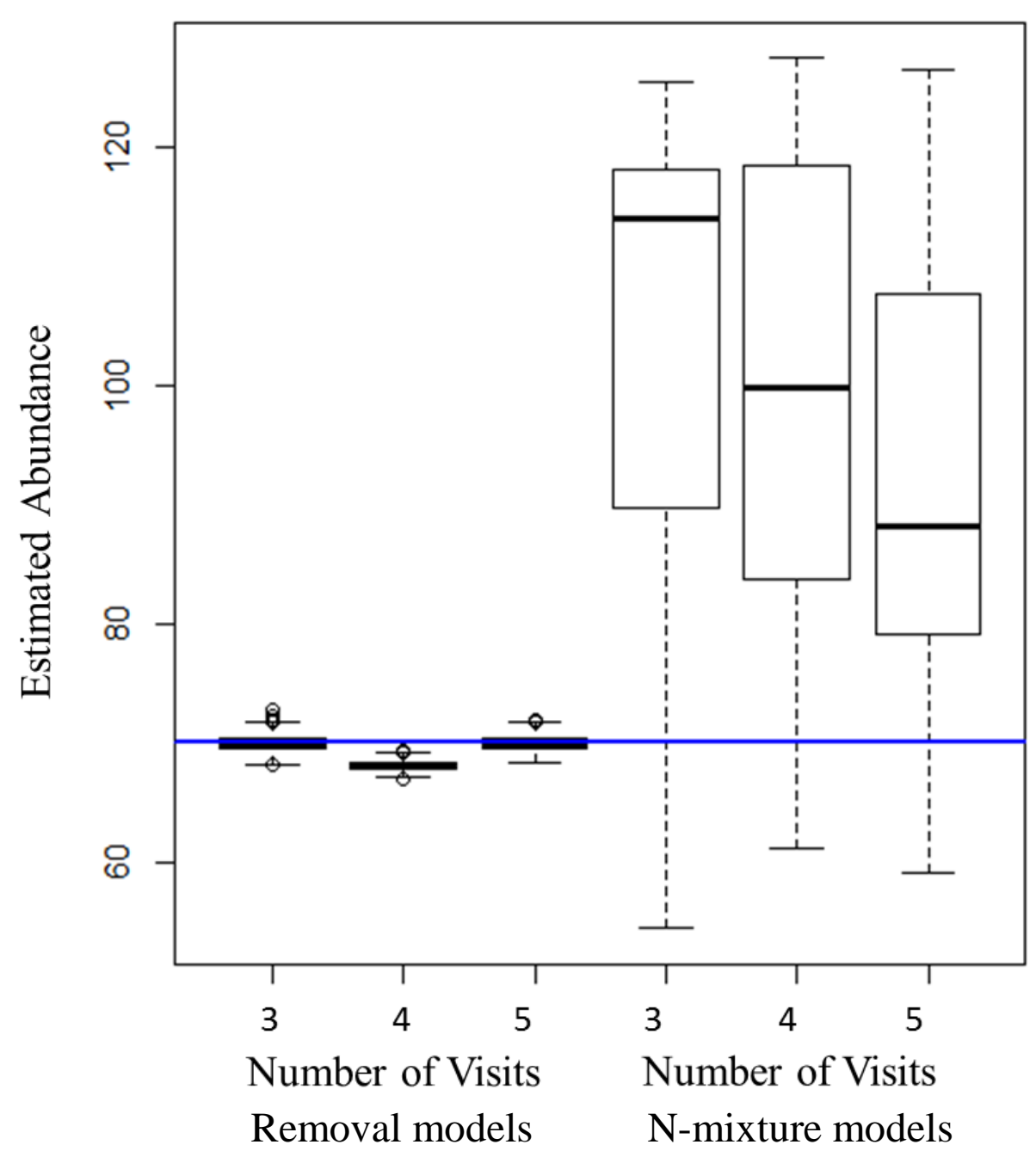

Figure 2. Abundance estimates by the removal and n-mixture models fit in the package UNMARKED with simulated data for 3, 4, or 5 visits to a site and known population size $=70$. 


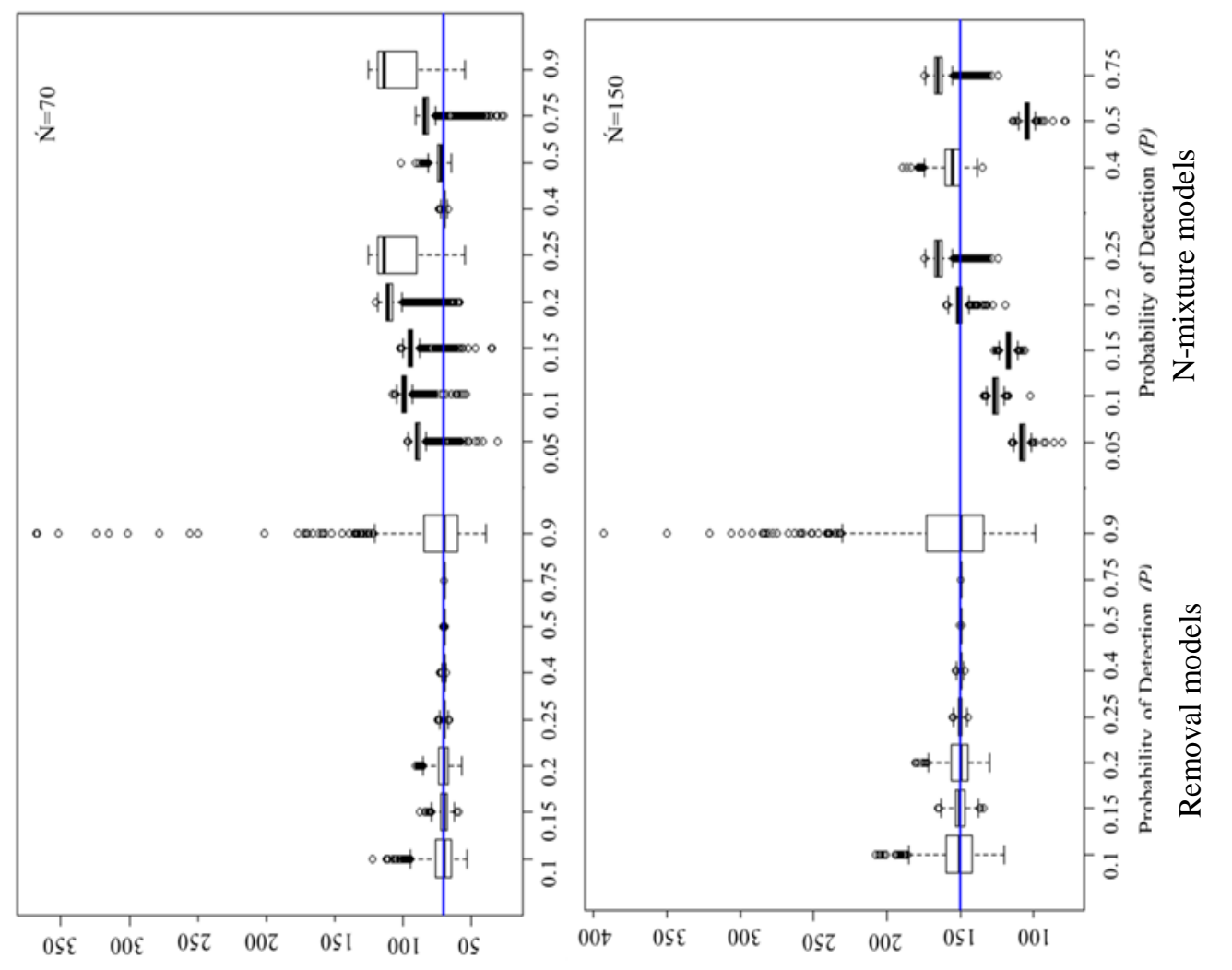

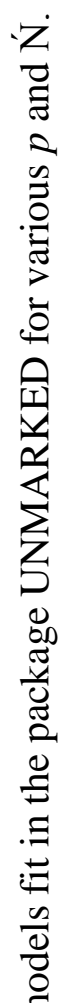

ํำ

。응

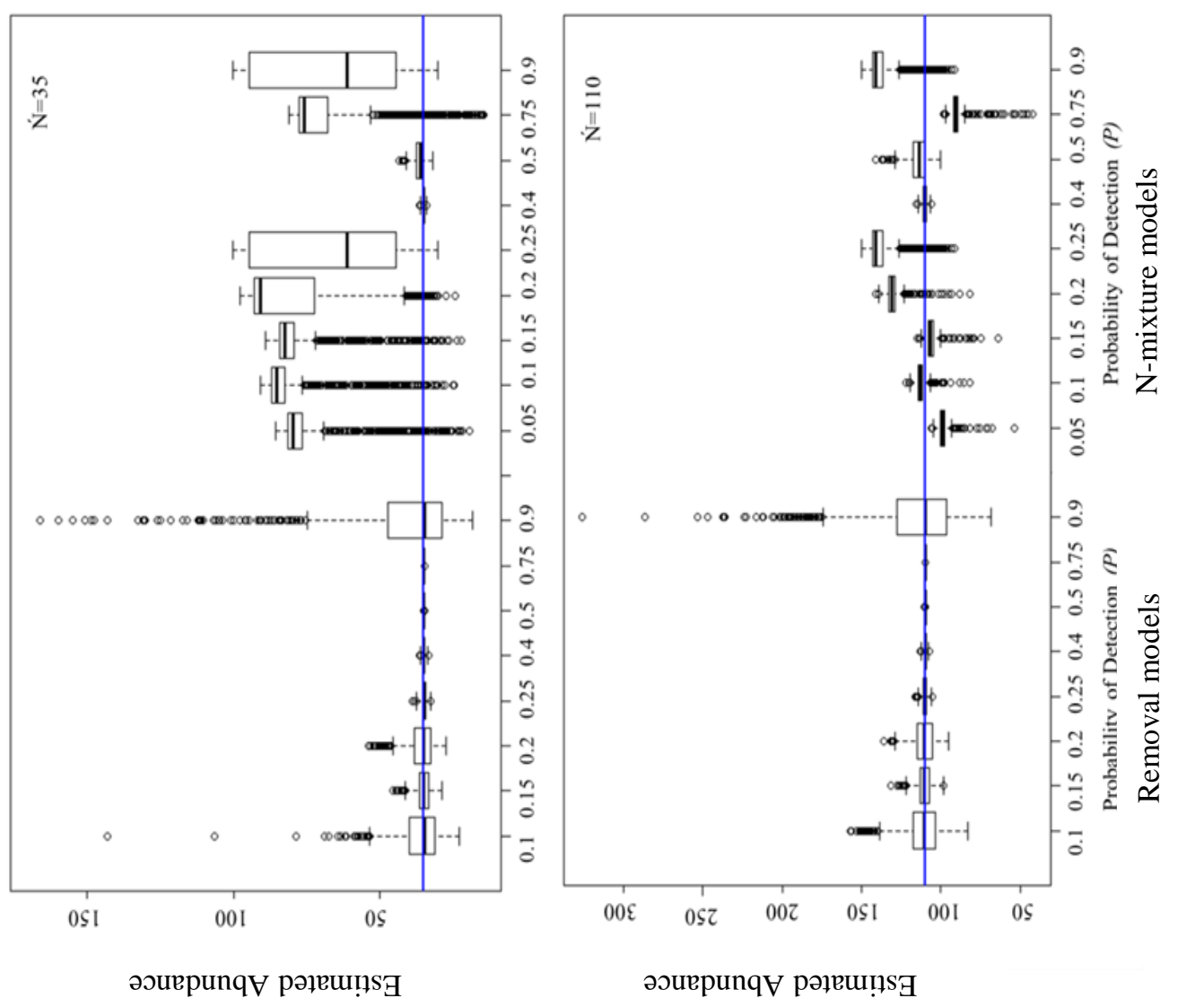

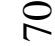

กิ

Z

릉

bs

ฮี

.

7

氖

莗

d

क

음

ह

을

กั

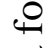

䒕

$\vec{\Xi}$

\& 0

ల్

胥

灵

온

$=$

¿

ल 3

站 


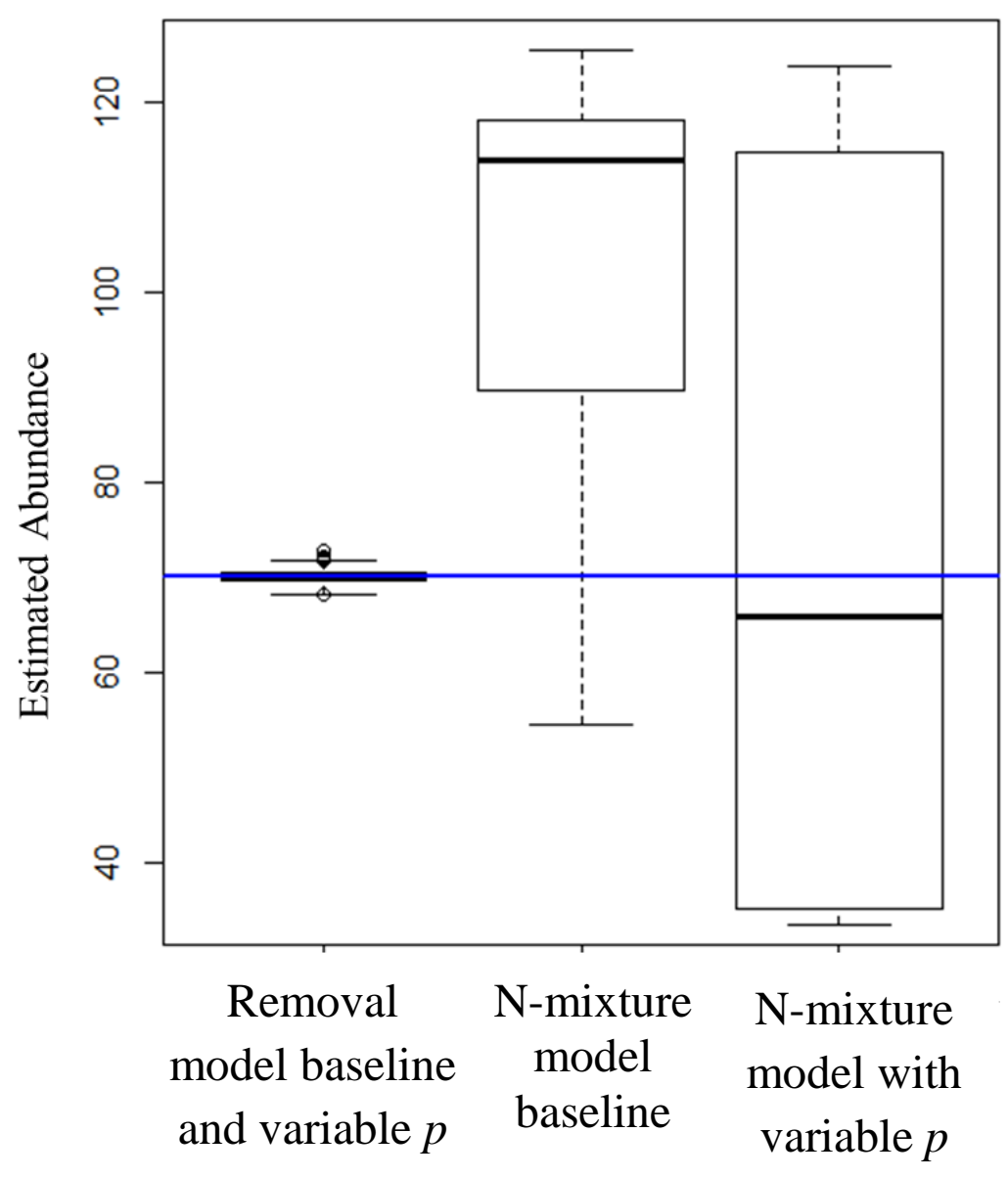

Figure 4. Abundance estimates by the removal and n-mixture models fit in the package UNMARKED for the removal model and n-mixture model with constant detection probability (baseline) and with detection probability changing from 0.5 to 0.1 after an individual's first capture to simulate net avoidance behavior and known population size $=70$. Results do not change for the removal model since it only uses an individual's first capture. 


\title{
CHAPTER 3. Relationships of prescribed fire and vegetation structure with insect abundances across a gradient of savannas, woodlands, and non-managed forests in the Ozark Highlands, USA
}

\author{
Kathryn M. Womack ${ }^{1}$, Frank R. Thompson III' ${ }^{2}$, and Sybill K. Amelon ${ }^{2}$ \\ ${ }^{1}$ School of Natural Resources, 302 Natural Resource Building, University of Missouri, \\ Columbia, MO 65211, USA \\ ${ }^{2}$ Northern Research Station, U.S.D.A. Forest Service, 202 Natural Resource Building, \\ Columbia MO 65211, USA \\ ${ }^{3}$ Corresponding author: E-mail: kmwhr5@mail.missouri.edu
}

\begin{abstract}
Savannas and woodlands lost due to landscape conversion and fire suppression in the Midwest are being restored using prescribed fire and mechanical tree thinning. Information is needed on the effects of restoration practices on bat species site use and their insect prey to inform management decisions for species of conservation concern. Our objective was to understand the relationships between prescribed fire and vegetation structure on insect abundance across a gradient of savannas, woodlands, and nonmanaged forests in the Ozark Highlands in Missouri. We sampled insects at active and passive plots within $250 \mathrm{~m}$ of bat mist-net sites during summer 2014-2016. We used light trapping, malaise, panel, and pitfall traps to collect insect representative of the prey community potentially available to bats. We identified insects to Order, and evaluated multiple insect response variables for active and passive plots using generalized linear mixed models. We fit models to evaluate our a priori hypotheses, and used site as a random effect in all models. We found support for the effects of microclimate, fire frequency, years since burned, stand structure, and environmental covariates on insect abundance. Insect abundances were negatively related to dry and hot microclimates
\end{abstract}


(aspects $135-315^{\circ}$ ) at passive plots. Insect abundance was highest at plots burned 2 or 3 times compared to four times or non-managed within the last 10 years for two insect response variables. Stand overstory structure influenced insect abundances at passive plots while temperature was positively related to insect abundances at active plots. We found no relationship between understory vegetation classes and insect abundance, likely a result of the type of vegetation data collected in our study. We found evidence of positive, negative, and no relationship of restoration management on abundance of various insect species groups dependent on plot type and insect response variable. Managers can consider the response of targeted species or group of species to better understand how they may respond to savanna woodland restoration practices, however, temperature and plot aspect influenced more of our insect response variables than did fire and vegetation structure. We suggest savanna and woodland restoration results in similar or slightly greater potential insect prey abundances for bats than non-managed forest. Fire intensity and seasonality likely influence insect abundances in addition to the factors we considered

\section{INTRODUCTION}

Savannas and woodlands in the Midwest United States are transitional ecosystems between tall grass prairies to the west, and dense forest to the east (Braun 1950, Taft 1997, Abrams 1992, Reidy et al. 2014). The number and area of these ecosystems on the Midwest landscape have drastically decreased over the last two centuries due to anthropogenic landscape conversion and fire suppression (Taft 1997, Abrams 1992). Grasses are the dominate ground cover in savannas and forbs and tree canopy cover range 
25-50\% (Anderson et al. 1999, Taft 1997). Woodlands have up to 80\% canopy cover and an understory that is a dynamic mixture of grasses, forbs, woody shrubs, and seedlings (Taft 1997). Savannas and woodlands are disturbed systems requiring reoccurring fire to maintain their structure and dynamic understory vegetation. Forest succession leads to changes in the microclimate and composition of the understory. Savannas and woodlands develop into closed canopy forests in the absence of disturbance and the understory composition of woody shrubs and small trees changes. The recruitment of shade intolerant species such as oaks, a dominate canopy tree in savanna and woodland systems, is low without disturbances that create gaps in the canopy to allow for light penetration to the understory (Johnson et al. 2009). Restoration efforts to create and maintain these disturbance-dependent systems usually consists of prescribed fire and mechanical tree thinning to reduce canopy cover and tree densities. These tools can change the species composition, stand structure, and vegetation of managed stands (Jacobs and Nix. 2015, Pitt et al. 2014). Understanding how wildlife, especially species of conservation concern, are affected by restoration practices compared to sites with no restoration is critical in order to ensure sound management of these species.

Linking restoration and wildlife use of these areas has become a focus of many ecological studies. For example, songbird species that require early-successional habitats and species that use woodlands are positively associated with structural changes found within restored savannas and woodlands in Missouri (Reidy et al. 2014). Similarly, earlysuccessional and generalist songbird species have greater densities, and forest-interior species lower densities at sites managed with prescribed fire or mechanical tree thinning 
at restored pine woodland sites compared to non-managed forests in Missouri, Oklahoma, and Arkansas (Roach 2016). Reduced tree densities and increased fire frequencies is positively related to site occupancy of evening bats in the Ozarks of Missouri (Starbuck et al. 2015). Site occupancy of eastern red bats and tri-colored bats is negatively related to higher basal areas while occupancy of eastern red bats and tri-colored bats are positively related to increased canopy (Yates and Muzika 2006). Roosting habitat increased for evening bats after prescribed fire was used to restore savanna and woodland habitats in Taney County, Missouri (Boyles and Aubrey 2006). Most wildlife studies assume habitat selection is based on potential roost, den, or nest sites, or based on reduced energy costs by avoiding vegetation clutter; however, species may also select these restored habitats due to greater food availability. Relatively few studies make the link from prescribed-fire effects on wildlife and the relationship to increases in potential insect prey availability. Northern long-eared bats, a known forest interior species, has increased acoustic activity at burned sites having greater insect abundances than unburned sites in Kentucky (Lacki et al. 2009). Understanding this link between insects and wildlife is imperative as changes in habitat association found in studies may not be driven by habitat structure, but rather by changes in prey abundances. Understanding how prescribed fire as a restoration tool affects food availability for wildlife will also provide a clearer picture of the potential ultimate factors affecting resource selection and site use to help guide management decisions.

Insect responses to prescribed fire vary among studies, between sites within the same treatment, and within and between insect Orders (Niwa and Peck 2002, Seimann et al. 
1997). Litter arthropod abundance varies by species initially at burned sites compared to unburned sites but over time, the differences decrease due to recolonization and vegetation responses post fire in Oregon (Niwa and Peck 2002). Hemipterans abundances and species richness are greater in unburned than burned tall-grass prairies for 2 years following a burn, but there is no difference between sites burned every 3-5 years compared to unburned sites in Illinois (Wallner et al. 2012). Conversely, captures of Coleopterans, Dipterans, and total insects increase at sites managed with prescribed fire compared to unmanaged sites in Kentucky (Lacki et al. 2009). Arthropod abundance is higher at burned sites than thinned or unmanaged pine plantations in the southeastern United States (Zebehazy 2002). These studies suggest that fire may cause an increase in certain plant species or vegetation structure that provides better resources for arthropod communities. However, burning has little effect on the arthropod species richness and abundance in oak savannas compared to non-managed sites in Minnesota (Siemann et al. 1997). With time, oak savanna sites managed with prescribed fire became more similar in vegetation structure resulting in similar arthropod communities (Siemann et al. 1997). Generally sites with diverse vegetation communities and structure generally have higher arthropod abundances.

Fire not only directly affects insect abundances through mortality, but also indirectly by causing changes to the vegetation. Nevertheless, fire is not the only factor that affects insect abundances; site characteristics can also affect arthropods. Ground beetle species richness differs within treatment groups with similar vegetation structure in Illinois (Willand et al. 2011). Differences in Coleopteran species richness are linked to 
microclimate factors associated with site aspect; the southerly site had lower Coleopteran richness compared to easterly facing sites (Willand et al. 2011).

We used multiple trap types to survey the volant insect and leaf litter communities to have a comprehensive view of potential insect prey for wildlife species, but with a focus on Missouri's bat community. Additionally, we sought to understand the differences in insect abundance based on savanna woodland restoration sites managed mainly with prescribed fire compared to non-managed sites. We evaluated a priori hypotheses for relationships of vegetation structure, prescribed fire, and other environmental factors with insect abundance across a gradient of restoration, and non-managed forests in the Ozark Highlands of Missouri. Ferrenberg (2006) found that arthropod abundance increased with understory heterogeneity, therefore, we hypothesized that insect abundance should increase with percent forb and herbaceous cover at sites (Table 1). Insect abundance can also be lower at sites with a southerly aspect and lower humidity (Willard 2011) so we evaluated the hypothesis that insect abundances would be lower at plots with more southerly aspects (Table 1). Wallner (et al. 2012) found that arthropod abundances are lower at sites burned every 1 to 2 years and that sites burned once every 3-5 years have high insect abundances. We hypothesized insect abundance should have a negative quadratic relationship with number of fires at plots within the last 10 years and plots burned 2 or 3 should have the highest insect abundances (Table 1). Insect abundances are generally greater at burned sites than non-managed sites locations (Lacki et al. 2009, Zabehazy 2002), however, these sites did not evaluate the time since the site burned. Fire decreased ground insect abundances, but increased diversity in mixed-conifer forests in 
California (Ferrenberg et al. 2006). Our fourth hypothesis was that insect abundances should be lower at sites recently burned (0-3 years), and increase as insects recolonized burned plots (Table 1). Ground Coleopteran abundance was lower at sites at 1 year since burned compared to sites burned 2 or 3 years previously, and unburned sites (Willard et al. 2011). Our fifth hypothesis was that insect abundances will be higher at sites with lower tree densities for all size classes, and at plots with decreased percent canopy cover (Table 1). Sites with greater age diversity and heterogeneity in vegetation supported more arthropods due to increased food resources (Stamps and Linit 1998, Ferrenberg et al. 2006, Hahn and Orrock 2015), and that a reduction in canopy cover increased understory vegetation diversity and insect abundance compared to closed canopy sites (Lacki et al. 2009). Our sixth hypothesis was that insect abundances should increase as temperature and barometric pressure increase at plots (Table 1). We also hypothesized that insect abundances will be inversely related to the number of lunar light hours at plots (Table 1). Previous works document the positive correlation between temperature and insect activity (Womack 2008, Womack 2011). Barometric pressure also affects insect activity and abundances because low-pressure systems cause a reduction in overall insect activity (Pellegrino et al. 2013, Womack 2008). Nocturnal insect activity is negatively related to increased moonlight (Lang et al. 2006, Womack 2008). Finally, our seventh a priori hypothesis was that insect abundances should increase at plots with greater amounts of leaf litter (Table 1). Leaf litter was positively related to ground dwelling arthropod abundances due to the creation of microhabitats for shelter and foraging (Willard et al. 2011). 


\section{METHODS}

\subsection{Study areas}

Our study sites were in the Ozarks of Missouri, and predominantly the Ozark Highland ecological section. The Ozark Highlands is divided into sixteen ecological subsections based on differences in lithology, landform, soils, and vegetation (Nigh and Schroeder 2002). The Ozarks have many karst features due to the characteristic carbonate bedrock in this region (Nigh and Schroeder 2002). Soils are generally rocky, and have historically supported mainly oak and oak-pine savannas, woodlands, and forests. The Ozarks are dominated by oak-hickory, pine-oak, and mixed-oak woodland, and forest communities (Nelson 2012). Common upland tree species include post oak (Quercus stellata), blackjack oak (Q. marilandica), white oak (Q. alba), northern red oak (Q. rubra), hickory (Carya spp.), shortleaf pine (Pinus echinata), and flowering dogwood (Cornus florida) with open woodlands and savannas containing bluestem grasses (Andropogon gerardii, Schizachyrium scoparium), sedges (Cyperaceae spp.), woody shrubs such as fragrant sumac (Rhus aromatic) and blackberry (Rubus spp.), and saplings (Nelson 2012). Most streams in the area are spring-fed and clear. This region has high biological diversity and endemism (Ethridge 2009).

Due to the regional scale of this study, we sampled study areas that would allow for multiple survey locations with suitable mist-net sites, and that were at least $2 \mathrm{~km}$ apart to prevent pseudo-replication. Study sites were located in: Caney Mountain Conservation Area (538 ha), Peck Ranch Conservation Area (9,616 ha), Drury-Mincy Conservation Area (1,655 ha), and Little Black Conservation Area (1,201 ha) managed by the Missouri 
Department of Conservation (MDC); Roaring River State Park (1,657 ha), Ha Ha Tonka State Park (1,501 ha), Lake of the Ozarks State Parks (7,133 ha), and Knob Noster State Park (1,592 ha) managed by the Missouri Department of Natural Resources; and the Salem, Ava/Willow Springs/Cassville, Houston/Rolla, and Poplar Bluff districts of Mark Twain National Forest (MTNF; 607,029 ha).

\subsection{Study design}

Our study was part of a larger project that included nightly mist-net surveys of bats to determine multi-scale factors that affected bat abundance at sites undergoing restoration management compared to non-burned forests throughout the Ozark Highlands of Missouri from May 15th -August 15th in 2014 -2016 (Figure 1). We designed study sites to have a central mist-net location (i.e., pond, creek, or road rut) with corresponding insect plots within $250 \mathrm{~m}$ from the mist-net site. We measured insect abundance and vegetation on 8 (2014) or 4 (2015 and 2016) sampling plots associated with a central bat mist-net location. We treated each insect plot as an independent survey location for our study.

We located plots by creating a donut-shaped buffer around each mist-net site with the inner boundary $50 \mathrm{~m}$, and the outer bounder $250 \mathrm{~m}$ from mist-net location. We randomly generated 8 or 4 points within this buffer area making sure that each point was at least 50 $\mathrm{m}$ from all other points to prevent pseudo replication, and bias between active and passive traps. We programed plot locations using universal transverse Mercator coordinate systems (UTM) into handheld Garmin eTrex 10 global positioning system 
(GPS) units (St. Louis, Missouri) to navigate to plot locations. Half of our plots were randomly assigned to be either "active" or "passive" plot locations. We used a random number table with random azimuths and distances between $50-250 \mathrm{~m}$ to locate plots for any mist-net locations that were modified in the field due to unsuitable conditions at the planned mist-net location.

\subsection{Insect surveys}

We used a variety of traps to obtain a broad measure of insect abundance which could be affected by trap biases, and different targeted arthropod Orders for each trap (Brigham and Saunders 1990, Sleep and Brigham 2003, Whitaker 1994). We sampled insects at our passive plots with 1 malaise trap (Bioquip Product \# 2875A; Rancho Dominguez, CA), 1 cross vane panel trap (panel trap; Forestry Distributing; Boulder, CO), and 5 pitfall traps. We placed either quart or gallon plastic zip-lock bags with approximately $15-30 \mathrm{~mL}$ of anhydrous reagent ethanol (Carolina Scientific; Burlington, NC) inside the malaise and panel kill jars, respectively. Pitfall traps were pint sized (approximately $747.3 \mathrm{~mL}$ ) restaurant plastic to-go containers that buried such that the container's top edge was flush with the ground surface. We used approximately $70 \mathrm{~mL}$ of polypropylene glycol in each pitfall trap. We placed a plastic reusable plate over each pitfall trap to prevent water and non-targeted species take (e.g., amphibians and small mammals). We set up passive plots with a central pitfall location, and 4 pitfall traps at $9 \mathrm{~m}$ from the plot center in each cardinal direction. Malaise and panel intercept traps were placed approximately $6 \mathrm{~m}$ from the center plot northwest $\left(315^{\circ}\right)$ or southeast $\left(135^{\circ}\right.$; Figure 2$)$. 
We sampled insects at our active plots with a single 12W DC universal black-light trap with bucket set located at the center of the active plot (light trap; Bioquip Products $2851 \mathrm{U}$ and 2851A). We used approximately $30-45 \mathrm{~mL}$ of anhydrous reagent ethanol in gallon zip lock bags placed within the kill jars of our light trap. We powered light traps with 12 V 18AH AJC Panasonic Sealed Lead Acid Batteries (www.amazon.com). We sampled insects for three consecutive days in conjunction with mist-net surveys at the site. We collected light, malaise, and panel trap samples daily (mid-day on day 2, day 3, and day 4). Once collected, we froze insect samples until further processing in the lab. We collected pitfall traps once on day 4 at sites after the conclusion of our $3^{\text {rd }}$ night of mist-net sampling. We combined all five pitfall traps into one container per plot. Pitfall samples were stored in one of the pint to-go containers with a lid in a cool and dark location within our lab until further processing.

\subsection{Insect processing protocol}

We dried insect samples collected from light, malaise, and panel traps in a soil-drying oven at $60^{\circ} \mathrm{C}$ for 24 hours after each field season. We placed samples directly into the drying ovens from freezer storage. We identified all insects into Order categories: Coleopteran, Lepidopteran, Dipteran, Tricopteran, and an "other" group using diagnostic keys and handheld magnifying glasses. We divided each Order into prey size groups relevant to Missouri bat species (see Chapter 4 for more details); however, for our study we did not subdivide Orders. We counted the number of insects within each Order or group from each trap type at a plot. We created an additional column that totaled all individuals captured for each trap (Total).We did not dry samples from pitfall traps and 
counted the total number of insects for each sample. We stored processed samples in a cool, dark place.

\subsection{Vegetation and management covariates}

We measured vegetation in 11.3-m fixed radius plot. We visually estimated the percent cover within a 5-m radius of the plot center of woody or herbaceous shrubs (SHRUB), forbs (FORB), leaf litter (LEAF), and bare ground (BARE; Table 2) with a total percent equaling 100. We determined aspect (ASPECT) using a compass and later transformed it to reach a maximum value at southwest $\left(225^{\circ}\right)$ because this aspect represents the hottest and driest conditions. We measured the diameter at breast height (DBH) of all stems $>1$ in $\mathrm{DBH}$ and calculated tree densities of seedlings and saplings ( $\mathrm{DBH}<6$ in; TPHs), pole timber $(6<\mathrm{DBH}>11 \mathrm{in}$; TPH5), and saw timber $(\mathrm{DBH}>11$; TPH11). We measured percent canopy cover using a spherical densiometer. We visually estimated the percent mid-story and understory. We used a clinometer to estimate slope and height of the canopy, mid-story, and understory. We measured the leaf-litter depth at $2 \mathrm{~m}$ from plot center using a compass and a metric ruler. We measured litter depth in the four cardinal directions, and estimated mean leaf litter to be used in our analysis (LITTER; Table 2). We obtained the years a site was burned in the last 10 years from area managers.

\subsection{Environmental and temporal covariates}

We collected barometric pressure, wind speed, and temperature at sites using a Kestrel 2500 Pocket Weather Meter (AllKestrel.com, Downingtown, PA) at the beginning, middle, and end of each nightly mist-net survey. We noted cloud cover and moon phase 
on our datasheets on a nightly basis. We used the closest National Climatic Data Center (NCDC) weather station to verify our minimum nightly temperatures collected at our mist-net sites, and recorded lunar hours for each survey night. We calculated the following climatic covariates for use in our analyses: mean minimum nightly temperature (mnTEMP), mean barometric pressure (Pressure), and mean lunar light hours (LUNAR) over the 3 survey nights (Table 2). We included temporal covariates Julian date (JUL), and year (YR; Table 2) as fixed effects in candidate models to account for annual variation and variation over the summer on insect abundance at plots (Table 1).

\subsection{Data analysis}

We used an information theoretic approach (Burnham and Anderson 2002) to evaluate our a priori hypotheses represented by candidate models that potentially predicted insect abundances at plots (Table 2). We fit generalized linear mixed models using GLMER within the LMe4 package in $\mathrm{R}$ (version 3.2). We used site as a random effect in all models to account for potential correlated responses at plots in the same site. We scaled numeric covariates using the SCALE function in R. Our candidate models included combinations of our fixed effects covariates, JUL and YR, and a NULL model. We considered four response variables based on captures at active plots over our 3-night sampling period: mean total captures, mean Lepidopteran, mean Coleopteran, and mean Tricopteran (Figure 2). We considered three response variables based on captures in malaise and panel traps over our 3-day survey period: mean total captures, mean Coleopterans, and mean Dipterans (Figure 3). We evaluated total pitfall captured over our 3-day sampling period at a plot (Figure 4). 
We used a multi-step approach to fit models. We first determined if a Poisson or negative binominal distribution was the most appropriate distribution for our generalized mixed linear models by evaluating the over dispersion parameter estimates for our top model from our active and passive datasets using the mean total response variable (a.Total and p.Total). We also simultaneously tested for multicollinearity between model covariates by testing tolerance using the CORR package in R. Next, we used the supported distribution, the negative binomial distribution, to fit our eight candidate models and ranked them using Akaike's Information Criterion for small sample size (AICc). If multiple models were supported for a response variable, we created meaningful post-hoc models by combining the top model with one or more additional covariates that had $95 \%$ confidence intervals that did not overlap zero in other models that ranked higher than the NULL. We model averaged coefficients from supported models with a $\Delta$ AICc value $<2$, and ranked higher than our NULL model to account for model selection uncertainty (Burnham and Anderson 2002). We generated model-averaged predictions of our model results based on supported covariates while holding other model-averaged covariates at their mean. We validated our top models using a k-fold approach (Boyce et al. 2002). We randomly removed $20 \%$ of our sites, and fit our top model with the remaining data, and calculated the correlation between predicted and observed values for the reserved data; we repeated this five times and report the mean correlation. 


\section{RESULTS}

We processed 179 active plots and 174 passive plots collected across a gradient of savanna, woodlands, and non-managed forests in summers 2014-2016. We averaged insects collected at each plot over the 3-day sampling period. We combined insects from our panel and malaise traps at our passive plots. We collected pitfall samples at 174 passive plots. We calculated descriptive statistics of our model covariates for active (Table 4) and passive plots (Table 5), and histograms of our capture frequencies at each plot for all insect response variables (Figures 2, 3, and 4).

\subsection{Active plots}

The top model for mean total insect abundance included the effect of environmental covariates, mnTemp, Pressure, and LUNAR and had an AIC weight $\left(w_{i}\right)=0.887$ (Table 6). The mean k-fold correlation between predicted and observed values was 0.77 indicating a reasonable model fit. Total insect abundance was positively related to increases in mnTemp, and confidence intervals did not overlap zero (Table 8). We predicted on average, 77 individuals at an active plot when mnTemp was $6.5^{\circ} \mathrm{C}$ and 153 when mnTemp was $26^{\circ} \mathrm{C}$ (Figure 5). The next highest model was the Null model (Table 6). The NULL model was the top model with $w_{i}=0.306$ for mean Lepidopteran abundance indicating no support for any covariates (Table 6). The top model for mean Coleopteran abundance included the effect of environmental covariates on insect abundances, and had a $w_{i}=0.945$ (Table 6). The mean k-fold correlation between predicted and observed values was 0.70 indicating a reasonable model fit. Coleopteran abundance was positively related to mnTemp at active plots, and confidence intervals did 
not overlap zero (Table 8). We predicted 21 individuals at an active plot when mnTemp was $6.5^{\circ} \mathrm{C}$ and 153 Coleopterans when mnTemp was $26^{\circ} \mathrm{C}$ (Figure 6). The next highest model was the Null model (Table 6).

The top model for mean Tricopteran abundance was the environmental covariate model, and had a $w_{i}=0.701$ (Table 6). Three additional models were ranked above the Null and included additional covariates with $95 \%$ confidence intervals that did overlap zero. We we created four post-hoc models by adding these covariates to the top model: three examined our top model and each additional model, and our fourth model combined all models ranked above the Null. We ranked the post hoc models with our 8 a priori candidate models using AIC (Table 7). The top model was now the post hoc model that combined all top model covariates with the addition of all vegetation and fire, and had a $w_{i}=0.36$ (Table 7). The mean k-fold correlation between predicted and observed values was 0.64 indicating a reasonable model fit. Tricopteran abundance was positively related to mnTemp, and confidence intervals did not overlap zero (Table 8). LUNAR and YRburned were negatively related in Tricopteran abundances at active plots, and confidence intervals did not overlap zero (Table 8). We found a negative quadratic relationship for FireFreq at plots, and confidence intervals did not overlap zero (Table 8). Pressure, YR2, and YR3 were negatively related to Tricopteran abundances, and confidence intervals did overlap zero (Table 8). JUL and Aspect were positively related to Tricopteran abundances, and confidence intervals did overlap zero (Table 8). Our original top model was second best, and was within $\Delta$ AICc value $<2$, and had $w_{i}=0.28$. We model averaged predictions, and predicted 1 individual at passive plots when 
mnTemp was $6.5^{\circ} \mathrm{C}$, and 10 when mnTemp was $26^{\circ} \mathrm{C}$ (Figure 7). We predicted 23 individuals at active plots when LUNAR was $0 \mathrm{hr}$, and 19 Tricopterans when LUNAR was $10 \mathrm{hr}$ (Figure 7). We predicted 3 individuals at active plots when Aspect was 225 and 5 when Aspect was $40^{\circ}$ (Figure 7). We predicted 3 individuals at active plots when FireFreq was 0, 7 Tricopterans when FireFreq was 2 at plots, and 6 individuals when FireFreq was 4 or greater at plots (Figure 7). We predicted 32 individuals at active plots at non-managed sites, 9 individuals at plots burned 7-10 years ago, 4 individuals at plots burned 4-6 years ago, and 3 individuals at sites burned 0-3 years ago (Figure 7).

\subsection{Passive plots}

The top model for mean total insect abundance included Aspect, and had a $w_{i}=0.239$ (Table 9). Two additional models were ranked above the Null and included covariates with 95\% confidence intervals that did not overlap zero (Table 9). We evaluated three post hoc models that included two-way combinations with the top model, and the other supported model covariates, and a combination model that included all supported covariates. We ranked the post hoc models with our eight a priori candidate models using AIC (Table 10). Our new top model for mean total insect abundance included Aspect, TPH11, TPH5, and TPHs, and had a $w_{i}=0.303$ (Table 10). The mean k-fold correlation between predicted and observed values was 0.60 indicating a reasonable model fit. Aspect was negatively related to total insect abundance at passive plots, and confidence intervals did not overlap zero (Table 11). TPH5 was positively related to total insect abundances at passive plots, and confidence intervals did not overlap zero (Table 11). TPH11 and YR2 were positively related to mean total insect abundance at passive plots 
and, confidence intervals did overlap zero (Table 11). TPHs, YR3, and JUL were negatively related to mean total abundance, and confidence intervals did overlap zero (Table 11). The two additional post hoc models were ranked within $\Delta$ AICc value $<2$; however, our post hoc 1 model was uninformative as it ranked below our combination post hoc model (Burnham and Anderson 2002). We model averaged predictions for our two top models. We predicted 17 individuals at passive plots when Aspect was $225^{\circ}$ and 33 when Aspect was $40^{\circ}$ (Figure 8). We predicted 19 individuals at passive plots when THP5 was 0 and 54 when TPH5 was 32 trees/ha (Figure 8). We predicted 21 individuals at active plots when FireFreq was 0, 27 Tricopterans when FireFreq was 2 at plots, and 27 individuals when FireFreq was 4 or greater at plots (Figure 8). The NULL model was the top model with $w_{i}=0.563$ for mean Coleopteran, indicating no support for any covariates (Table 9). The NULL model was the top model with $w_{i}=0.317$ for mean Dipteran indicating no support for any covariates (Table 9).

\subsection{Pitfall traps}

None of our candidate models would converge in GLMER with either Poisson or negative binomial distributions, even with extended model iterations because of low counts (Figure 4). Counts of total insects captured at sites across the Ozarks in summers 2014-2016 were highly skewed toward zero (Figure 4).

\section{DISCUSSION}

We successfully fit models for seven out of eight response variables. Only our pitfall insect abundance response variable failed to converge using generalized linear mixed 
models. Our 7 candidate models represented six a priori hypotheses addressing insect abundance at active, passive, or both plots - the effect of understory vegetation, microclimate, quadratic effect of number of burns at plots, effect of year since burned, effect of stand structure, and effect of environmental covariates (Table 1). We found at least some support for each hypothesis for one or more response variables and trap types, except for the effect of understory vegetation.

We found no support for any hypotheses concerning Lepidopteran abundance at active plots, and Coleoptera and Diptera abundance at passive plots, nor for effects of understory vegetation or percent canopy cover on any insect response variable. We could not evaluate our seventh hypothesis because models would not converge with our pitfall trap data. We felt that insects captured in pitfall traps were not likely to be potential prey for our bat species because all species aerially hawk prey. The northern long-eared bat was our only focal species that has been shown to glean insects off vegetation; however, these cases appear to be rare among individuals (Faure et al. 1993).

Mean total insects at passive plots was negatively related to Aspect, which indicated warmer and drier aspects had lower insect abundance. Similarly, Willard et al. (2011) found lower ground beetle diversity and species richness at a an oak forest plot with a more southernly aspect compared to two other oak forest plots with easternly aspects suggesting that microclimate conditions at the southernly plot were likely drier, and not as favorable conditions for ground Coleopterans. Mean Tricopteran abundance at active plots had a weak positive relationship with site aspect. 
We found support for effects of prescribed fire on insect abundances at active and passive plots. Mean total abundance at passive plots had a weak positive relationship to sites with one or more fires due to model uncertainty while mean Tricopteran abundance at active plots increased as the number of fires increased to 3 prescribed burns within the last 10 years compared to non-managed plots (Hypothesis 3). We found a decrease in Trichopteran abundances at plots when the number of fires was greater than 4 fires within the last 10 years compared to non-managed plots (Hypothesis 3). Captures of nocturnal volant insects were similarly greater at burned than non-managed sites in Kentucky (Lacki et al. 2009). Zebehazy (2002) also found arthropod abundances were greater at burned sites than sites managed only with thinning or no management, consistent with our results. We found support for a negative relationship between mean Tricopteran abundances at active plots recently burned 0-3 years, 4-6 years, and 7-10 years ago compared to non-managed active plots. Similar to YRburned, and contradictory to our FireFreq results, Hemiptera species richness was negatively related to sites recently burned, or with high burn frequencies in tall grass prairies in Illinios (Wallner et al. 2012). Fire response varies by species for ground dwelling arthropods with species richness increasing as time since fire increases, likely resulting from recolonization, changes to the vegetation structure, and communities becoming more similar to nonmanaged sites (Niwa and Peck 2002, Swengel 2014). Similar to our other 5 insect response variables, prescribed fire did not directly affect insect abundances in a savanna restoration study in the upper Midwest (Siemann et al. 1997). The mixed response we observed to fire are consistent with the literature; studies have found positive, negative, 
or neutral relationships for prescribed fire on insect abundances (Niwa and Peck 2002,

Siemann et al. 1997, Jacobs and Nix 2015, Heikkala et al. 2015, Hahn and Orrock 2015).

We found support for relationships between abundance and vegetation structure for mean total insects captured at passive plots. Insect abundance was negatively related to sawtimber and sapling tree density; whereas, insect abundance was positively related to pole timber densities. Insect abundance is often positively related to high vegetation diversity and structure (Ferrenberg et al. 2006, Stamps and Linit 1998, Hahn and Orrock 2015, Jacobs and Nix 2015); however, we did not find any effect for our understory vegetation covariates SHRUB, FORB, LEAF, and BARE. We suspect our assessment of these covariates were too coarse. More detailed measurements including species composition, and more quantitative measures of vegetation density or cover may have performed better. Many insect species require host plants for foraging, various developmental stages, and reproduction (Summerville and Crist 2008, Vehviläinen et al. 2008).

We found support for relationships between abundance and environmental covariates for 3 insect response variables. Mean total and mean Coleopteran abundance at active plots was positively related to mnTemp measured at mist-net sites within $250 \mathrm{~m}$ of each plot at a site. Mean Tricopteran abundance at active plots had a weaker positive relationship with minimum temperature due to model uncertainty. Temperature had a positive effect on Coleoptera captures in Brazil, but not on other insect Orders (Pinheiro et al. 2002). Nightly insect biomass had a positive relationship with increases in temperature in red 
pine forests in Michigan which supports our findings (Tibbels and Kurta 2003). Although most insect studies do not directly measure the effect of temperature on insect abundances, it is assumed that seasonal and annual variation in insect abundances is often thought to be driven by climatic conditions, especially temperature and rainfall events in temperate regions (Willard et al. 2011, Highland et al. 2013).

Our null model was the most supported model for multiple insect response variables. This may be a result of our overall project goal, the resulting study design, and spatial extent of our study. Our overall goal was to understand multi-scaled factors that affect bat species abundances across savannas, woodlands, and non-managed forests. We examined insect abundances to determine if bat abundances at sites were driven by potential food availability, or the structural changes caused by restoration management, and secondarily, to understand factors affecting insect abundances. Thus, the spatial extent and grain of our study was perhaps more appropriate for understanding multi-scaled factors that influence bat species compared to insects which we only evaluated at the plot spatial scale. We likely did not collect enough fine-scale detailed measurements at our active and passive plots (e.g., identify and count understory plant species) that are likely driving insect abundances at sites. Nevertheless, we did find restoration effects, climatic, and microclimate effects for several insect response groups.

Our study design focused on obtaining the largest sample size possible by surveying as many mist-net sites over the 3 survey years. Due to model constraints, we did not revisit sites after the one time, 3-day sampling event; although, we did revisit study areas and 
ecological sub-regions. Nevertheless, most insect studies repeatedly sampled at the same plots over an extended period, and sought to compare sites that were relatively close together (within $43 \mathrm{~km}$ or less) (Summerville et al. 2005, Summerville et al. 2007, Dietötter et al. 2007, Womack 2008). We used vegetation measures that are appropriate for bats and bird studies, but potentially not detailed enough for insects, especially our understory vegetation measures. Studies have shown various species within Orders respond differently to prescribed fire, and these variations may be driven by trophic level differences between species or Families (Niwa and Peck 2002, Tscharntke and Brandl 2004).

In conclusion, we found that both prescribed fire and structural changes in tree densities by size class caused by restoration practices influenced insect abundances at plots. Temperature and plot aspect also affected insect abundances at plots. We did not find support for understory vegetation on insect abundances likely a result of the type of understory vegetation data collected. We suggest that future work investigating how forest management, habitat, landscape, and potential prey availability affects bat species should consider a study design that allows for repeated sampling at sites over a summer and over years following burns. This would allow for a more comprehensive understanding of the effects of restoration practices on bats and insect communities by eliminating uncertainties between sites. By focusing on fewer sites, more detailed vegetation can be collected within each sampling period to understand how vegetation communities change, especially understory vegetation, over a single growing season, and between years at burned and non-managed sites.. We found evidence of positive, 
negative, and no relationship of restoration management on insect abundance dependent on plot type and insect response variable being analyzed. The same response variable, mean Tricopteran abundances at active plots had complex relationships to prescribed fire. While Tricopterans had lowered abundances 0-3 years' post-fire, abundances increased as years since burn increased ( $4-10$ years). Whereas, plots burned 2 to 3 times in the last 10 years had higher Tricopteran abundances compared to non-managed plots. Overall, restoration practices did not have a lasting negative effect on insect abundances, and some positive effects. Mangers should be mindful that abiotic factors will influence insect abundances at both restoration and non-managed sites. Managers should also be cognizant that effects of restoration practices on insect abundances will likely be temporally dependent on when a site has been last burned and the number of fires within the last 10 years. 


\section{LITERATURE CITED}

Abrams, M.D. 1992. Fire and the development of oak forests: in eastern North America, oak distribution reflects a variety of ecological paths and disturbance conditions. BioScience 42(5): 346-353.

Anderson, R.C., J S. Fralish, and J.M. Baskin. 1999. Savannas, barrens, and rock outcrop plant communities of North America. Cambridge University Press, Cambridge, UK.470 pp.

Boyles, J.G. and D.P. Aubrey. 2006. Managing forest with prescribed fire: implications for a cavity-dwelling bat species. Forest Ecology and Management 222(1): 108-115.

Diekötter, T., K.J. Hayes, D. Mazeffa, and T.O. Crist. 2007. Direct and indirect effects of habitat area and matrix composition on species interactions among flower-visiting insects. Oikos 116(9): 1558-1598.

Ethridge, M. (2009). The Ozark Highlands: U.S. Geological Fact Sheet. 2009-3065

Faure, P. A., J.H. Fullard, and J.W. Dawson. 1993 The gleaning attacks of the northern long-eared bat, Myotis septentrionalis, are relatively inaudible to moths. Journal of Experimental Biology 178: 173-189.

Ferrenberg, S.M., D.W. Schwilk, E.E. Knapp, E. Groth, and J.E. Keeley. 2006. Fire decreases arthropod abundance but increases diversity: early and late season prescribed fire effects in a Sierra Nevada mixed-conifer forest. Fire Ecology 2: 79102.

Hahn P.G. and J.L. Orrock. 2015. Land-use history alters contemporary insect herbivore community composition and decouples plant=herbivore relationships. Journal of Animal Ecology 84: 745-754.

Heikkala, O., P. Martikainen, and J. Kouki. 2017. Prescribed burning is an effective and quick method to conserve rare pyrophilous forest-dwelling flat bugs. Insect Conservation and Diversity 10: 32-41.

Highlands, S.A., J.C. Miller, and J.A. Jones. 2013. Determinants of moth diversity and community in a temperate mountain landscape: vegetation, topography, and seasonality. Ecosphere 4(10): 1-22.

Jacobs, K.A. and B. Nix. 2015. The effects of prescribed burning on soil and litter invertebrate diversity and abundance in an Illinois oak woodland. Natural Areas Journal 35(2): 318-327.

Johnson, P.S., S.R. Shifley, and R. Rogers. 2009. The ecology and silviculture of oaks, second edition. CABI Publishing, New York, NY. 592 pp. 
Lacki, M. J., D. R. Cox, L. E. Dodd, and M. B. Dickinson. 2009. Response of northern bats (Myotis septentrionalis) to prescribed fires in eastern Kentucky forests. Journal of Mammalogy 90(5): 1165-1175.

Lang, A.B., E.K.V. Kalko, H. Romer, C. Bockholdt, and D.K.N. Dechmann. 2006. Activity levels of bats and katydids in relation to the lunar cycle. Oecologia 146: 659-666.

Nelson, P. W. 2012. Fire-adapted natural communities of the Ozark Highlands at the time of European settlement and now. In: Dey, D. C., M. C. Stambaugh, S. L.Clark, C. J. Schweitzer, eds. Proceedings of the 4th fire in eastern oak forests conference. 2011 May 17-19. Springfield, MO. Gen. Tech. Rep. NRS-P-102. Newtown Square, PA: U.S. Department of Agriculture, Forest Service, Northern Research Station: 92-102.

Nigh, T. A. and W. A. Schroeder. 2002. Atlas of Missouri Ecoregions. The Conservation Commission - State of Missouri, Jefferson City, MO.

Niwa, C.G. and R.W. Peck. 2002. Influence of prescribed fire on carabid beetle (Carabidae) and spider (Aranae) assemblages in forest litter in southwestern Oregon. Environmental Entomology 31(5): 785-796.

Nowacki, G.J. and M.D. Abrams. 2008. The demise of fire and "mesophication" of forests in the eastern United States. BioScience 58(2): 123-138.

Pellegrino A.C., M.F.G.V. Peñaflor, C. Nardi, W. Bezner-Kerr, C.G. Guglielmo, J.M. Somões Bento, and J.N. McNeil. 2013. Weather forecasting by insects: modified sexual behavior in response to atmospheric pressure changes. PLoS ONE 8(10): e75004. doi:10.1371/journal.pone.0075004

Pinheiro, F., I. R. Diniz, D. Coelho, and M.P.S. Bandeira. 2002. Seasonal pattern of insect abundance in the Brazilian cerrado. Austral Ecology 27: 132-136.

Pitt, A.L., R.F. Baldwin, J.J. Tavano, T.A. Waldrop, and R.J. Phillips. 2014. Synthesis of the effects of fire on southern Appalachian fauna. In proceedings Wildland fire in the Appalachians: Discussions among managers and scientists (T.A. Waldrop, editor). General Technical Report SRS-199. Ashville, NC 208 pp.

Reidy, J. L., F. R. Thompson III, and S. W. Kendrick. 2014. Breeding bird response to habitat and landscape factors across a gradient of savanna, woodland, and forest in the Missouri Ozarks. Forest Ecology and Management 313: 34-36.

Roach, M. 2016. Breeding bird response to pine-savanna and woodland restoration in the Ozark-Ouachita interior highlands. Masters Thesis. University of Missouri, Columbia, MO. Ix + 126 pp. 
Siemann, E. H., J. Haarstad, and D. Tilman. 1997. Short-term and long-term effects of burning on oak savannah arthropods. American Midland Naturalist 137(2):349-361.

Stamps, W.T. and M.J. Linit. 1998. Plant diversity and arthropod communities: implications for temperate agroforestry. Agroforestry Systems 39: 73-89.

Starbuck, C.A., S.K. Amelon, and F.R. Thompson. 2015. Relationships between bat occupancy and habitat and landscape structure along a savanna, woodland, forest gradient in the Missouri Ozarks. Wildlife Society Bulletin. 39(1): 20-30.

Summerville, K.S., A.C. Bonte, and L.C. Fox. 2007. Short-tern temporal effects on community structure of lepidoptera in restored and remnant tallgrass prairies. Restoration Ecology 15(2): 179-188.

Summerville, K.S. and T.O. Crist. 2008. Structure and conservation of lepidopteran communities in managed forests of northeastern North America: a review. Entomological Society of Canada 140: 475-494.

Summerville, K.S., R.M. Steichen, and M.N. Lewis. 2005. Restoring lepidopteran communities to oak savaanas: contrasting influences of habitat quantity and quality. Restoration Ecology 13(1): 120-128.

Taft, J.B. 1997. Savanna and open-woodland communities. Pg. 24-54 in Conservation in highly fragmented landscapes. (M.W. Schwartz, ed.). Springer, New York, NY. 436 pp.

Tibbels, A. E. and A. Kurta. 2003. Bat activity is low in thinned and unthinned stands of red pine. Canadian Journal of Forest Research 33: 2436-2442.

Tscharntke, T. and R. Brandl. 2004. Plant-insect interactions in fragmented landscapes. Annual Review of Entomology 49: 405-430.

Vehviläinen, H., J. Koricheva, and K. Ruohomäki. 2008. Effects of stand tree species composition and diversity on abundance of predatory arthropods. Oikos 177: 935943.

Wallner, A.M., B. Molano-Flores, and C.H. Dietrich. 2012. The influence of fire on Illinois hill prairie Auchenorrhyncha (Insecta: Hemiptera) diversity and integrity. Journal of Insect Conservation 16: 433-445.

Willand, J.E., B.R. Wodika, J, Palmer, S.E. Jenkins, and K.W. McCravy. 2011. Diversity of ground beetles (Coleoptera: Carabidae) in relation to habitat type in west-central Illinois. American Midland Naturalist 166: 266-282.

Womack, K.M. 2008. Bat community dynamics and foraging activity patterns in young regenerating southern pine plantations and mixed hardwood forests. Senior Honor Thesis. Longwood University, Farmville, VA.vii+47 pp. 
Womack, K.M. 2011. Habitat and management effects on foraging activity of Indiana bats (Myotis sodalis) in Northeastern Missouri. Master's Thesis. University of Missouri, Columbia, MO. x+83 pp.

Yates, M. D., and R. M. Muzika. 2006. Effect of forest structure and fragmentation on site occupancy of bat species in Missouri Ozark forests. Journal of Wildlife Management 70: 1238-1248.

Zebehazy, L.A. 2002. Avian and arthropod responses to fuel reduction treatments in the upper Piedmont of South Carolina. Masters Thesis. Clemson University, Clemson, SC, USA.86 pp. 
Table 1. Hypotheses and candidate models used for effects on insect response variables based on passive and active plot surveys across a gradient of savannas, woodlands, and non-managed forests in the Ozarks of Missouri, 2014-2016. Site was used as a random effect and year (YR) and Julian date (JUL) were included as fixed effects in all models.

\begin{tabular}{|c|c|c|c|}
\hline Trap types & Hypotheses & Model name & Model structure $^{1}$ \\
\hline All & $\begin{array}{l}\text { 1: Effect of understory } \\
\text { vegetation }\end{array}$ & 1 & $\beta_{0}+\beta_{1}\left(X_{\text {Herb }}\right)+\beta_{2}\left(X_{\text {Grass }}\right)$ \\
\hline All & $\begin{array}{l}\text { 2: Effect of } \\
\text { microclimate }\end{array}$ & 2 & $\beta_{0}+\beta_{1}\left(X_{\text {Asp }}\right)$ \\
\hline All & $\begin{array}{l}\text { 3: Quadratic effect of } \\
\text { fire frequency }\end{array}$ & 3 & $\beta_{0}+\beta_{1}\left(X_{\text {FireFreq }}\right)+\beta_{2}\left(X_{\text {FireFreq }}\right)^{2}$ \\
\hline All & $\begin{array}{l}\text { 4: Effect of year since } \\
\text { burned }\end{array}$ & 4 & $\beta_{0}+\beta_{1}\left(X_{\text {YRburn }}\right)$ \\
\hline All & $\begin{array}{l}\text { 5: Effect of stand } \\
\text { structure }\end{array}$ & 5.1 & $\begin{array}{l}\beta_{0}+\beta_{1}\left(X_{\mathrm{TPH} 11}\right)+\beta_{2}\left(X_{\mathrm{TPH} 5}\right)+ \\
\beta_{3}\left(\mathrm{X}_{\mathrm{TPHs}}\right)\end{array}$ \\
\hline All & & 5.2 & $\beta_{0}+\beta_{1}\left(X_{\text {Canopy }}\right)$ \\
\hline Active & $\begin{array}{l}\text { 6: Effect of } \\
\text { environmental } \\
\text { covariates }\end{array}$ & $6 . \mathrm{a}$ & $\begin{array}{l}\beta_{0}+\beta_{1}\left(X_{\text {Mxtemp }}\right)+\beta_{2}\left(X_{\text {Pr }}\right)+ \\
\beta_{3}\left(X_{\text {LUNAR }}\right)\end{array}$ \\
\hline Passive & & 6.p & $\beta_{0}+\beta_{1}\left(X_{\text {Mxtemp }}\right)+\beta_{2}\left(X_{\mathrm{Pr}}\right)$ \\
\hline Pitfall & 7: Effect of leaf litter & 7.pit & $\beta_{0}+\beta_{1}\left(X_{\text {Leaf }}\right)$ \\
\hline
\end{tabular}


Table 2. Descriptions of model covariates used in generalized linear mixed models with a negative binomial distribution to predict abundances of insects across a gradient of actively managed savanna-woodlands and non-managed forests in the Ozark Highlands of Missouri, 2014-2016.

\begin{tabular}{llll}
\hline Covariate type & Covariate & Covariate description & Code \\
\hline Habitat & Leaf litter & Percent leaf litter within 5 m of plot & LEAF \\
& $(\%)$ & $\begin{array}{l}\text { center. Percent leaf litter, forb, } \\
\text { herbaceous/shrub, and bare ground total } \\
\end{array}$ & \\
& $100 \%$ at each plot. Percent bare ground is \\
& & \\
& & \\
& & \\
& & \\
& &
\end{tabular}

Forb $(\%) \quad$ Percent forbs within $5 \mathrm{~m}$ of plot center. FORB Percent leaf litter, forb, herbaceous/shrub, and bare ground total $100 \%$ at each plot. Percent bare ground is the reference covariate in candidate models.

Herbaceous/ Percent herbaceous or woody plants $(<0.5$ SHRUB woody $\quad \mathrm{m}$ tall and $\mathrm{DHB}<1 \mathrm{in}$ ) within $5 \mathrm{~m}$ of plot shrubs $(\%) \quad$ center. Percent leaf litter, forb, herbaceous/shrub, and bare ground total $100 \%$ at each plot. Percent bare ground is the reference covariate in candidate models.

Bare ground Percent bare ground (dirt or rocks) within BARE (\%) $5 \mathrm{~m}$ of plot center. Percent leaf litter, forb, herbaceous/shrub, and bare ground total $100 \%$ at each plot. Percent bare ground is the reference covariate in candidate models.

Canopy Mean percent of canopy cover calculated Canopy cover (\%) using a densiometer at each plot. 


\begin{tabular}{|c|c|c|c|}
\hline Covariate type & Covariate & Covariate description & Code \\
\hline & $\begin{array}{l}\text { Saw timber } \\
\text { tree density }\end{array}$ & $\begin{array}{l}\text { Mean tree density (trees per hectare; } \\
\text { TPH) calculated for all trees with DBH } \\
<11 \text { within } 11.3 \text { m of each plot center. We } \\
\text { kept all tree density covariates together in } \\
\text { our candidate models (TPH11, TPH5, and } \\
\text { TPHs). }\end{array}$ & TPH11 \\
\hline & $\begin{array}{l}\text { Pole timber } \\
\text { tree density }\end{array}$ & $\begin{array}{l}\text { Mean tree density }(\mathrm{TPH}) \text { calculated for } \\
\text { trees with } \mathrm{DBH}>5 \text { in and } \mathrm{DBH}<11 \text { in } \\
\text { within } 11.3 \mathrm{~m} \text { of each plot center. We } \\
\text { kept all tree density covariates together in } \\
\text { our candidate models (TPH11, TPH5, and } \\
\text { TPHs). }\end{array}$ & TPH5 \\
\hline & $\begin{array}{l}\text { Sapling/ } \\
\text { seedling tree } \\
\text { density }\end{array}$ & $\begin{array}{l}\text { Mean tree density }(\mathrm{TPH}) \text { calculated for } \\
\text { trees with } \mathrm{DBH}<4.9 \text { within } 11.3 \text { m of } \\
\text { each plot center. We kept all tree density } \\
\text { covariates together in our candidate } \\
\text { models (TPH11, TPH5, and TPHs). }\end{array}$ & TPHs \\
\hline Microclimate & Aspect & $\begin{array}{l}\text { We measure aspect to represent } \\
\text { microclimate conditions at plots. We used } \\
\text { transformed aspect to reach a maximum } \\
\text { value at southwest }\left(225^{\circ}\right) \text { because this } \\
\text { aspect represents plots with the hottest } \\
\text { and driest conditions. }\end{array}$ & ASPECT \\
\hline \multirow[t]{2}{*}{ Management } & $\begin{array}{l}\text { Year since } \\
\text { plot burned }\end{array}$ & $\begin{array}{l}\text { The year since the mist-net site was } \\
\text { burned within the last } 10 \text { years. Plots } \\
\text { burned in the past } 0-3 \text { years }=4,4-6=3 \text {, } \\
7-10 \text { years }=2 \text {, and non-managed or } 10+ \\
\text { years since burned }=1\end{array}$ & YRburn \\
\hline & $\begin{array}{l}\text { Fire } \\
\text { frequency }\end{array}$ & $\begin{array}{l}\text { The number of fires at a plot within the } \\
\text { last } 10 \text { years. Non-managed plots }=0 \text {. } \\
\text { Plots burned once }=1 \text {, twice }=2 \text {, three } \\
\text { times }=3 \text {, four or more times }=4 \text {. }\end{array}$ & FireFreq \\
\hline Environmental & Lunar light & $\begin{array}{l}\text { Mean number of lunar hours over our } \\
\text { three-day survey period. *Only used for } \\
\text { active data. }\end{array}$ & LUNAR \\
\hline
\end{tabular}




\begin{tabular}{|c|c|c|c|}
\hline Covariate type & Covariate & Covariate description & Code \\
\hline & $\begin{array}{l}\text { Barometric } \\
\text { pressure }\end{array}$ & $\begin{array}{l}\text { Mean barometric pressure (inHg) } \\
\text { measured at associated mist-net location } \\
\text { within } 250 \mathrm{~m} \text { of each plot location and } \\
\text { from the closest National Climatic Data } \\
\text { Center (NCDC) weather station over our } \\
\text { three-day survey period. }\end{array}$ & Pressure \\
\hline & $\begin{array}{l}\text { Minimum } \\
\text { Temperature }\end{array}$ & $\begin{array}{l}\text { Mean minimum temperature collected at } \\
\text { associated mist-net location within } 250 \mathrm{~m} \\
\text { of each plot location over our three-day } \\
\text { survey period. }\end{array}$ & mnTemp \\
\hline \multirow[t]{2}{*}{ Temporal $^{1}$} & Year & $\begin{array}{l}\text { Survey years } 2014-2016.2014 \text { is the } \\
\text { reference year in all models. }\end{array}$ & YR \\
\hline & Julian date & Julian date. & JUL \\
\hline
\end{tabular}

${ }^{1}$ The temporal covariates were fixed effects in all candidate models to account for variation in insect abundance base on Julian date and annual variability. 
Table 3. Response variables used in generalized linear mixed models with a negative binomial distribution examining the effects of restoration management, habitat, and climate covariates on insect abundance across a gradient of savanna, woodland, and forests in the Ozarks of Missouri, 2014-2016. Response variables represent the mean captures at plots over the 3 survey days. We combined malaise and panel trap yields for each plot for analysis.

\begin{tabular}{llll}
\hline Trap type & Plot type & Code & Insect response variable description \\
\hline Light & Active & a.Total & Mean total number of insects captured at a plot. \\
& & a.Lep & Mean number of Lepidopterans captured at a plot. \\
& a.Tri & Mean number of Tricopteran captured at a plot. \\
Malaise/ & Passive & p.Total & Mean total number of insects captured at a plot. \\
panel & & p.Coleo & Mean number of Coleopterans captured at a plot. \\
& & p.Dip & Mean number of Dipterans captured at a plot. \\
Pitfall & Passive & pit.Total & Total number of insects captured over the 3-day \\
& & survey. \\
& & $\begin{array}{l}\text { All five pitfall traps were combined into one } \\
\text { sample at a plot. }\end{array}$ \\
\hline
\end{tabular}


Table 4. Descriptive statistics for covariates measured at plots where active methods were used to sample insects in a study of relationships between insect abundances and savanna woodland restoration in the Ozarks of Missouri, 2014-2016.

\begin{tabular}{llcccc}
\hline Covariate & Code & Mean & Min & Max & SD \\
\hline Percent leaf litter & LEAF & 51.06 & 0 & 96 & 28.82 \\
Percent forb & FORB & 16.4 & 0 & 90 & 19.21 \\
$\begin{array}{l}\text { Percent herbaceous/woody } \\
\text { shrubs }\end{array}$ & SHRUB & 22.83 & 0 & 95 & 19.7 \\
Percent bare ground & BARE & 10.1 & 0 & 85 & 18.74 \\
Percent canopy cover & Canopy & 58.47 & 2 & 97 & 24.1 \\
Saw timber tree density & TPH11 & 100.4 & 0 & 679 & 88.42 \\
Pole timber tree density & TPH5 & 7.22 & 0 & 37.48 & 6.87 \\
Sapling tree density & TPHs & 0.75 & 0 & 7.02 & 1.07 \\
Aspect & ASPECT & 158 & 0 & 360 & 105 \\
Year since burned & Yrburn & 2.23 & 1 & 4 & 1.235 \\
Fire Frequency & FireFreq & 1.15 & 0 & 5 & 1.23 \\
Lunar Light & LUNAR & 4.95 & 0 & 10 & 2.63 \\
Barometric Pressure & Pressure & 28.99 & 28.43 & 30.19 & 0.34 \\
Minimum Temperature & mnTemp & 19.63 & 6.39 & 26.33 & 3.88 \\
Year & YR & 2 & 1 & 3 & 0.77 \\
Julian Date & JUL & 175.12 & 135 & 225 & 29.2 \\
\hline & & & & &
\end{tabular}


Table 5. Descriptive statistics for covariates measured at plots where passive methods were used to sample insects in a study of relationships between insect abundances and savanna woodland restoration in the Ozarks of Missouri, 2014-2016.

\begin{tabular}{|c|c|c|c|c|c|}
\hline Covariate & Code & Mean & Min & $\operatorname{Max}$ & SD \\
\hline Percent leaf litter & LEAF & 49.98 & 0 & 98 & 28.3 \\
\hline Percent forb & FORB & 15.32 & 0 & 95 & 17.52 \\
\hline $\begin{array}{l}\text { Percent herbaceous/woody } \\
\text { shrubs }\end{array}$ & SHRUB & 23.91 & 0 & 85 & 21.15 \\
\hline Percent bare ground & BARE & 10.03 & 0 & 70 & 16.57 \\
\hline Percent canopy cover & Canopy & 55.1 & 0 & 100 & 24.15 \\
\hline Saw timber tree density & TPH11 & 115.15 & 1.96 & 668 & 118.91 \\
\hline Pole timber tree density & TPH5 & 6.79 & 0 & 32.18 & 5.7 \\
\hline Sapling tree density & TPHs & 0.73 & 0 & 5.95 & 1.05 \\
\hline Aspect & ASPECT & 170.7 & 0 & 360 & 107.47 \\
\hline Year since burned & Yrburn & 2.27 & 1 & 4 & 1.2 \\
\hline Fire Frequency & FireFreq & 1.22 & 0 & 5 & 1.21 \\
\hline Lunar Light & LUNAR & 5.3 & 0 & 10 & 2.75 \\
\hline Barometric Pressure & Pressure & 29.02 & 28.39 & 30.07 & 0.35 \\
\hline Minimum Temperature & mnTemp & 19.78 & 9.39 & 25.94 & 3.86 \\
\hline Year & YR & 1.55 & 1 & 3 & 0.77 \\
\hline Julian Date & JUL & 175 & 135 & 223 & 30 \\
\hline
\end{tabular}


Table 6. Support for generalized linear mixed models of different insect responses including the number of model parameters (k), log likelihood (LogLik), Akaike's Information Criterion for small sample size (AICc), delta AICc ( $\triangle \mathrm{AICc})$, and AICc weight $\left(w_{\mathrm{i}}\right)$. Models were fit to data from 179 active plots collected across a gradient of savanna, woodland, and forest in the Missouri Ozarks in summers, 2014-2016.

\begin{tabular}{|c|c|c|c|c|c|c|}
\hline $\begin{array}{l}\text { Insect response } \\
\text { variable, Model } \\
\text { name }\end{array}$ & Model covariates & $\mathrm{k}$ & LogLik & $\mathrm{AIC}_{\mathrm{c}}$ & $\Delta \mathrm{AIC}_{\mathrm{c}}$ & $w_{\mathrm{i}}$ \\
\hline \multicolumn{7}{|l|}{ Total } \\
\hline $6 . \mathrm{a}$ & $\begin{array}{l}\text { PRESSURE + mnTemp } \\
+ \text { LUNAR + JUL + YR }\end{array}$ & 9 & -1182.93 & 2384.9 & 0 & 0.887 \\
\hline NULL & JUL + YEAR & 6 & -1189.33 & 2391.2 & 6.23 & 0.039 \\
\hline 3 & $\begin{array}{l}\text { FireFreq +FireFreq }^{2}+ \\
\text { JUL + YR }\end{array}$ & 8 & -1187.66 & 2392.2 & 7.24 & 0.024 \\
\hline 2 & $\mathrm{ASPECT}+\mathrm{JUL}+\mathrm{YR}$ & 7 & -1189.07 & 2392.8 & 7.86 & 0.017 \\
\hline 5.2 & Canopy + JUL + YR & 7 & -1189.31 & 2393.3 & 8.34 & 0.014 \\
\hline 4 & Yrburn + JUL + YR & 7 & -1189.33 & 2393.3 & 8.39 & 0.013 \\
\hline 1 & $\begin{array}{l}\text { SHRUB + LEAF + } \\
\mathrm{FORB}+\mathrm{JUL}+\mathrm{YR}\end{array}$ & 9 & -1188.61 & 2396.3 & 11.36 & 0.003 \\
\hline 5.1 & $\begin{array}{l}\text { THP11 + THP5 + TPHs } \\
+ \text { JUL + YR }\end{array}$ & 9 & -1188.88 & 2396.8 & 11.9 & 0.002 \\
\hline
\end{tabular}

Lepidopterans

NULL

$$
\mathrm{JUL}+\text { YEAR }
$$$$
\begin{array}{ll}
6 & -975.25
\end{array}
$$$$
1963
$$$$
0
$$$$
0.306
$$

Canopy + JUL + YR

$7 \quad-974.61$

1963.9

0.89

0.196 


\begin{tabular}{|c|c|c|c|c|c|c|}
\hline $\begin{array}{l}\text { Insect response } \\
\text { variable, Model } \\
\text { name }\end{array}$ & Model covariates & $\mathrm{k}$ & LogLik & $\mathrm{AIC}_{\mathrm{c}}$ & $\Delta \mathrm{AIC}_{\mathrm{c}}$ & $w_{\mathrm{i}}$ \\
\hline 4 & Yrburn + JUL + YR & 7 & -974.96 & 1964.6 & 1.6 & 0.137 \\
\hline 2 & ASPECT + JUL + YR & 7 & -975.13 & 1964.9 & 1.94 & 0.116 \\
\hline $6 . \mathrm{a}$ & $\begin{array}{l}\text { PRESSURE + mnTemp } \\
+ \text { LUNAR + JUL + YR }\end{array}$ & 9 & -973.03 & 1965.1 & 2.14 & 0.105 \\
\hline 3 & $\begin{array}{l}\text { FireFreq +FireFreq }^{2}+ \\
\mathrm{JUL}+\text { YR }\end{array}$ & 8 & -974.40 & 1965.6 & 2.66 & 0.081 \\
\hline 5.1 & $\begin{array}{l}\text { THP11 + THP5 + TPHs } \\
+ \text { JUL + YR }\end{array}$ & 9 & -974.03 & 1967.1 & 4.14 & 0.039 \\
\hline 1 & $\begin{array}{l}\mathrm{SHRUB}+\mathrm{LEAF}+ \\
\mathrm{FORB}+\mathrm{JUL}+\mathrm{YR}\end{array}$ & 9 & -974.64 & 1968.3 & 5.37 & 0.021 \\
\hline
\end{tabular}

Coleopterans

\begin{tabular}{|c|c|c|c|c|c|c|}
\hline $6 . \mathrm{a}$ & $\begin{array}{l}\text { PRESSURE + mnTemp } \\
+ \text { LUNAR + JUL + YR }\end{array}$ & 9 & -1018.09 & 2055.2 & 0 & 0.945 \\
\hline NULL & JUL + YEAR & 6 & -1025.46 & 2063.4 & 8.16 & 0.016 \\
\hline 3 & $\begin{array}{l}\text { FireFreq +FireFreq } \\
\text { JUL + YR }\end{array}$ & 8 & -1023.29 & 2063.4 & 8.18 & 0.016 \\
\hline 4 & Yrburn + JUL + YR & 7 & -1025.17 & 2065 & 9.74 & 0.007 \\
\hline 2 & ASPECT + JUL + YR & 7 & -1025.26 & 2065.2 & 9.92 & 0.007 \\
\hline 5.2 & Canopy + JUL + YR & 7 & -1025.43 & 2065.5 & 10.27 & 0.006 \\
\hline 1 & $\begin{array}{l}\mathrm{SHRUB}+\mathrm{LEAF}+ \\
\mathrm{FORB}+\mathrm{JUL}+\mathrm{YR}\end{array}$ & 9 & -1024.05 & 2067.2 & 11.92 & 0.002 \\
\hline 5.1 & $\begin{array}{l}\text { THP11 + THP5 + TPHs } \\
+ \text { JUL }+ \text { YR }\end{array}$ & 9 & -1024.78 & 2068.6 & 13.37 & 0.001 \\
\hline
\end{tabular}

Tricopterans 


\begin{tabular}{|c|c|c|c|c|c|c|}
\hline $\begin{array}{l}\text { Insect response } \\
\text { variable, Model } \\
\text { name }\end{array}$ & Model covariates & $\mathrm{k}$ & LogLik & $\mathrm{AIC}_{\mathrm{c}}$ & $\Delta \mathrm{AIC}_{\mathrm{c}}$ & $w_{\mathrm{i}}$ \\
\hline $6 . \mathrm{a}$ & $\begin{array}{l}\text { PRESSURE + mnTemp } \\
+ \text { LUNAR + JUL + YR }\end{array}$ & 9 & -685.478 & 1390 & 0 & 0.701 \\
\hline 3 & $\begin{array}{l}\text { FireFreq +FireFreq }^{2}+ \\
\text { JUL + YR }\end{array}$ & 8 & -688.677 & 1394.2 & 4.18 & 0.087 \\
\hline 4 & Yrburn + JUL + YR & 7 & -690.076 & 1394.8 & 4.79 & 0.064 \\
\hline 2 & ASPECT + JUL + YR & 7 & -690.103 & 1394.9 & 4.84 & 0.062 \\
\hline NULL & JUL + YEAR & 7 & -690.122 & 1394.9 & 4.88 & 0.061 \\
\hline 5.1 & $\begin{array}{l}\text { THP11 + THP5 + TPHs } \\
+ \text { JUL + YR }\end{array}$ & 9 & -688.973 & 1397 & 6.99 & 0.021 \\
\hline 1 & $\begin{array}{l}\text { SHRUB + LEAF + } \\
\mathrm{FORB}+\mathrm{JUL}+\mathrm{YR}\end{array}$ & 10 & -689.834 & 1401 & 10.96 & 0.003 \\
\hline
\end{tabular}


Table 7. Support for post hoc and a priori candidate generalized linear mixed models for mean Tricopteran response variable including the number of model parameters $(\mathrm{k}), \log$ likelihood (LogLik), Akaike's Information Criterion for small sample size (AICc), delta AICc $(\triangle \mathrm{AICc})$, and AICc weight $\left(w_{\mathrm{i}}\right)$. Models were fit to data from 179 active plots collected across a gradient of savanna, woodland, and forest in the Missouri Ozarks in summers, 2014-2016.

\begin{tabular}{|c|c|c|c|c|c|c|}
\hline Model name & Model covariates & $\mathrm{k}$ & LogLik & $\mathrm{AIC}_{\mathrm{c}}$ & $\Delta \mathrm{AIC}_{\mathrm{c}}$ & $w_{\mathrm{i}}$ \\
\hline Post Hoc 4 & $\begin{array}{l}\text { PRESSURE + mnTemp + } \\
\text { FireFreq + FireFreq }{ }^{2}+ \\
\text { Yrburned + ASPECT + } \\
\text { LUNAR + JUL + YR }\end{array}$ & 13 & -679.015 & 1386.2 & 0 & 0.36 \\
\hline $6 . \mathrm{a}$ & $\begin{array}{l}\text { PRESSURE + mnTemp + } \\
\text { LUNAR + JUL + YR }\end{array}$ & 9 & -683.838 & 1386.7 & 0.5 & 0.28 \\
\hline Post Hoc 3 & $\begin{array}{l}\text { PRESSURE + mnTemp + } \\
\text { FireFreq + FireFreq2 + } \\
\text { LUNAR + JUL + YR }\end{array}$ & 11 & -682.478 & 1388.5 & 2.3 & 0.12 \\
\hline Post Hoc 2 & $\begin{array}{l}\text { PRESSURE + mnTemp + } \\
\text { LUNAR + YRburned + JUL } \\
+ \text { YR }\end{array}$ & 10 & -683.669 & 1388.6 & 2.4 & 0.11 \\
\hline Post Hoc 1 & $\begin{array}{l}\text { PRESSURE + mnTemp + } \\
\text { LUNAR + ASPECT + JUL + } \\
\text { YR }\end{array}$ & 10 & -683.767 & 1388.8 & 2.6 & 0.1 \\
\hline 3 & $\begin{array}{l}\text { FireFreq + FireFreq } \\
\text { YR }\end{array}$ & 8 & -688.218 & 1393.3 & 7.1 & 0.01 \\
\hline 4 & Yrburned + JUL + YR & 7 & -690.076 & 1393.4 & 7.2 & 0.06 \\
\hline 2 & ASPECT + JUL + YR & 7 & -689.59 & 1393.8 & 7.6 & 0.01 \\
\hline NULL & JUL + YEAR & 7 & -690.122 & 1394.9 & 8.7 & 0.06 \\
\hline
\end{tabular}




\begin{tabular}{clccccc}
\hline Model name & Model covariates & $\mathrm{k}$ & $\operatorname{LogLik}$ & $\mathrm{AIC}_{\mathrm{c}}$ & $\Delta \mathrm{AIC}_{\mathrm{c}}$ & $w_{\mathrm{i}}$ \\
\hline 5.2 & Caonpy + JUL + YR & 7 & -689.624 & 1396 & 9.8 & 0.01 \\
& & & & & & \\
5.1 & THP11 + THP5 + TPHs + & 9 & -688.973 & 1397 & 10.8 & 0.02 \\
& JUL + YR & & & & & \\
1 & SHRUB + LEAF + FORB + & 10 & -689.834 & 1401 & 14.8 & 0 \\
& JUL + YR & & & & & \\
\hline
\end{tabular}


Table 8. Parameter estimates ( $\beta$ ), standard errors (SE), and 95\% confidence limits (LCL, UCL) for parameters in our top model for mean total insects, Coleopterans, and Tricopterans captured at 179 active plots during bat mist-net surveys at 89 sites across a gradient of savanna, woodland, and forest in the Ozark Highlands of Missouri, 20142016. Reference covariates are YR1 (2014). We did not include mean Lepidopterans, as the NULL model was the top model for this response variable.

\begin{tabular}{|c|c|c|c|c|}
\hline Insect response variable, Model parameter & $\beta$ & SE & LCL & UCL \\
\hline \multicolumn{5}{|l|}{ Total } \\
\hline Intercept & 5.388 & 0.189 & 5.018 & 5.759 \\
\hline Pressure & -0.049 & 0.103 & -0.251 & 0.152 \\
\hline MnTemp & 0.317 & 0.097 & 0.127 & 0.507 \\
\hline LUNAR & -0.085 & 0.127 & -0.334 & 0.163 \\
\hline YR2 & 0.192 & 0.321 & -0.437 & 0.820 \\
\hline YR3 & -0.617 & 0.324 & -1.251 & 0.018 \\
\hline JUL & -0.024 & 0.150 & -0.318 & 0.270 \\
\hline \multicolumn{5}{|l|}{ Coleopterans } \\
\hline Intercept & 4.209 & 0.235 & 3.748 & 4.671 \\
\hline Pressure & -0.106 & 0.128 & -0.357 & 0.145 \\
\hline MnTemp & 0.356 & 0.115 & 0.131 & 0.580 \\
\hline LUNAR & -0.270 & 0.154 & -0.573 & 0.032 \\
\hline YR2 & 0.437 & 0.396 & -0.338 & 1.213 \\
\hline YR3 & -0.267 & 0.400 & -1.051 & 0.516 \\
\hline JUL & -0.042 & 0.187 & -0.408 & 0.323 \\
\hline
\end{tabular}

Tricopterans

$\begin{array}{lllll}\text { Intercept } & 2.951 & 0.398 & 2.170 & 3.732 \\ \text { Pressure } & -0.171 & 0.197 & -0.558 & 0.216\end{array}$




\begin{tabular}{ccccc}
\hline Insect response variable, Model parameter & $\beta$ & SE & LCL & UCL \\
\hline MnTemp & 0.430 & 0.163 & 0.112 & 0.749 \\
LUNAR & -0.447 & 0.214 & -0.866 & -0.029 \\
YR2 & -0.953 & 0.532 & -1.997 & 0.090 \\
YR3 & -0.323 & 0.545 & -1.391 & 0.744 \\
JUL & 0.394 & 0.246 & -0.088 & 0.877 \\
firefreq & 1.991 & 0.722 & 0.577 & 3.406 \\
firefreq & -0.704 & 0.230 & -1.155 & -0.253 \\
Aspect & 0.062 & 0.153 & -0.239 & 0.362 \\
Yrburned & -1.650 & 0.622 & -2.869 & -0.431 \\
\hline
\end{tabular}


Table 9. Support for generalized linear mixed models of different insect responses variable including the number of model parameters (k), log likelihood (LogLik), Akaike's Information Criterion for small sample size (AICc), delta AICc ( $\triangle \mathrm{AICc}$ ), and AICc weight $\left(w_{\mathrm{i}}\right)$. Models were fit to data from 174 passive plots collected across a gradient of savanna, woodland, and forest in the Missouri Ozarks in summers, 20142016.

\begin{tabular}{|c|c|c|c|c|c|c|}
\hline $\begin{array}{l}\text { Insect response } \\
\text { variable, Model } \\
\text { name }\end{array}$ & Model Covariates & $\mathrm{k}$ & LogLik & $\mathrm{AIC}_{\mathrm{c}}$ & $\Delta \mathrm{AIC}_{\mathrm{c}}$ & $w_{\mathrm{i}}$ \\
\hline \multicolumn{7}{|l|}{ Total } \\
\hline 2 & ASPECT + JUL + YR & 7 & -709.36 & 1433.4 & 0 & 0.239 \\
\hline 3 & $\begin{array}{l}\text { FireFreq +FireFreq }{ }^{2}+\mathrm{JUL} \\
+\mathrm{YR}\end{array}$ & 8 & -708.42 & 1433.7 & 0.33 & 0.203 \\
\hline 5.1 & $\begin{array}{l}\text { THP11 + THP5 + TPHs + } \\
\text { JUL + YR }\end{array}$ & 9 & -707.43 & 1434 & 0.57 & 0.180 \\
\hline NULL & $\mathrm{JUL}+$ YEAR & 6 & -710.83 & 1434.2 & 0.78 & 0.162 \\
\hline 4 & Yrburn + JUL + YR & 9 & -708.15 & 1435.4 & 2 & 0.088 \\
\hline 5.2 & Canopy + JUL + YR & 7 & -710.56 & 1435.8 & 2.4 & 0.072 \\
\hline 6.p & $\begin{array}{l}\text { PRESSURE + mnTemp + } \\
\text { JUL + YR }\end{array}$ & 8 & -710.04 & 1437 & 3.56 & 0.040 \\
\hline 1 & $\begin{array}{l}\text { SHRUB + LEAF + FORB } \\
+\mathrm{JUL}+\mathrm{YR}\end{array}$ & 9 & -709.89 & 1438.9 & 5.49 & 0.015 \\
\hline
\end{tabular}

Coleopterans

$\begin{array}{clccccc}\text { NULL } & \text { JUL + YEAR } & 4 & -446.52 & 901.3 & 0 & 0.563 \\ 1 & \text { SHRUB + LEAF + FORB } & 10 & -441.36 & 904.1 & 2.79 & 0.139 \\ & + \text { JUL + YR } & & & & & \\ 6 . p & \text { PRESSURE + mnTemp + } & 9 & -443.22 & 905.5 & 4.26 & 0.067 \\ & \text { JUL + YR }\end{array}$




\begin{tabular}{clccccc}
$\begin{array}{l}\text { Insect response } \\
\text { variable, Model } \\
\text { name }\end{array}$ & Model Covariates & $\mathrm{k}$ & $\operatorname{LogLik}$ & $\mathrm{AIC}_{\mathrm{c}}$ & $\Delta \mathrm{AIC}_{\mathrm{c}}$ & $w_{\mathrm{i}}$ \\
\hline 4 & Yrburn + JUL + YR & 10 & -442.15 & 905.7 & 4.38 & 0.063 \\
2 & ASPECT + JUL + YR & 8 & -444.42 & 905.7 & 4.44 & 0.061 \\
5.2 & Canopy + JUL + YR & 8 & -444.69 & 906.3 & 4.99 & 0.047 \\
5.1 & THP11 + THP5 + TPHs + & 10 & -442.48 & 906.3 & 5.04 & 0.045 \\
& JUL + YR & & & & & \\
3 & $\begin{array}{l}\text { FireFreq +FireFreq } \\
+ \text { YR }\end{array}$ & 9 & -444.73 & 908.5 & 7.28 & 0.015
\end{tabular}

Dipterans

\begin{tabular}{|c|c|c|c|c|c|c|}
\hline NULL & JUL + YEAR & 4 & -571.99 & 1152.2 & 0 & 0.317 \\
\hline 5.1 & $\begin{array}{l}\text { THP11 + THP5 + TPHs + } \\
\text { JUL + YR }\end{array}$ & 10 & -565.70 & 1152.8 & 0.54 & 0.242 \\
\hline 5.2 & Canopy + JUL + YR & 8 & -568.23 & 1153.3 & 1.12 & 0.181 \\
\hline 2 & $\mathrm{ASPECT}+\mathrm{JUL}+\mathrm{YR}$ & 8 & -568.65 & 1154.2 & 1.96 & 0.119 \\
\hline 6.p & $\begin{array}{l}\text { PRESSURE + mnTemp + } \\
\text { JUL + YR }\end{array}$ & 9 & -568.20 & 1155.5 & 3.28 & 0.061 \\
\hline 3 & $\begin{array}{l}\text { FireFreq +FireFreq }{ }^{2}+\mathrm{JUL} \\
+\mathrm{YR}\end{array}$ & 9 & -568.34 & 1155.8 & 3.56 & 0.053 \\
\hline 4 & Yrburn + JUL + YR & 10 & -568.40 & 1158.1 & 5.93 & 0.016 \\
\hline 1 & $\begin{array}{l}\mathrm{SHRUB}+\mathrm{LEAF}+\mathrm{FORB} \\
+\mathrm{JUL}+\mathrm{YR}\end{array}$ & 10 & -569.00 & 1159.3 & 7.12 & 0.009 \\
\hline
\end{tabular}


Table 10. Support for post hoc and a priori candidate generalized linear mixed models of different mean total insect response variable including the number of model parameters (k), log likelihood (LogLik), Akaike’s Information Criterion for small sample size $(\mathrm{AICc})$, delta $\mathrm{AICc}(\triangle \mathrm{AICc})$, and $\mathrm{AICc}$ weight $\left(w_{\mathrm{i}}\right)$. Models were fit to data from 174 passive plots collected across a gradient of savanna, woodland, and forest in the Missouri Ozarks in summers, 2014-2016.

\begin{tabular}{|c|c|c|c|c|c|c|}
\hline Model name & Model covariates & $\mathrm{k}$ & LogLik & $\mathrm{AIC}_{\mathrm{c}}$ & $\Delta \mathrm{AIC}_{\mathrm{c}}$ & $w_{\mathrm{i}}$ \\
\hline Post Hoc 2 & $\begin{array}{l}\text { Aspect + TPH11 + TPH5 } \\
+ \text { TPHs + JUL + YR }\end{array}$ & 10 & -704.83 & 1431 & 0 & 0.303 \\
\hline Post Hoc 3 & $\begin{array}{l}\text { Aspect }+ \text { TPH } 11+\text { TPH5 } \\
+ \text { TPHs + FireFreq + } \\
\text { FireFreq }^{2}+\text { JUL }+ \text { YR }\end{array}$ & 12 & -703.02 & 1432 & 0.98 & 0.186 \\
\hline Post Hoc 1 & $\begin{array}{l}\text { Aspect + FireFreq + } \\
\text { FireFreq } 2+\text { JUL + YR }\end{array}$ & 9 & -706.85 & 1432.8 & 1.79 & 0.124 \\
\hline 2 & ASPECT + JUL + YR & 7 & -709.35 & 1433.4 & 2.38 & 0.092 \\
\hline 3 & $\begin{array}{l}\text { FireFreq + FireFreq }^{2}+ \\
\text { JUL + YR }\end{array}$ & 8 & -708.42 & 1433.7 & 2.7 & 0.078 \\
\hline 5.1 & $\begin{array}{l}\text { THP11 + THP5 + TPHs + } \\
\text { JUL + YR }\end{array}$ & 9 & -707.43 & 1434 & 2.95 & 0.069 \\
\hline NULL & $\mathrm{JUL}+\mathrm{YEAR}$ & 6 & -710.83 & 1434.2 & 3.15 & 0.063 \\
\hline 4 & Yrburn + JUL + YR & 9 & -708.14 & 1435.4 & 4.38 & 0.034 \\
\hline 5.2 & Canopy + JUL + YR & 7 & -710.55 & 1435.8 & 4.78 & 0.028 \\
\hline 6 & $\begin{array}{l}\text { PRESSURE + mnTemp + } \\
\text { JUL + YR }\end{array}$ & 8 & -710.04 & 1437 & 5.94 & 0.016 \\
\hline 1 & $\begin{array}{l}\text { SHRUB + LEAF + FORB } \\
+ \text { JUL + YR }\end{array}$ & 9 & -709.89 & 1438.9 & 7.87 & 0.006 \\
\hline
\end{tabular}


Table 11. Parameter estimates $(\beta)$, standard errors (SE), and $95 \%$ confidence limits (LCL, UCL) for parameters in our top model for mean total insect captured at 174 passive plots during bat mist-net surveys at 89 sites across a gradient of savanna, woodland, and forest in the Ozark Highlands of Missouri, 2014-2016. Reference covariates are YR1 (2014). We did not include mean Coleopterans or Dipterans as the NULL model was the top model.

\begin{tabular}{|c|c|c|c|c|}
\hline $\begin{array}{l}\text { Insect response variable, Model } \\
\text { parameter }\end{array}$ & $\beta$ & SE & LCL & UCL \\
\hline \multicolumn{5}{|l|}{ Total } \\
\hline Intercept & 3.049 & 0.181 & 2.694 & 3.404 \\
\hline Aspect & -0.180 & 0.078 & -0.334 & -0.027 \\
\hline ТPH11 & 0.006 & 0.111 & -0.211 & 0.223 \\
\hline TPH5 & 0.215 & 0.071 & 0.075 & 0.355 \\
\hline THPs & -0.099 & 0.092 & -0.280 & 0.081 \\
\hline YR2 & 0.303 & 0.316 & -0.317 & 0.924 \\
\hline YR3 & -0.018 & 0.309 & -0.624 & 0.588 \\
\hline JUL & -0.130 & 0.116 & -0.358 & 0.098 \\
\hline
\end{tabular}




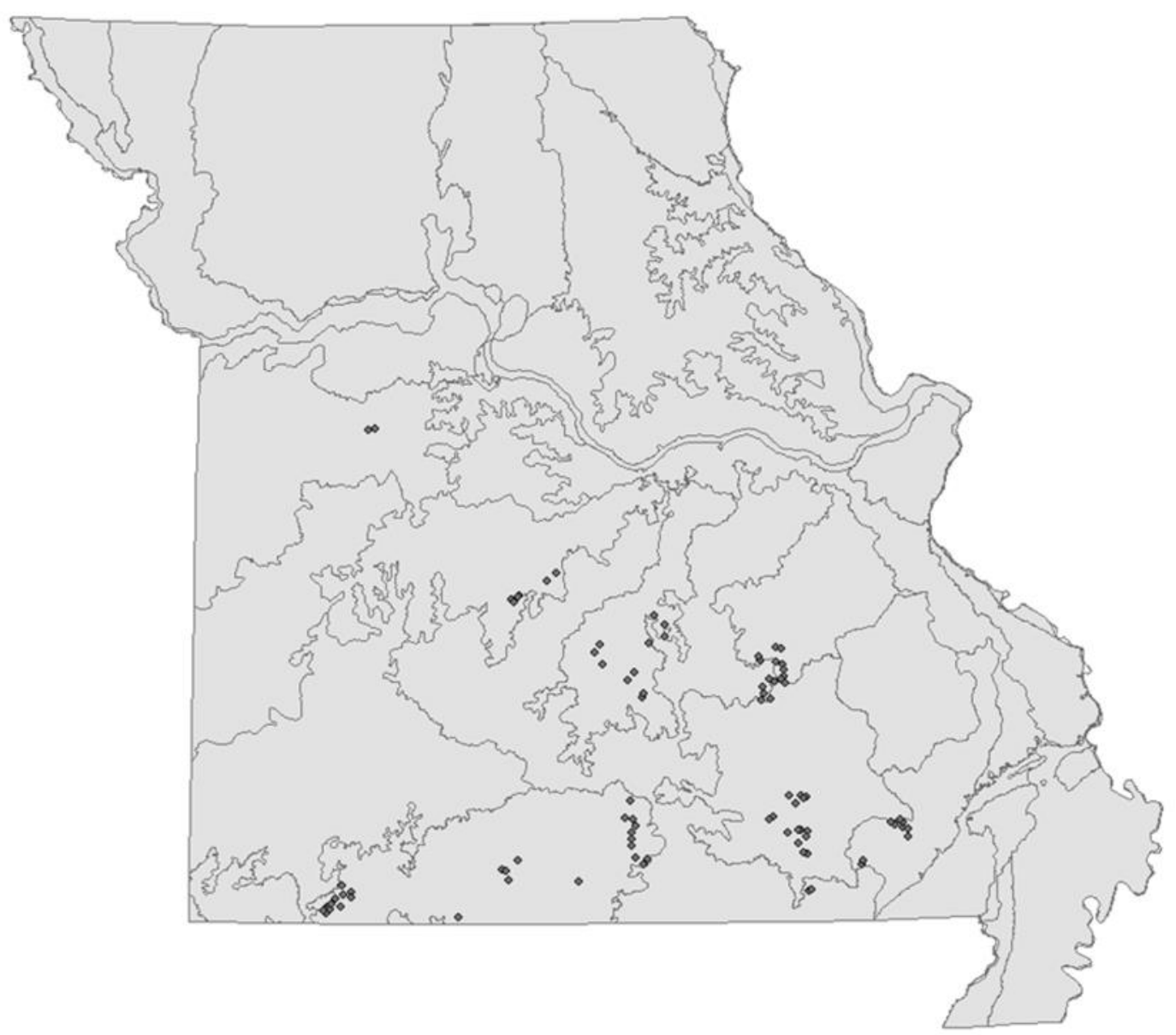

Figure 1. Mist-net site locations (dark magenta circles) with either 8 insect plots (2014) or 4 insect plots (2015-2016) surveyed within $250 \mathrm{~m}$ of sites across a gradient of savanna, woodlands, and non-managed forests on state and federal lands within the Ozarks of Missouri between May $15^{\text {th }}$-August $15^{\text {th }}, 2014-2016$. 

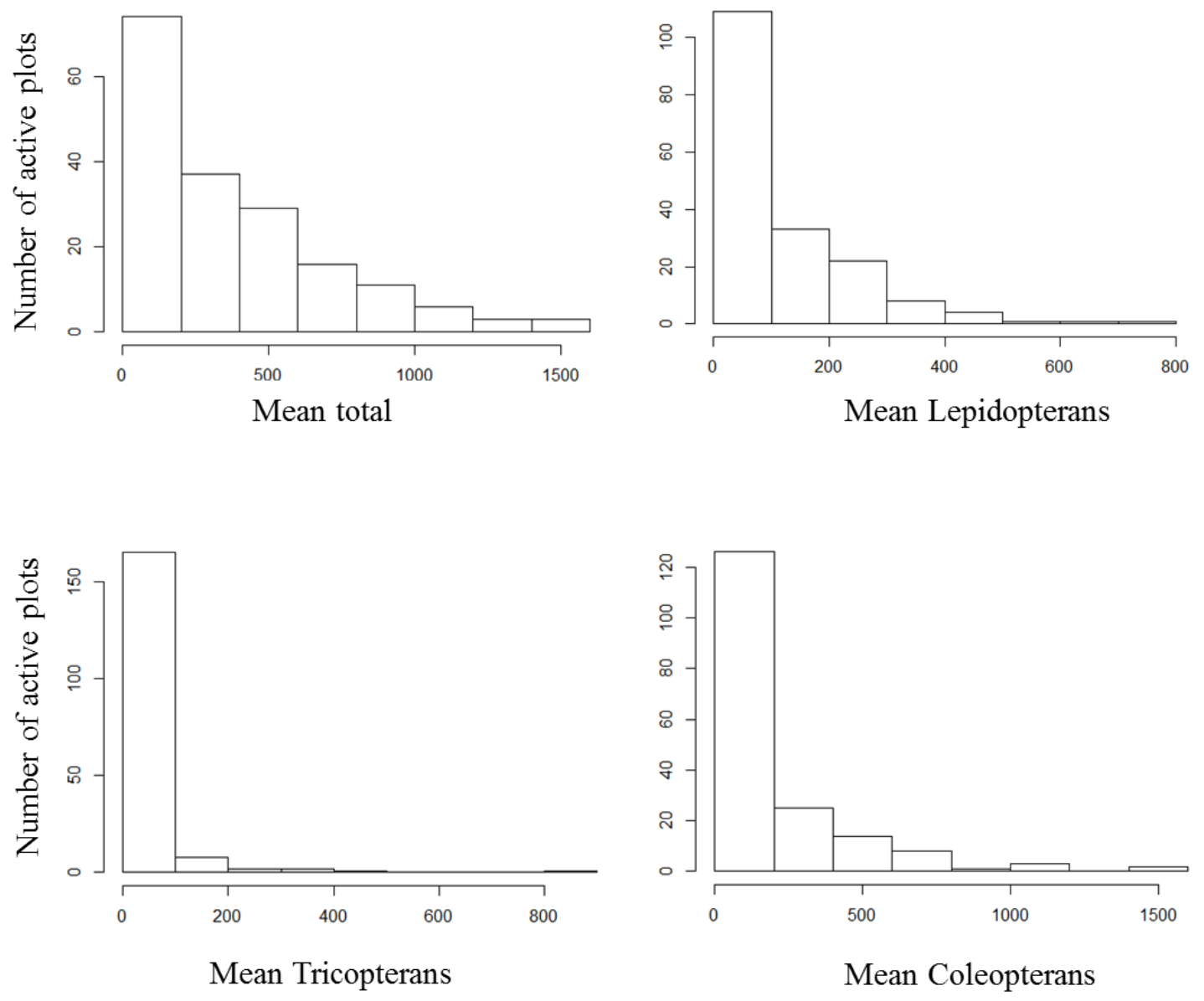

Figure 2. Frequency of captures expressed as mean total, Lepidopteran, Tricopterans, Coleopterans insects captured per active trap $(\mathrm{N}=179)$ across a gradient of savanna, woodlands, and non-managed forests in the Ozarks of Missouri, 2014-2016. 

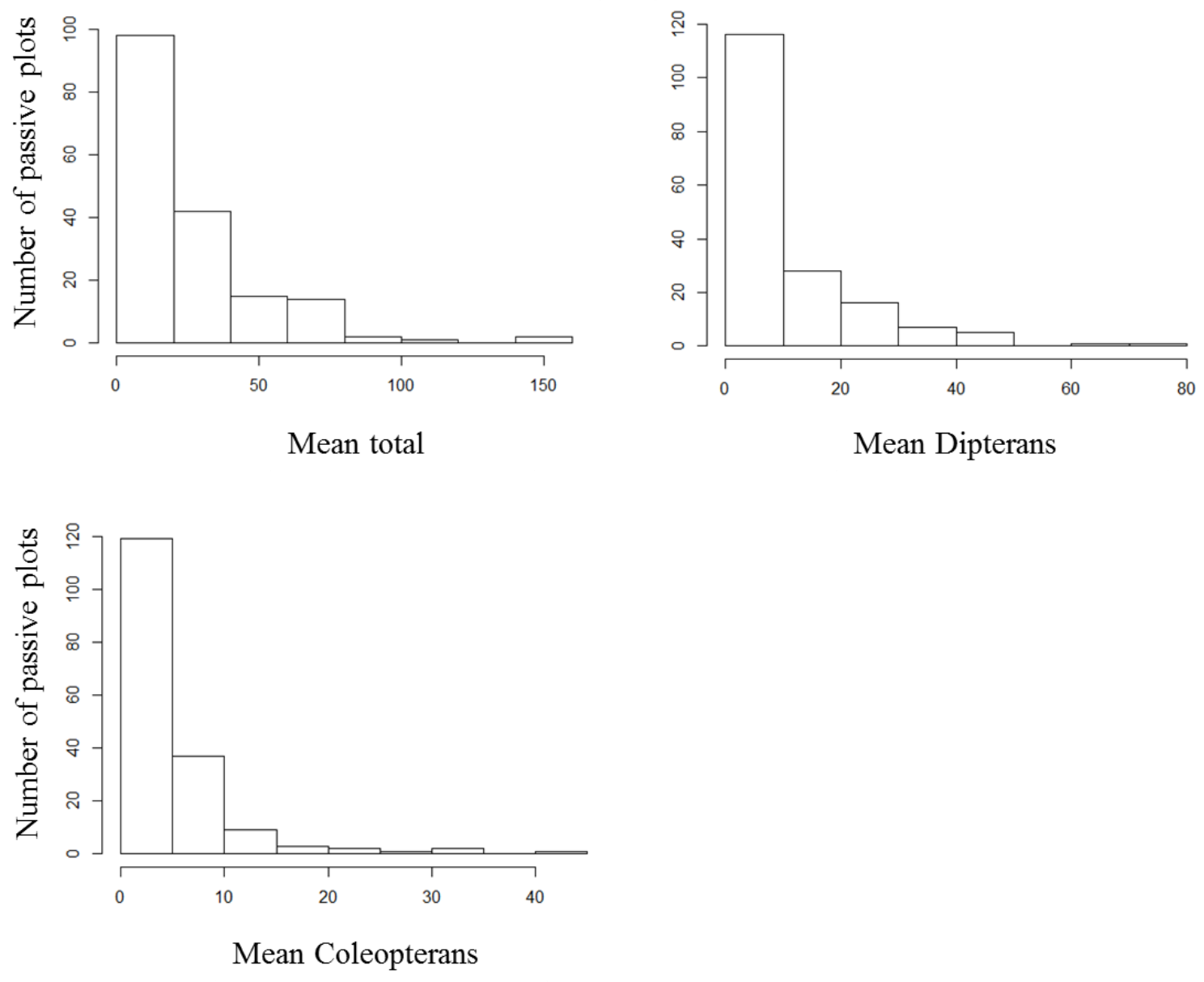

Figure 3. Frequency of captures expressed as mean total, Dipterans, Coleopterans insects captured per passive trap $(\mathrm{N}=174)$ across a gradient of savanna, woodlands, and nonmanaged forests in the Ozarks of Missouri, 2014-2016. 


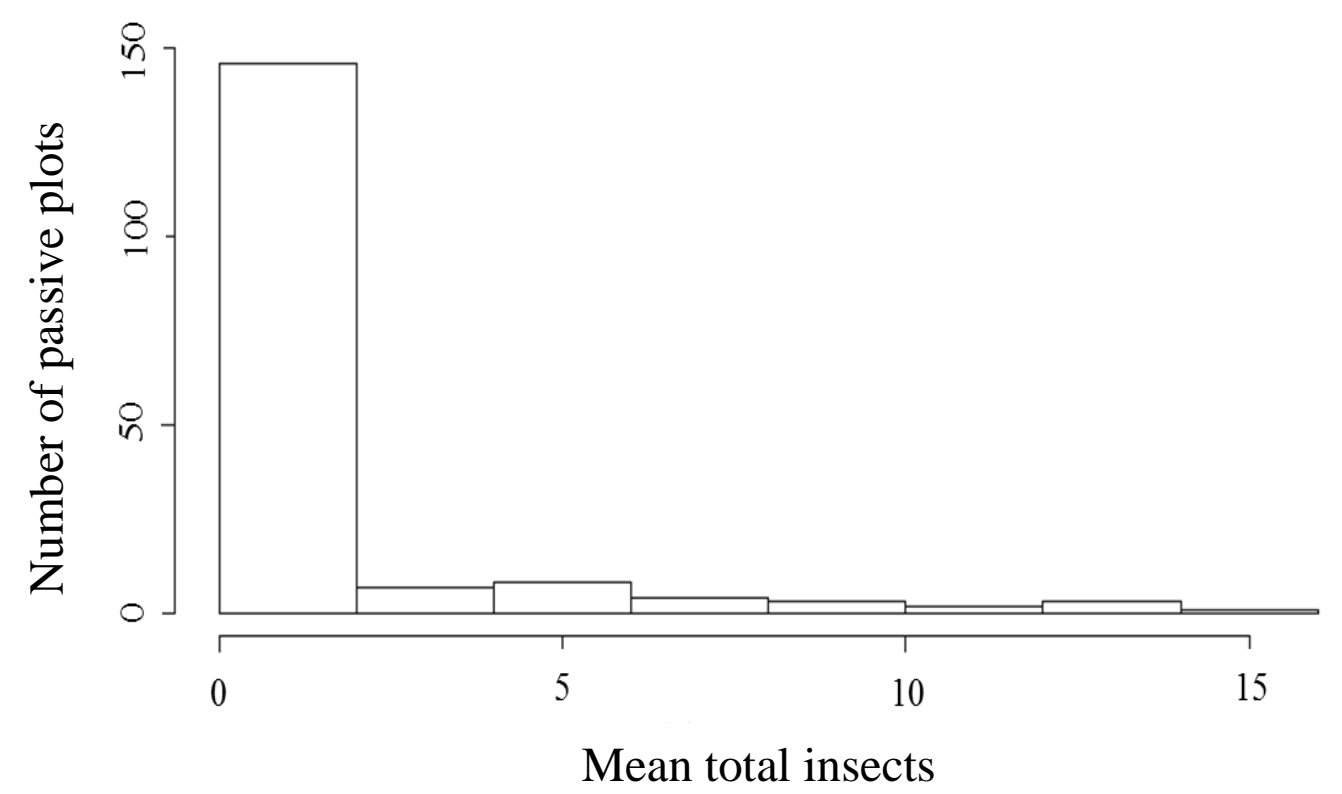

Figure 4. Frequency of captures expressed as mean total insects captured in pitfall traps at 174 passive plots across a gradient of savanna, woodlands, and non-managed forests in the Ozarks of Missouri, 2014-2016. 

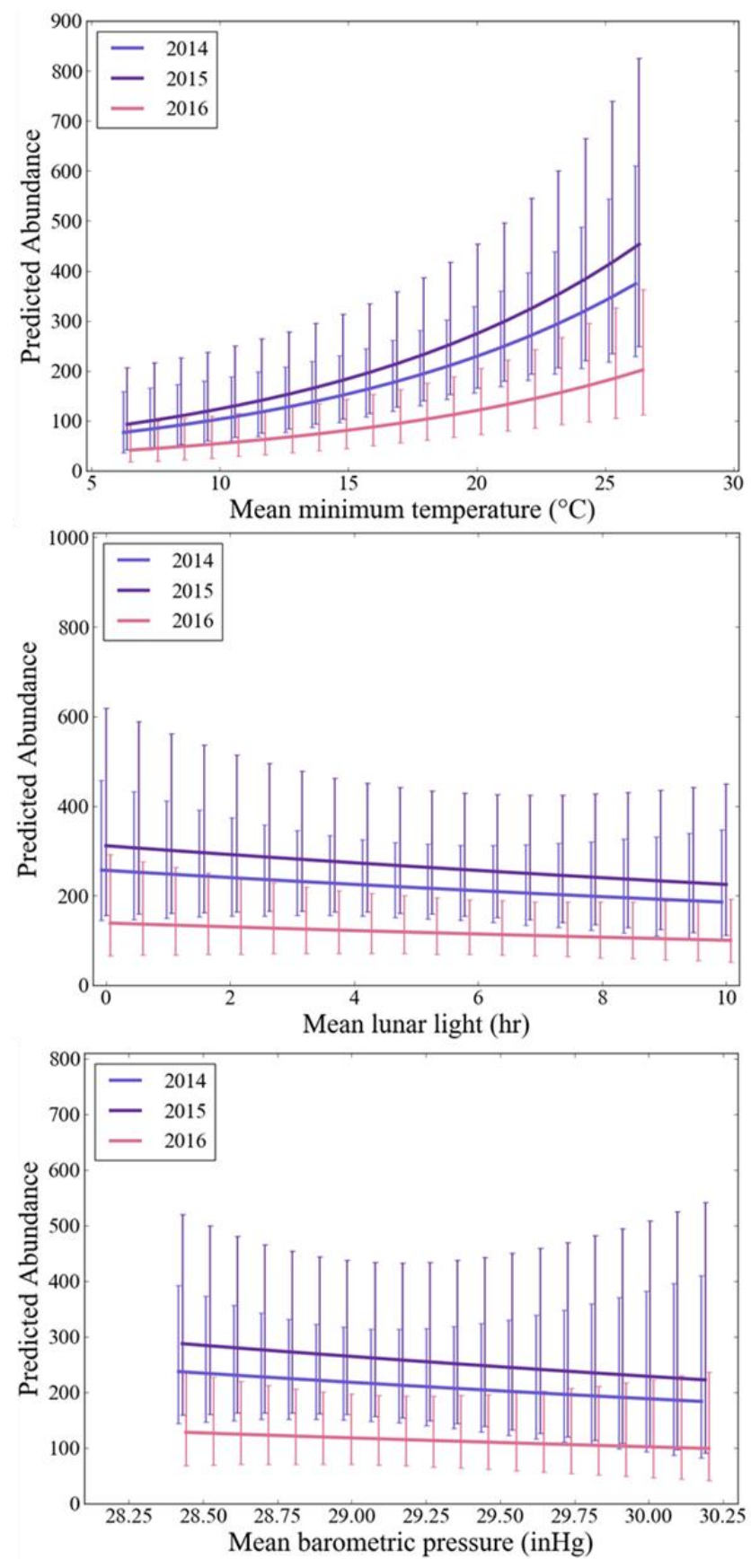

Figure 5. Predicted abundance and $95 \%$ confidence limits for mean total insects at active plots across ranges of supported restoration, habitat, and environmental covariates in the Ozarks of Missouri, 2014-2016. 

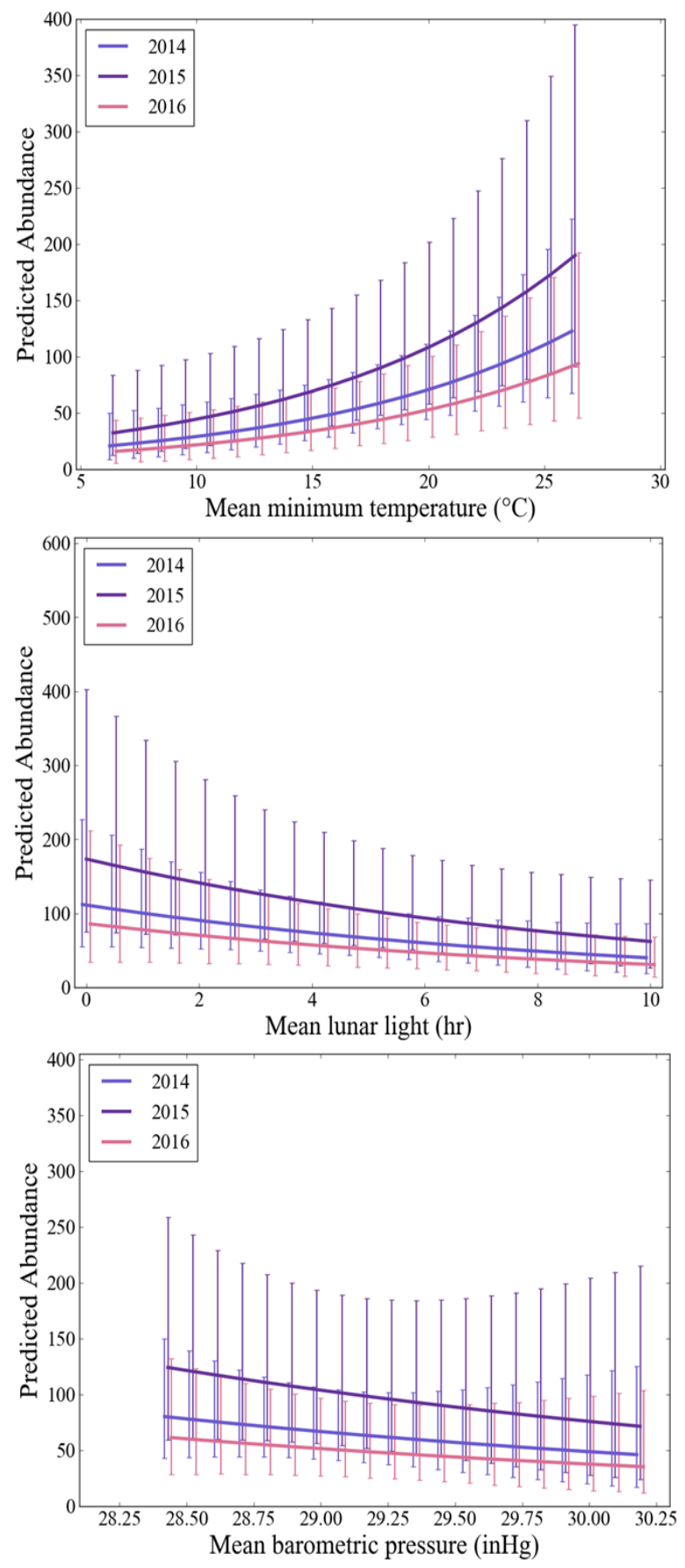

Figure 6. Predicted abundance and $95 \%$ confidence limits for mean Coleopterans captured at active plots across ranges of supported restoration, habitat, and environmental covariates in the Ozarks of Missouri, 2014-2016. 

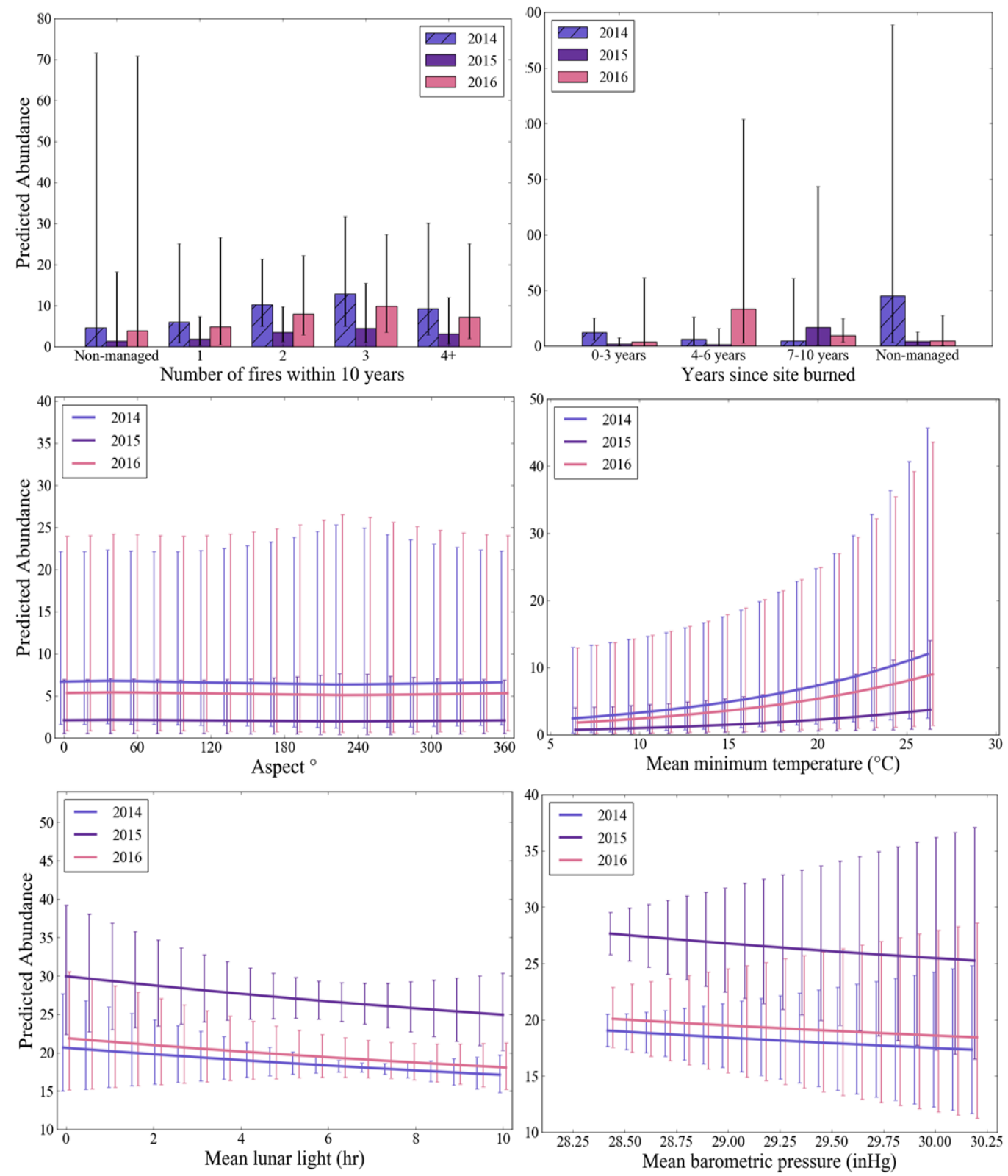

Figure 7. Predicted abundance and $95 \%$ confidence limits for mean Trichopterans captured at active plots across ranges of supported restoration, habitat, and environmental covariates in the Ozarks of Missouri, 2014-2016. Non-managed are sites either never burned or sites not burned within the last 10 years. 

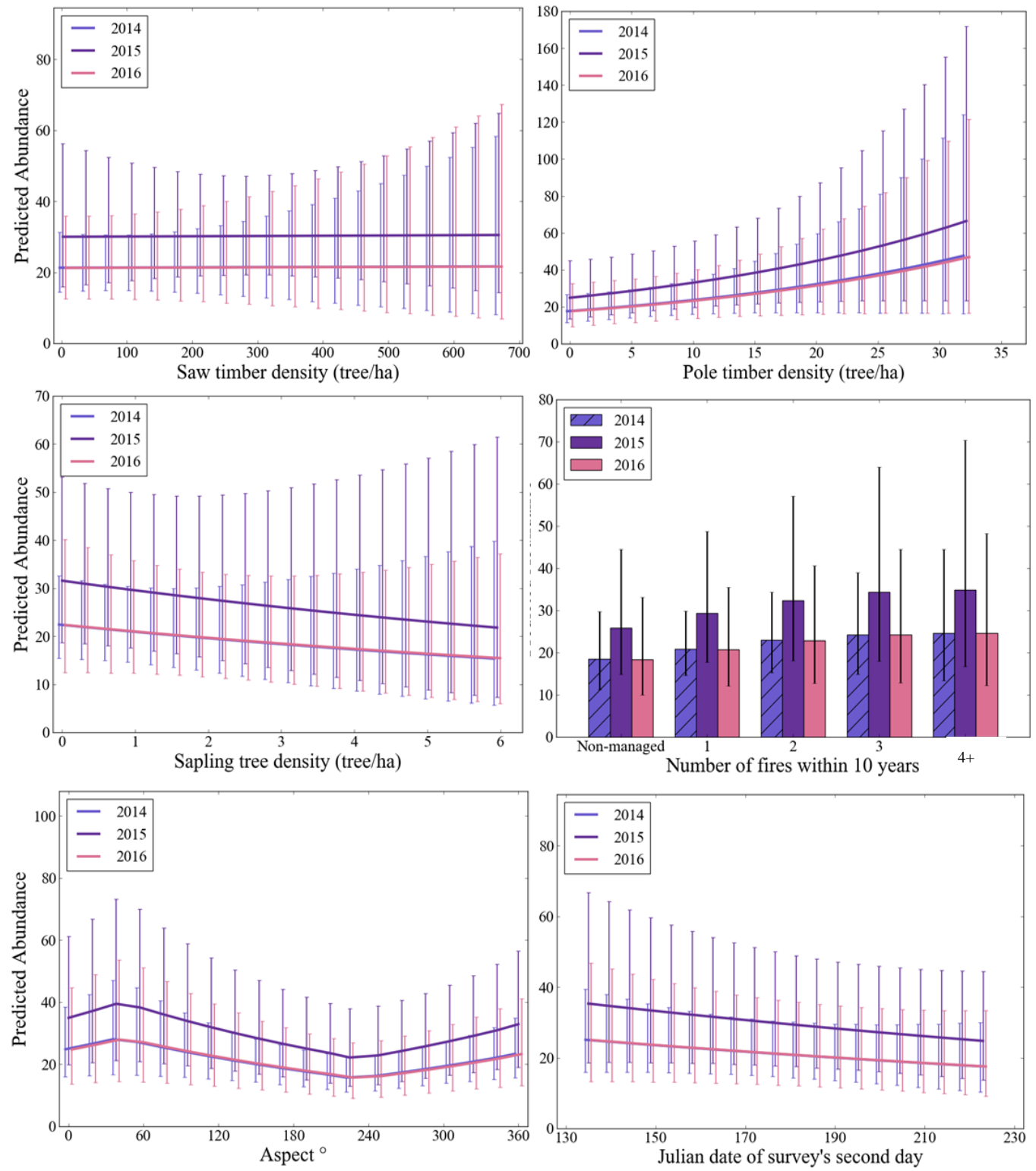

Figure 8. Predicted abundance and $95 \%$ confidence limits for mean total insects captured at passive plots across ranges of supported restoration, habitat, and environmental covariates in the Ozarks of Missouri, 2014-2016. Non-managed are sites either never burned or sites not burned within the last 10 years. 
CHAPTER 4. Bat abundance in relationship to prescribed fire, vegetation, and landscape composition across savannas, woodlands, and forests in the Missouri

\title{
Ozarks
}

\author{
Kathryn M. Womack ${ }^{1,3}$, Sybill K. Amelon ${ }^{2}$, and Frank R. Thompson III $^{2}$ \\ ${ }^{1}$ School of Natural Resources, 302 Natural Resource Building, University of Missouri, \\ Columbia, MO 65211, USA \\ ${ }^{2}$ Northern Research Station, U.S.D.A. Forest Service, 202 Natural Resource Building, \\ Columbia MO 65211, USA \\ ${ }^{3}$ Corresponding author: E-mail: kmwhr5@mail.missouri.edu
}

\begin{abstract}
Savanna and woodland ecosystems were common throughout the Midwest, but fire suppression and land use changes dramatically reduced these systems to isolated remnant patches. These ecosystems are now being restored across the Midwest. There is also heightened concern for bat populations in the region and a need to collect demographic data during the summer maternity season because of white-nose syndrome (WNS) and other threats. We evaluated the effect of restoration and other habitat factors at multiple spatial scales on bat species abundances across a gradient of savannas, woodlands, and forest. We conducted mist-net surveys at 89 sites across the Ozark region of Missouri in 2014-2016, and collected demographic data on 4 bat species captured: northern longeared bat (Myotis septentrionalis), tri-colored bat (Perimyotis subflavus), evening bat (Nycticeius humeralis), and eastern red bat (Lasiurus borealis). We used general multinomial Poisson models with removal sampling to evaluate multi-scale a priori hypotheses on the effects of savanna and woodland restoration as well as other landscape
\end{abstract}


factors and prey availability at sites that potentially affect either the detection or abundance of bats at sites. Northern long-eared bat abundance was positively related to saw- and pole-timber tree densities at our site scale and percent cover of forest, and savanna-woodland within $1 \mathrm{~km}$ of mist-net sites at the patch scale. Tri-colored bat abundance was positively related to sites that were recently burned (1-3 years). Evening bats abundance was positively related to sites burned 4-6 years ago, and increased fire frequency within a 1-km radius. Eastern red bat abundance was negatively related to percent canopy cover and tree densities, and positively related to percent forest within $1 \mathrm{~km}$ and percent urban within $16 \mathrm{~km}$ of mist-net sites. Abundance of northern long-eared bat and tri-colored bat were lower in 2015 and 2016, respectively, compared to 2014. Eastern red bat abundance was greater in 2015 and 2016 compared to 2014. Overall, we found no evidence that savanna-woodland restoration negatively affected any of these bat species; although, northern long-eared bat abundance was more strongly positively related to percent forest cover and tree densities than to percent savanna-woodland cover within $1 \mathrm{~km}$. Our study is the first to predict abundances from repeated count data from mist-net surveys and we successfully used these models to identify factors at multiple scales that were important for bat species in the Ozark Region of Missouri during the maternity season. We suggest general multinomial Poisson models with removal sampling is a better approach to understanding factor affecting abundance than use of uncorrected counts.

\section{INTRODUCTION}

State and federal agencies in Missouri are restoring savanna and woodland habitats to conserve historic fragments and restore these systems and their characteristic species. 
Savannas and woodlands were maintained historically by frequent wild and anthropogenic fire as well as grazing by large herbivores (Nelson 2012). The Ozarks of Missouri had approximately 11-13 million hectares of oak savannas that bordered the tall grass prairies before European settlement (Taft 1997). Fire suppression, anthropogenic landscape conversion, and fragmentation led to the loss of most savannas and woodlands in this region (Nowacki and Abrams 2008, Abrams 1992). Fire suppression resulted in succession to closed canopy forest that changed the microclimate and composition of the understory (Nowacki and Abrams 2008). The recruitment of shade-intolerant species such as oaks, one of the dominant trees in savannas and woodlands, is low without disturbances that create gaps in the canopy (Johnson et al. 2009). Prescribed fire and mechanical thinning are the primary silvicultural practices used to restore these ecosystems. Given the growing interest in restoring savanna and woodland, it is important to understand how restoration affects wildlife and especially species of conservation concern (SCC). In addition, incorporating a hierarchical, multi-scale approach to evaluate habitat use at multiple spatial scales provides a more comprehensive understanding in species resource needs as species rarely respond to habitat features at only one spatial scale (Hilden 1965, Hutto 1985, Lawler and Edwards 2006).

Savanna and woodlands are important for many wildlife species, and have been the focus of recent studies. Many early successional and woodland songbird species select savanna and woodland habitats over non-managed forests. Songbirds are affected by restoration at multiple spatial scales from site to landscape including the amount of forest cover within $10 \mathrm{~km}$ (Reidy et al. 2014). Reptile captures in western Arkansas are higher at restoration locations compared to non-managed forests with several reptile species only captured in 
restored woodlands (Perry et al. 2009). Knowledge on how bat abundance related to savanna-woodland restoration can provide additional information on drivers of habitat selection. We worked across a gradient of savanna, woodland, and non-managed forest in the Missouri Ozark highlands to address concerns about how management affects abundance for four Missouri bat species. We used a hierarchical multi-scale approach to determine how restoration practices (i.e., prescribed fire) and other habitat covariates affect bat abundance at multiple spatial scales.

Restoration management utilizing prescribed fire is generally thought to improve bat habitat due to the creation of snags (potential roosts), reduction of structural clutter in the mid and understory, and increase in prey abundance and diversity (Lacki et al. 2009, Dickinson et al. 2009, Dodd et al. 2012). However, there are conflicting results among some studies. No difference in tri-color bat activity was found between managed and non-managed forests in Ohio (Titchell et al. 2001); whereas, structural changes associated with restoration management are related to increased site occupancy of red, tri-colored, and evening bats, but not northern-long eared bats in the Ozarks of Missouri (Starbuck et al. 2015). Roosting habitat increases after prescribed burns for evening bats in Taney County, Missouri, likely because of a reduction in canopy cover that allowed light to penetrate to roosting locations (Boyles and Aubrey 2006). Most studies assume bats select habitat based on roost sites or reduced vegetation clutter for easier flight and foraging; however, bats may select for habitats that have greater foraging potential (Lacki et al. 2009). Forests treated by prescribed fire have greater insect abundance and bat activity than unburned forests in Kentucky (Lacki et al 2009). Pine plantations treated by 
prescribed fire also have greater arthropod abundances than non-managed stands (Zebehazy 2002).

Anthropogenic environmental stressors affecting bats include landscape conversion, infectious disease, and wind energy (Kasso and Balakrishnan 2013). White-nose syndrome (WNS) is an infectious disease that has caused over 5.5 million deaths of seven hibernating bat species in the Eastern United States (USFWS 2012). WNS affects three federally-listed species found in Missouri including the northern long-eared bat, which was listed as threatened in 2015 due to population declines attributed to WNS (USFWS 2015). Our study species include two WNS affected species: the northern long-eared and tri-colored bat, and two unaffected WNS species: the evening bat and eastern red bat. Although the eastern red bat is unaffected by WNS, this species has seen population declines linked to wind energy over the past 15 years (Cryan et al. 2014). Wind turbines occur along known migratory routes for birds and bats resulting in massive mortality events for migrating bat species during spring and fall migration events (Cryan et al. 2014, Kunz et al. 2007). Both WNS and wind energy affect bat populations at unknown rates during critical life stages; therefore, questions related to population viability are warranted to understand the rates of declines during key life stages to provide vital information for conservation efforts.

Abundance estimates collected over time can be used to determine if species abundance increases, decreases, or stabilizes. Recent threats to bat populations in the eastern United States provide an increased demand for methodologies that can estimate abundance at 
sites (Kunz et al. 2007, Walters et al. 2013, Puechmaille et al. 2011, Turner et al. 2011). Traditional abundance methods are labor intensive, and are often unfeasible for bats; however, recent analytical advances provide potential models that may allow for ecologically meaningful abundance estimates (Royle 2004a, Royle 2004b, Fiske and Chandler 2011). For example, Womack (chapter 2) demonstrated that the general multinomial Poisson model with removal sampling could correctly estimate abundance based on simulated bat capture data, and performed much better than the n-mixture model with repeated visits.

We used the general multinomial Poisson model with removal sampling to determine relationships between multi-scale landscape and habitat factors on abundance using mistnet data collected with repeated surveys at sites throughout the Ozarks. We focused on four bat species: the northern long-eared bat (Myotis septentrionalis), tri-colored bat (Perimyotis subflavus), evening bat (Nycticeius humeralis), and eastern red bat (Lasiurus borealis). We sought to determine abundance relationships during the summer maternity season throughout the Ozark region of Missouri for species affected by WNS (northern long-eared and tri-colored bat) and wind energy(eastern red bat) along with the evening bat which has not been documented to be affected by either population threat. Our objective was to determine relationships between landscape composition and pattern, habitat structure, prescribed fire, and insect availability on bat abundance in a continuum of savanna, woodland, and unmanaged forests in the Ozarks of Missouri. We used a hierarchical approach to evaluate $a$ priori hypotheses on relationships between bat abundances and site, patch, landscape, and multi-scaled factors. We evaluated support for 
relationships between bat abundance and prey availability, lunar light, stand structure, and prescribed fire at the site level, which we defined as within $250 \mathrm{~m}$ of a mist-net location. We evaluated support for relationships between bat abundance and percent forest, savanna-woodlands, and non-forest and prescribed fire within $1 \mathrm{~km}$ (patch scale), as well as percent forests, percent urban, and percent other land cover and forest-edge density within $16 \mathrm{~km}$ (landscape scale). We evaluated our multi-scale hypotheses by combining our top models at each spatial scale to understand multi-scaled effects for each bat species.

\section{METHODS}

\subsection{Study area}

Our study sites were in the Ozarks of Missouri, mainly the Ozark Highland ecological section. The Ozark Highlands is divided into sixteen ecological subsections based on differences in lithology, landform, soils and vegetation (Nigh and Schroeder 2002). The

Ozarks have many karst features due to the characteristic carbonate bedrock in this region (Nigh and Schroeder 2002). Soils are typically rocky and historically supported mainly oak and oak-pine savannas, woodlands, and forests. Oak-hickory, pine-oak, and mixedoak woodland and forest communities (Nelson 2012) dominate the Ozarks currently. Common upland tree species include post oak (Quercus stellata), blackjack oak ( $Q$. marilandica), white oak (Q. alba), northern red oak (Q. rubra), hickory (Carya spp.), shortleaf pine (Pinus echinata), and flowering dogwood (Cornus florida) with open woodland and savanna containing bluestem grasses (Andropogon gerardii, Schizachyrium scoparium), sedges (Cyperaceae spp.), woody shrubs such as fragrant sumac (Rhus aromatic) and blackberry (Rubus spp.), and saplings (Nelson 2012). Most 
streams in the area are spring-fed and clear. This region has high biological diversity and endemism (Ethridge 2009).

Due to the regional scale of this study, we sampled study areas that would allow for multiple survey locations with suitable mist-net sites and that were at least $2 \mathrm{~km}$ apart to prevent pseudo-replication. Study sites were located in: Caney Mountain Conservation Area (538 ha), Peck Ranch Conservation Area (9,616 ha), Drury-Mincy Conservation Area (1,655 ha), and Little Black Conservation Area (1,201 ha) managed by the Missouri Department of Conservation (MDC); Roaring River State Park (1,657 ha), Ha Ha Tonka State Park (1,501 ha), Lake of the Ozarks State Parks (7,133 ha), and Knob Noster State Park (1,592 ha) managed by the Missouri Department of Natural Resources; and the Salem, Ava/Willow Springs/Cassville, Houston/Rolla, and Poplar Bluff districts of Mark Twain National Forest (MTNF; 607,029 ha; Figure 1).

\subsection{Experimental design}

We captured bats over water using mist-nets from May 15-August 15 in 2014-2016. We determined mist-net sites by randomly stratifying suitable trappable locations over the gradient of savannas, woodlands, and forests within study areas. We used a nested plot design to evaluate site, patch, and landscape scale relationships defined as within $250 \mathrm{~m}$, $1 \mathrm{~km}$, and $16 \mathrm{~km}$ of the plot center (mist-net site), respectively. We assumed bats captured in the mist-nets were using a greater area around the nets. We surveyed insects and sampled vegetation at our site scale by identifying 8 random plots in 2014, and reduced the number of plots to 4 for sampling in 2015 and 2016. We randomly located 
plots $>50 \mathrm{~m}$ and $<250 \mathrm{~m}$ from the mist-net site and $>50 \mathrm{~m}$ from each other. Half the points were randomly selected for active insect sampling and half for passive sampling (see chapter 3 ). We used a $1 \mathrm{~km}$ radius to define the patch scale because it encompasses the $50 \%$ home range size for the northern long-eared bat and another similarly sized Myotis spp. (Elmore et al. 2005, Walters et al. 2007, Owen et al. 2005, Womack et al. 2013). Evening and tri-colored bats have no recorded home range size in the literature; however, body size and wing morphology suggests that home ranges should be similar to known Myotis spp. We chose a $16 \mathrm{~km}$ radius for the landscape scale because previous studies examining species occupancy find support for landscape variables at this scale (Amelon 2007, Starbuck et al. 2015).

\subsection{Mist-net survey and bat capture protocol}

We set up mist-nets over wildlife ponds, perennial creeks, and large road ruts that held water for at least to 1-2 weeks. For a site to be suitable, it required open water (no surface vegetation); however, we did trap sites with some surface vegetation to help funnel bats into our mist-nets placed over open water. We standardized our mist-net effort to consist of 1 triple high mist-net setup (10 m) and 2-3 single high mist-nets at a site (2-3m). Mistnet lengths varied from $6 \mathrm{~m}-15 \mathrm{~m}$, depending on what size was needed to cover the width of the water source. Most sites required 9 and $12 \mathrm{~m}$ mist-nets. We placed mist-nets approximately $20-\mathrm{cm}$ above the water surface to prevent bats captured in the lowest bag from getting wet. Mist-nets were placed over water sources in various designs dependent on the size and shape of the water source with the goal to funnel bats into mist-nets, and prevent water access to bats without being captured. We surveyed each site for 3 consecutive nights for 5 hours nightly starting at sunset. We followed the most recent 
WNS decontamination protocols issued by USFWS, and held bats in sterile cotton bags until they were processed. We identified all bats to species, recorded sex, reproductive condition, weight $(\mathrm{g})$, forearm length $(\mathrm{mm})$, noted the net number, and the capture time. We recorded WNS wing score for WNS affected species, and collected wing biopsies and swabbed for WNS on select species as part of another on-going project. No bat was held longer than 30 minutes before being released. We completed this study under University of Missouri Animal Care Quality Assurance Office protocol 8144. We mist-netted under several different USFWS Federal Permits, dependent on the mist-net leader's affiliations: either the University of Missouri or USDA U.S. Forest Service, permits: TE98063A1(Womack) or TE06809A-3(Amelon). Each mist-net site leader applied for their own MDC wildlife collectors permit in 2014-2016 (16003 (Womack), 16004 (Starbuck), 16403 (Womack), 16835 (Womack)) along with Missouri Department of Natural Resources State Park permits (Amelon and Womack). Insect collections were under Womacks MDC wildlife collector's annual permit 16003, 16403, and 16835.

\subsection{Site scale measurements and covariates}

We collected site-specific vegetation data using $11.3 \mathrm{~m}$ fixed radius plots at our 8 insect survey plots in 2014 and our 4 in 2015 and 2016. At each plot, we measured the diameter at breast height $(\mathrm{DBH})$ and species of all stems $>1$ in, and noted if the tree was a potential bat roost. We measured percent canopy cover using a densiometer, and visually estimated the percent mid-story and understory. We used a clinometer to estimate canopy height and slope. We estimated mid-story and understory height relative to the measured canopy height. We used a compass to record plot aspect. We visually estimated the percent cover within a 5-m radius of the center into the following categories: percent woody or 
herbaceous shrubs, forbs, leaf litter, and bare ground or rock cover. The total percent equals 100 . We measured the leaf litter depth at $2 \mathrm{~m}$ from plot center using a compass and a metric ruler; we measured litter depth in the four cardinal directions. We evaluated our hypothesis on the effects of stand structure by calculating tree densities of for different size classes: sapling/seedling (DBH $<6$ in.; TPHs); pole timber $(6>\mathrm{DBH}<11$ in., TPH5); and saw timber (DBH > 11 in., TPH11) and measuring percent canopy cover (Canopy; Table 1).

We sampled insects at half the plots with malaise, panel-intercept, and pitfall traps (passive traps), and the other half with a UV black light trap (active trap). We determined total insect abundance collected from malaise and panel-intercept traps and active traps based on prey size class. We defined prey size-classes that covered the range of potential prey size for Missouri bats (Fenton and Barclay 1980, Barclay 1985). We defined small, medium, and large insect classes as 3-10 mm, 10.1-15.0 mm, and 15.1-27 mm, respectively. We assumed tri-colored and northern long-eared bats were limited to the small size class due to similar skull size and shape of little brown bats (Fenton and Barclay 1980). Evening bats have longer and wider skulls (Schwartz and Schwartz 2001) than little brown bats, and would likely consume both small and medium sized prey. Eastern red bats prey size generally range from 10.1-27 mm (Feldhamer et al. 1995, Ross 1961), so we combined the medium and large size class to get the potential insect abundance for this species. We examined our a priori hypothesis on the effects of potential prey (PREY) by summing the number of insects within the predicted size class for each bat species across all insect traps at a mist-net location for each survey night (Table 1). 
We collected nightly climate data (barometric pressure, wind speed, and temperature) at mist-net sites using a Kestrel 2500 Pocket Weather Meter (AllKestrel.com, Downingtown, PA). We collected data at the beginning and end of the survey and at least once during the 5-hour mist-net (hour 2-4) survey. We noted cloud cover and total hours of lunar light (LUNAR) on our datasheets nightly. We also utilized data collected from the nearest National Climatic Data Center for the stations closest to each site which include Rolla, Kaiser Lake Ozark, West Plains, Springfield, and Poplar Bluff to correct/ verify our measurements, and to document the total number of LUNAR on a given night based on sunset and sunrise times. The following climatic covariates and temporal covariates were used in our detection probability models: Julian date (JUL), year (YR), minimum nightly temperature (mnTEMP), barometric pressure (PRESSURE), wind speed (WIND), and LUNAR (Table 2). Summer 2014 was our reference class for our YR variable in all detection and abundance models. We also evaluated an abundance hypothesis that determined the effect of LUNAR on bat abundance (Table 1).

We obtained information on the year(s) a site was burned or harvested within the last 10 years from area managers. We evaluated our hypothesis on the effect of prescribed fire by examining how the number years since burned (YRburned) affected bat abundance (Table 1). We created four YRburned classes: 0-3, 4-6, 7-10, and greater than 10 years or non-managed (referred to as non-managed hereafter). Our reference category was our non-managed class. 


\subsection{Patch scale covariates}

We calculated the percent forest, savanna-woodland forest, and non-forest using 2011 National Landcover Dataset (NLCD)'s canopy cover data layer in ArcMap (version 10.2.1; ESRI). We classified pixels as forest, savanna-woodland, or non-forest if canopy cover was $>70 \%, 1-70 \%$, or $0 \%$, respectively. We calculated the percent forest $(\%$ FOR $1 \mathrm{~km})$, savanna-woodland $(\% \mathrm{SW} 1 \mathrm{~km})$, and non-forest $(\% \mathrm{NON} 1 \mathrm{~km})$ in a $1-\mathrm{km}$ buffer around each site using Geospatial Modeling Environment (GME; Beyer 2014; Table 1). We used \%NON1 km as our reference covariate for candidate models, examining the patch scale effect of $\%$ FOR $1 \mathrm{~km}$ and $\% \mathrm{SW} 1 \mathrm{~km}$. We obtained fire history data from each managing agency for the last 10 years, and within $1 \mathrm{~km}$ of each mist-net site. We also used the USDA Forest Service's region 9 historic fire database along with Mark Twain National Forest's District records to determine fire histories for mist-net locations on national forests. We calculated fire frequency (FireFreq $1 \mathrm{~km}$ ) as the number of fires within $1 \mathrm{~km}$ of each mist-net site over 10 years (Table 1). We estimated the percent of area burned (\%Burned) within $1 \mathrm{~km}$ using GME (Beyer 2014) to determine the proportion of the $1 \mathrm{~km}$ area burned during the last 10 years (Table 1).

\subsection{Landscape scale covariates}

We determined the percent forest (For16km), percent urban (Urban16km), and percent other (Other16km) within $16 \mathrm{~km}$ of each mist-net site using 2011 NLCD (Table 1). We reclassified NLCD land covers into 3 categories: urban, forest, and other. All land classes that had any level of development were placed within our urban group which represents anthropogenic development to the natural landscape. Urban land cover was mostly 
farmsteads and small rural towns. All forest types were grouped within our forest category, and all other categories were put into our other land cover group. We used GME (Beyer 2014) to calculate the proportion of each reclassified land cover type within a 16-km buffer of our landscape buffer. We used Other16km as our reference class for all candidate models evaluating the landscape effect of For16km and Urban16km. We used 2011 NLCD canopy cover data to determine the forest edge density (Edge) in GME within $16 \mathrm{~km}$ radius for each site (Beyer 2014). We calculated Edge as the edge between non-forest, NLCD 2011 canopy cover $=0$ to forest, NLCD 2011 canopy cover $>0$ (Table $1)$.

\subsection{Data analysis}

We fit hierarchical abundance models using general multinomial-Poisson models for removal sampling in the UNMARKED package in $\mathrm{R}$ (version 3.2; Fiske and Chandler 2011). This model requires counts of individuals from repeated visits to a site. The model assumes a population is closed over the sampling period. The removal sampling function of the model requires captured individuals are removed from all subsequent visits to a site which we accomplished by marking individuals. The UNMARKED package provides a toolbox to evaluate abundance models by first estimating detection probabilities, and then evaluating model covariates that likely affect abundance for a given species (Fiske and Chandler 2011).

We used a multi-step information theoretic approach to evaluate a priori hypotheses, and ranked models plus a null model (Table 3 and Table 4) based on Akaike's Information Criterion (AIC; Burnham and Anderson 2002). We first evaluated relationships of abiotic 
factors (mnTemp, LUNAR, PRESSURE, and WIND; Table 1) and temporal factors (JUL and YR; Table 1) on detection probability. We examined 9 detection models with covariates that influence bat activity (Ciechanowski et al. 2007, Hayes 1997, Lang et al. 2006, Womack 2013; Table 3). Next, we used the top detection model for each bat species in all 12 single-scale candidate abundance models for that species (site, patch, and landscape; Table 4). Year (YR) was a fixed effect in all our abundance models to account for annual variability in abundance. Our final step incorporated our top model for each spatial scale, and examined all combinations of these models to evaluate multiscaled effects on bat abundance. This process created 4 additional models that we ranked together with our single scale models. We tested the top model(s) for each bat species for goodness of fit with the Freeman-Tukey test, and used parametric bootstrapping to run 1000 iterations (parboot; Fiske and Chandler 2011). We model averaged predictions from all models within $\triangle \mathrm{AIC}<2$ resulting in additional informative parameters (Anderson and Burnham 2002). We plotted model predictions across the range of a supported covariate while holding all other covariates at their mean, except for covariates measured as percentages, which were held at 0 . We calculated the $95 \%$ confidence intervals for covariates included in our top model, and primarily interpreted covariates whose confidence limits did not overlap 0 . We also report descriptive statistics for all detection and abundance model covariates (Table 5).

\section{RESULTS}

We surveyed 89 mist-net sites during $2014-2016$ (35, 32, and 22; respectively), which represented 267 trap nights and 1335 hours of mist netting. We did not catch any bats on 37 trap nights. We caught 1516 individuals comprising 11 species: eastern red bat 
(Lasiurus borealis), northern long-eared bat (Myotis septentrionalis), evening bat (Nycticeius humeralis), gray bat (Myotis grisescens), tri-colored (Perimyotis subflavus), big brown bat (Eptesicus fuscus), hoary bat (Lasiurus cinereus), silver-haired bat (Lasionycteris noctivagans), Indiana bat (Myotis sodalis), little brown bat (Myotis lucifugus), and southeastern Myotis (Myotis austroriparius). We recaptured only 10 individuals at the same mist-net site over this study. The number of recaptures was consistent with banding data that indicates recapture events are rare for bats in our study region (Amelon, unpublished data).

\subsection{Northern long-eared bat (Myotis septentrionalis)}

The top detection model was the global model (Table 6). Detectability was negatively related to JUL and PRESSURE, and confidence intervals did not overlap zero (Table 7). The best-supported abundance model was a multi-scaled model that included site and patch covariates, tree densities by size class at our site scale, percent forest and percent savanna-woodland habitat within $1 \mathrm{~km}$ of each mist-net site, and had an AIC weight $\left(w_{i}\right)$ of 0.68 (Table 8). There was no evidence of lack of fit (Freeman-Tukey test, $P=0.662$ ). TPH11, TPH5, \%For $1 \mathrm{~km}$, and $\% \mathrm{SW} 1 \mathrm{~km}$ were positively related to abundance, and confidence intervals did not overlap zero. Abundance was negatively related to TPHs but confidence intervals did overlap with zero (Table 9). Abundance was negatively related to YR2 (2015) and YR3 (2016) compared to 2014, and confidence intervals did not overlap zero (Table 9). The next model combined all three spatial scales, and had a $\Delta$ AIC of 1.54 (Figure 2; Table 8). Abundance was negatively related to For16km and Urban $16 \mathrm{~km}$, but confidence intervals did overlap zero. We model averaged predictions from the top two models to address model uncertainty. We predicted there were 4,0 , and 
0 individuals at a site in 2014, 2015, and 2016, respectively, when \%For $1 \mathrm{~km}$ was $22 \%$, and 40, 5, and 7 individuals, respectively, when \%For $1 \mathrm{~km}$ was $87 \%$ (Figure 2). There were 1,0 , and 0 individuals at a site in 2014, 2015, and 2016, respectively, when $\%$ SW $1 \mathrm{~km}$ was $20 \%$, and 5, 1, and 1 individuals, respectively, when $\%$ SW $1 \mathrm{~km}$ was $97 \%$ (Figure 2). There were 6, 1, and 1 individuals at a site in 2014, 2015, and 2016, respectively, at sites with 68 tree/ha of saw timber, and 102, 14, and 17 individuals, respectively, at sites with 405 tree/ha of saw timber (Figure 2). There were 5, 1, and 1 individuals at a site in 2014, 2015, and 2016, respectively, at sites with 4 tree/ha of pole timber, and 82, 11, and 14 individuals, respectively, at sites with 27 tree/ha of pole timber (Figure 2).

\subsection{Tri-colored bat (Perimyotis subflavus)}

The top detection model was the barometric pressure model (Table 6). Detectability was negatively related PRESSURE, and confidence intervals did not overlap zero (Table 7). The best-supported abundance model was a multi-scaled model that included site and patch covariates, YRburned, $\% \mathrm{SW} 1 \mathrm{~km}$, and $\%$ and had an AIC weight $\left(w_{i}\right)$ of 0.82 (Table 10). There was no evidence of lack of fit (Freeman-Tukey test, $P=0.618$ ). Abundance was positively related to sites burned within the last 3 years (YRBurned4) compared to sites not burned with the last 10 or more years, and confidence intervals did not overlap zero. Abundance was negatively related to YR3 (2016) compared to 2014, and confidence intervals did not overlap zero (Table 11). The next model combined the top model with the top landscape scale model but had a $\Delta$ AIC of 3.12, so we did not model average (Figure 3; Table 10). We predicted there were 2, 3, and 0 individuals at 
sites burned within the last 3 years in 2014, 2015, and 2016, respectively, compared to 1 , 1, and 0 individuals at sites not burned within the last 10 years (Figure 3).

\subsection{Evening bat (Nycticeius humeralis)}

The top detection model was the barometric pressure model (Table 6). Detectability was positively related to PRESSURE, and confidence intervals did overlap zero (Table 7). The best-supported abundance model was a multi-scaled model that included YRburned and FireFreq1km, and had an AIC weight $\left(w_{i}\right)$ of 0.38 (Table 12). There was no evidence of lack of fit (Freeman-Tukey test, $P=0.578$ ). Abundance was positively related to sites burned within the last 4-6 years compared to sites not burned, and confidence intervals did not overlap zero (Table 13). Abundance was positively related to sites burned within the last 1-3 years, and confidence intervals did overlap zero (Table 13). Abundance was negatively related to YR2 and YR3 (2015 and 2016; respectfully) compared to 2014, and confidence intervals did not overlap zero (Table 13). The next best model was our top patch scale model with FireFreq $1 \mathrm{~km}$ and had a $\triangle \mathrm{AIC}$ of 0.98 (Table 12). The combined model weight for the top 2 models was 0.61 (Table 12). There were two additional multiscaled models within a $\triangle \mathrm{AIC}$ of 2 ; however, both models only added uninformative parameters to the higher ranked models (Table 12; Anderson and Burnham 2002, Arnold 2010), so we model averaged predictions from the top two models. We predicted there were 5, 3, and 4 individuals in 2014, 2015, and 2016, respectively, at sites that were burned within the last 4-6 years compared to 4, 2, and 3 individuals, respectively, at sites not burned within the last 10 years (Figure 4). There were 13, 7, and 9 individuals in 2014, 2015, and 2016, respectively, at sites with >10 burns within $1 \mathrm{~km} ; 6,3$, and 4 
individuals, respectively, at sites with 5 fires, and 3, 1, and 2 individuals, respectively, at sites with no fires (Figure 4).

\subsection{Eastern Red Bat (Lasiurus borealis)}

The top detection model was the climate model (Table 6); detectability was negatively related to mnTEMP and positively related to PRESSURE and LUNAR (Table 7).

However, confidence intervals for all detection covariates overlapped zero (Table 7). The best-supported abundance model was our combined multi-scaled model (site, patch, and landscape); covariates included tree densities by size class and canopy cover at site level, percent forest, and percent savanna-woodland habitat within $1 \mathrm{~km}$ of each mist-net site, and percent urban and forested landcover within $16 \mathrm{~km}$. Our top model AIC weight was approximately 1 so there were no competing models or need to model average (Table 14). There was no evidence of lack of fit (Freeman-Tukey test, $P=0.555)$. Abundance was negatively related to TPH11, TPH5, TPHs, and Canopy and confidence intervals did not overlap zero (Table 15). Abundance was positively related to \%For $1 \mathrm{~km}$ and Urban $16 \mathrm{~km}$ and confidence intervals did not overlap zero (Table 15). Abundance was positively related to YR2 (2015) and YR3 (2016) compared to 2014, and confidence intervals did not overlap zero (Table 15). The next best model included site and patch covariates and had a $\triangle \mathrm{AIC}$ of 23.91 (Table 14). We predicted there were 9,12 , and 12 individuals at a site in 2014, 2015, and 2016, respectively, at sites with 68 tree/ha of saw timber, and 4, 5, and 5 individuals, respectively, at sites with 405 tree/ha of saw timber (Figure 5). There were 8, 11, and 12 individuals in 2014, 2015, and 2016, respectively, at sites with 4 tree/ha of pole timber, and 5, 6, and 6 individuals, respectively, at sites with 27 tree/ha of pole timber (Figure 5). There were 9, 12, and 12 individuals in 2014, 2015, 
and 2016, respectively, at sites with 0 tree/ha of sapling, and 4, 5, and 5 individuals, respectively, at sites with 7 tree/ha of sapling (Figure 5). There were 11, 15, and 15 individuals in 2014, 2015, and 2016, respectively, at sites with $23 \%$ canopy cover, and 5 , 7, and 7 individuals, respectively, at sites with 97\% canopy cover (Figure 5). There were 3, 4, and 4 individuals at a site in 2014, 2015, and 2016, respectively, when \%For $1 \mathrm{~km}$ was $22 \%$, and 5, 6, and 6 individuals, when $\%$ For $1 \mathrm{~km}$ was $87 \%$ (Figure 5). There were 4 , 5, and 5 individuals at sites with Urban16km was 2\% in 2014, 2015, and 2016, respectively, and 5, 6, and 6 individuals when Urban16km was 9\% (Figure 5).

\section{DISCUSSION}

We successfully fitted detection and abundance models for northern long-eared, tricolored, evening, and eastern red bats from mist net data collected from repeated surveys throughout the Ozark region of Missouri. No published study has fit hierarchical abundance models for bats from repeated mist net surveys in the summer. Low recapture rates reduce the feasibility for mark-recapture to estimate abundance or density of bats (Kunz and Kurta 1988); therefore, bat studies have focused instead on site occupancy (MacKenzie et al. 2002, Amelon 2007). Occupancy studies often use acoustic detectors to record echolocation calls to determine the presence or non-detection of a species at a survey location, and can estimate species detection probability based on habitat and environmental covariates (Marques et al. 2013, Amelon 2007, Starbuck et al. 2015, Yates and Muzika 2006). While abundance and occupancy are related, abundance can provide more detail on habitat quality or population status. Several studies use relative bat activity for species between habitats, or management classes as indices of abundance (Loeb and O’Keefe 2006, Womack 2008). Indices are useful, but do not incorporate detection 
probabilities beyond whether a species is present or absent at a site. Our methods estimated abundance by using repeated visits at mist-net sites to quantify detection probability, and simultaneously examining multi-scaled factors that affect bat abundance at sites across the Ozark region of Missouri. We found the general multinomial-Poisson model for removal sampling had high accuracy for predicting abundance in our simulation study (Chapter 2), and there was no evidence for lack of fit for these models in this study with field data based on the Freeman-Tukey test with parametric bootstrapping and 1000 iterations. Furthermore, our results are ecologically reasonable for our study species within our region. We provide an example of how abundance models with removal sampling from repeated mist-net surveys can successfully estimate abundance and habitat relationships for multiple bat species.

We found varying support for relationships between bat species detectability and environmental and temporal covariates. Barometric pressure was supported for all species which suggests the importance of low-pressure systems in bat activity. Bats can likely sense atmospheric pressure changes, and vary their behavior based on weather conditions. Barometric pressure directly affected bat activity in Canada, but there were conflicting results among species (Baerwald and Barclay 2011). Barometric pressure and temperature affected activity of the same species in Virginia (Womack 2008). Barometric pressure and temperature also influenced insect availability (Womack 2011, Womack 2008). In fact, climatic covariates have important effects on bat activity worldwide (Turbill 2008, Seidman and Zabel 2001, Meyer et al. 2004, Kunz et al. 2007, Starbuck et al. 2015). We observed a negative trend between lunar light and probability of capturing individuals for two bat species: the eastern red bat and northern long-eared bat. Baerwald 
and Barclay (2011) found a negative relationship between lunar light and bat activity using acoustic detectors in Canada consistent with our findings. Other bat studies have determined lunar light, or a correlated lunar covariate, to be insightful in understanding changes in bat activity and detection probability with increase lunar light decreasing bat detection probabilities and activity (Kunz et al. 2007, Womack 2008, Lang et al. 2006). Julian date had a significantly negative effect in detection probability for northern longeared bats which conflicts with previous knowledge on how bat activity changes throughout the maternity season (Womack 2011). Typically, as the maternity season progresses, there are more individuals on the landscape as the young of the year become volant in mid-July. This negative effect of Julian date is likely due to WNS, and the disease progression in northern long-eared bats during the summer (Francl et al. 2012). Consistent with our findings, capture rates of northern long-eared bats decreased over the summer field season in West Virginia; this is likely linked to lower body condition that decreased reproduction success and WNS wing damage post-hibernation (Francl et al. 2012).

Site-scale relationship hypotheses were supported in models for all four bat species. Eastern red bat and northern long-eared bat abundance was related to habitat structure, specifically saw, pole, and sapling tree densities. Northern long-eared bat abundance was positively related to tree density while eastern red bat abundance was negatively related to tree density and canopy cover. Our results are consistent with studies examining species occupancy. Eastern red bats have higher occupancy at open forests sites with reduced vegetation clutter (Loeb and Waldrop 2008, Loeb and O'Keefe 2006, Starbuck et al. 2015, Morris et al. 2010). Northern long-eared bats have higher activity in forest 
interior sites compared to forest edge in North Carolina forests (Morris et al. 2010). Northern long-eared bat site occupancy is positively related to forest, but negatively related to immature forests, or those with high sapling tree densities (Starbuck et al. 2015, Amelon 2007). Evening and tri-colored bat abundances were positively related to sites that were burned (YRburned). Loeb and Waldrop (2008) similarly found tri-color and evening bat activity is greater in thinned or burned stands than non-managed stands in South Carolina. Evening bat occupancy is also negatively related to increased tree densities in the Ozarks (Starbuck et al. 2015). Starbuck et al. (2015) also found a positive relationship between site occupancy and fire frequency, but the confidence interval overlapped zero. We found no support for our insect prey hypothesis, likely caused by various factors. We were trapping over water sources so individuals may have only used the area for drinking. Also, we measured available insects as the total number of insect within size classes reasonable for each bat species to consume, not based on actual prey species or Orders that are consumed by our four bat species. This was due to lack of diet information and multiple papers suggesting that most bats are opportunistic in their dietary strategy (Fenton and Morris 1976, Kunz et al. 2011).

We also found support for patch-level hypotheses. Abundance of eastern red bats and northern long-eared bats was positively related to \%For $1 \mathrm{~km}$. Brooks and Fords (2005) similarly found northern long-eared bats have the greatest occupancy in dense forest interior sites near water sources in Massachusetts. Northern long-eared bat site occupancy also increases with percent forest within 16km in the Ozarks (Starbuck et al. 2015, Amelon 2007); these found support for forest cover at a 16-km scale compared to our 1 $\mathrm{km}$ patch scale. Site occupancy of eastern red bats is positively related to percent forest 
within $16 \mathrm{~km}$ in Missouri (Starbuck et al. 2015) while we only found support for this effect at our patch-level.) Eastern red bats occupancy is higher when forests had greater numbers of gaps or openings at smaller spatial scales ( $<4 \mathrm{~km}$; Amelon 2007). Abundance of evening bats was positively related to FireFreq $1 \mathrm{~km}$. Boyles and Aubrey (2006) similarly found higher roost potential and activity for evening bats at sites recently burned and Evening bat site occupancy is positively related to number of fires in the Ozarks (Starbuck et al. (2015).

We found support for landscape-level hypotheses. Eastern red bat abundance was positively related to Urban $16 \mathrm{~km}$; Starbuck et al. (2015) similarly found Eastern red bat site occupancy was positively related to percent urban landcover within $16 \mathrm{~km}$. However, Amelon (2007) found site occupancy was positively related to percent forest cover and not urban area at a $16-\mathrm{km}$ scale, but she grouped urban and non-forest habitats into the same class. Foraging eastern red bats also avoid urban landcover in the Ozark region (Amelon et al. 2014) which is also contradictory to our results. Contradictory findings are likely a result of the type of data being collected and the level of detail each collection method gathers (occupancy vs. abundances vs. radio telemetry). We suggest this may be due to the fundamental differences between occupancy and abundance data. Both are correlated with occupancy being the coarser metric, and therefore, potentially limited in evaluating more fine scale site or patch environmental factors that influence abundance when examining multiple spatial scales.

The importance of multiple spatial scales to habitat section and species abundance is a fundamental concept in ecology (Hilden 1965, Hutto 1985). We found multi-scale 
models to be the top supported models for all bat species. Northern long-eared, tricolored, and evening bats had site and patch covariates in their top abundance model while eastern red bats had all three spatial scale covariates in the top model. Most previous studies of our focal species examine only one spatial scale (Morris et al. 2010, Loeb and O'Keefe 2006); however, Lacki et al. (2009) suggests that northern long-eared bats are more tolerant of prescribed fire in the broader landscape, and utilize these areas for foraging. Northern long-eared bat activity was not negatively related to prescribe fire in Kentucky (Lacki et al.2009) which is consistent with our results. Determining which spatial scales are important for a species is crucial because it allows for better conservation of species by ensuring management addresses features at scales that affect a species (Wiens 1989, Saab 1999).

We documented a significant effect of year for all bat species. Our WNS-affected species had a negative effect of 2016 on abundance compared to 2014. Northern long-eared bats had a negative effect of 2015, while tri-colored bats had a positive effect of 2015 compared to 2014. Our findings for tri-colored bat support suggestions that abundance of this WNS affected species may be highest the summer after the first mass mortality events at hibernacula; several states have documented a spike in captures for this species during the first summer after mass mortality events were reported within the state (Elliott, personal communication). The working hypothesis is that tri-colored bats may be the super spreaders of WNS and are on the leading edge of the disease range as it spreads. MDC documented the first mass mortality event in spring 2015 at hibernacula near Hannibal, Missouri. The red bat, which is potentially affected by wind energy development during spring and fall migration, had significantly positive changes in 
abundances in summer 2015 and 2016 compared to 2014, suggesting summer populations may be increasing in the Ozark region. This trend may be linked to newly implemented changes in wind energy protocols that lock down turbines during low wind periods and during key migration periods (Cryan et al. 2014), or unmeasured population shifts from other factors such as climate change or normal annual variation. Understanding multiscaled factors that affect species abundance is critical for sound management which includes ensuring adequate habitat and habitat composition is available for surviving individuals within these species. Continued monitoring using repeated mist-net surveys across the region will allow for additional knowledge of the post-mass mortality effects of WNS on the entire bat community as a whole, and if affected species numbers continue to decline or slowly stabilize and increase over time.

\section{MANAGEMENT IMPLICATIONS}

The ability to estimate abundance of bats using counts from repeated surveys rather than capture/recapture methods is a meaningful contribution for bat research and conservation. Savanna woodland restoration practices that reduce tree densities of all size classes and percent canopy cover resulted in increased abundances for eastern red bats; however, abundances of northern long-eared bats was greatest at sites with high tree densities of pole and saw timber. Managers wanting to create habitat for the entire bat community should be aware of the tradeoff between sites managed to create savanna and woodlands ecosystems should increase abundance for evening, tri-colored, and eastern red bats, but may have a negative impact on northern long-eared bats at the site scale. However, at the patch scale of $1 \mathrm{~km}$ we found that percent forest and savanna woodlands had higher abundances for eastern red bats and northern long-eared bats compared to non-forest 
landscapes. This suggests that creating a forest matrices with stands managed as savanna and woodlands communities while still managing non-managed forests within $1 \mathrm{~km}$ will likely not have a negative impact on northern long-eared bats. In addition, northern longeared and tri-colored bat abundances will likely keep decreasing as a result of WNS;

however, we urge managers to collect and estimated abundances for bat species using repeated mist-net capture data to document the changes in population size for these two species and the overall bat community. 


\section{LITERATURE CITED}

Abrams, M.D. 1992. Fire and the development of oak forests: in eastern North America, oak distribution reflects a variety of ecological paths and disturbance conditions. BioScience 42(5): 346-353.

Amar, A., S. Redpath, I. Sim, and G. Buchanan. 2010. Spatial and temporal associations between recovering populations of common raven Corvus corax and British upland wader populations. Journal of Applied Ecology 47(2): 253-262.

Amelon, S. K. 2007. Multi-scale factors influencing detection, site occupancy and resource use by foraging bats in the Ozark Highlands of Missouri. PhD Dissertation. University of Missouri, Columbia, MO. Xiv + 223 pp.

Amelon, S.K., F.R. Thompson III, and J.J. Millspaugh. 2014. Resource utilization by foraging eastern red bats (Lasiurus borealis) in the Ozark region of Missouri. Journal of Wildlife Management 78(3): 483-493.

Arnold, T. W. 2010. Uninformative parameters and model selection using Akaike's Information Criterion. The Journal of Wildlife Management 74 (6): 1175-78.

Baerwald, E.F. and R.M.R. Barclay. 2011. Patterns of activity and fatality of migratory bats at a wing energy facility in Alberta, Canada. Journal of Wildlife Management 75(5): 1103-1114.

Barclay, R.M. 1985. Long-versus short-range foraging strategies of hoary (Lasiurus cinereus) and silver-haired (Lasionycteris noctivagans) bats and the consequences for prey selection. Canadian Journal of Zoology 63(11): 2507-2515.

Beyer, H.K. 2014. Geospatial Modeling Environmental Software. www.spatialecology.com.

Boyles, J.G. and D.P. Aubrey. 2006. Managing forest with prescribed fire: implications for a cavity-dwelling bat species. Forest Ecology and Management 222(1): 108-115.

Brooks, R.T. and W.M. Ford, 2005. Bat activity in a forest landscape of central Massachusetts. Northeastern Naturalist, 12(4): 447-462.

Burnham, K. P. and D. R. Anderson, 2002. Model Selection and Multimodel Inference: A Practical Information-Theoretic Approach. Springer Verlag, New York, New York, USA. 488 pp.

Ciechanowski, M., T. Zajac, A. Bilas, R. Dunajski. 2007. Spatiotemporal variation in activity of bat species differing in hunting tactics: effects of weather, moonlight, food abundance, and structural clutter. Canadian Journal of Zoology 85: 1249-1263. 
Cryan, P.M., P.M. Gorresen, C.D. Hein, M.R. Schirmacher, R.H. Diehl, M.M. Huso, D.T. Hayman, P.D. Fricker, F.J. Bonaccorso, D.H. Johnson, and K. Heist. 2014. Behavior of bats at wind turbines. Proceedings of the National Academy of Sciences, 111(42), pp.15126-15131.

Dickinson, M.B., M.J. Lacki, and D.R. Cox. 2009. Fire and the endangered Indiana bat. Pp. 52-75 in the Proceedings of the third fire in eastern oak forests conference. (T. F. Hutchinson, ed.). USDA Forest Service General Technical Report GTR-NRS-P46.Northern Research Station, Newtown Square, PA.154 pp.

Dodd, L.E., M.J. Lacki, E.R. Britzke, D.A. Buehler, P.D. Keyser, J.L. Larkin, A.D. Rodewald, T.B. Wigley, P.B. Wood, and L.K. Rieske. 2012. Forest structure affects trophic linkages: how silvicultural disturbance impacts bats and their insect prey. Forest Ecology and Management 267: 262-270.

Elliot, A., 2015. Personal communication. Missouri Department of Conservation Wildlife Division. Bat Ecologist. Kirksville, Missouri, USA.

Elmore, L.W., D.A. Miller, and F.J. Vilella. 2005. Foraging area size and habitat use by red bats (Lasiurus borealis) in an intensively managed pine landscape in Mississippi. The American Midland Naturalist 153(2): 405-417.

Ethridge, M. (2009). The Ozark Highlands: U.S. Geological Fact Sheet. 2009-3065.

Feldhamer, G.A., J.O. Whitaker, Jr., J.K. Krejca, and S.J. Taylor. 1995. Food of the evening bat (Nycticeius humeralis) and red bat (Lasiurus borealis) from South Illinois. Transactions of the Illinois State Academy of Science 88(3): 139-143.

Fenton, M.B. and R.M. Barclay. 1980. Myotis lucifugus. Mammalian species 1-8.

Fenton, M.B. and G.K. Morris. 1976. Opportunistic feeding by desert bats (Myotis spp.). Canadian Journal of Zoology 54(4): 526-530.

Fiske, I.J. and R.B. Chandler. 2011. Unmarked: an R package for fitting hierarchical models of wildlife occurrence and abundance. Journal of Statistical Software. 43(10): $1-23$.

Francl, K.E., Ford, W.M., Sparks, D.W. Brack Jr., 2012. Capture and reproductive trends in summer bat communities in West Virginia: assessing the impact of white-nose syndrome. Journal of Fish and Wildlife Management 3(1): 33-42.

Hayes, J. P., and S.C. Loeb. 2007. The influences of forest management on bats in North America. Pp. 207-235 in Bats in forests: conservation and management (Lacki M.J., J.P. Hayes, and A. Kurta, eds.). Johns Hopkins University Press, Baltimore, MD. 329pp. 
Hilden, O. 1965. Habitat selection in birds: a review. Annales Zoologici Fennici 2: $53-$ 75.

Hutto, R.L. 1985. Habitat selection by nonbreeding, migratory land birds. Pp 455-476 in Habitat selection in birds. (M.L. Cody, ed.). Academic Press, New York, NY. 558 pp.

Johnson, P.S., S.R. Shifley, and R. Rogers. 2009. The ecology and silviculture of oaks, second edition. CABI Publishing, New York, NY. 592 pp

Kasso, M. and M.Balakrishnan. 2013. Ecological and economic importance of bats (Order Chiroptera). ISRN Biodiversity, 2013.

Kunz, T.H., E.B. Arnett, W.P. Erickson, A.R. Hoar, G.D. Johnson, R.P. Larkin, M.D. Strickland, R.W. Thresher, and M.D. Tuttle. 2007. Ecological impacts of wind energy development on bats: questions, research needs, and hypotheses. Frontiers in Ecology and the Environment. 5(6): 315-324.

Kunz, T.H., E. Braun de Torrez, D. Bauer, T. Lobova, and T.H. Fleming. 2011. Ecosystem services provided by bats. Annals of the New York Academy of Sciences, 1223(1): 1-38.

Lacki, M. J., D. R. Cox, L. E. Dodd, and M. B. Dickinson. 2009. Response of northern bats (Myotis septentrionalis) to prescribed fires in eastern Kentucky forests. Journal of Mammalogy 90(5): 1165-1175.

Lang, A.B., E.K.V. Kalko, H. Romer, C. Bockholdt, and D.K.N. Dechmann. 2006. Activity levels of bats and katydids in relation to the lunar cycle. Oecologia 146: 659-666.

Lawler, J.J. and T.C. Edwards Jr. 2006. A variance-decomposition approach to investigating multiscale habitat associations. The Condor 108: 47-58.

Loeb, S.C. and J.M. O'Keefe. 2006. Habitat use by forest bats in South Carolina in relation to local, stand, and landscape characteristics. Journal of Wildlife Management 70(5): 1210-1218.

Loeb, S.C. and T.A. Waldrop. 2008. Bat activity in relation to fire and fire surrogate treatments in southern pine stands. Forest Ecology and Management 255(8): 31853192.

Marques J.T., M.J. Ramos Pereira, T.A. Marques, C.D. Santos, J. Santana, et al. 2013. Optimizing Sampling Design to Deal with Mist-Net Avoidance in Amazonian Birds and Bats. PLoS ONE. 8(9): e74505.

Meteyer, C.U., E.L. Buckles, D.S. Blehert, A.C. Hicks, D.E. Green, V. Shearn-Bochsler, N.C. Thomas, A. Gargas, M.J. Behr. 2009. Histopathologic criteria to confirm whitenose syndrome in bats. Journal of Veterinary Diagnostic Investigation 21: 411-414. 
Morris, A.D., D.A. Miller, and M.C. Kalcounis-Rueppell. 2010. Use of forest edges by bats in a managed pine forest landscape. Journal of Wildlife Management 74(1): 2634.

Nelson, P. W. 2012. Fire-adapted natural communities of the Ozark Highlands at the time of European settlement and now. In: Dey, D. C., M. C. Stambaugh, S. L.Clark, C. J. Schweitzer, eds. Proceedings of the 4th fire in eastern oak forests conference. 2011 May 17-19. Springfield, MO. Gen. Tech. Rep. NRS-P-102. Newtown Square, PA: U.S. Department of Agriculture, Forest Service, Northern Research Station: 92-102.

Nigh, T. A. and W. A. Schroeder. 2002. Atlas of Missouri Ecoregions. The Conservation Commission - State of Missouri.

Nowacki, G.J. and M.D. Abrams. 2008. The demise of fire and "mesophication" of forests in the eastern United States. BioScience 58(2): 123-138.

Owen, S.F., M.A. Menzel, W.M. Ford, B.R. Chapman, K.V. Miller, J.W. Edwards, and P.B. Wood. 2003. Home range size and habitat used by the northern Myotis (Myotis septentrionalis). American Midland Naturalist 150(2): 352-359.

Perry, R.W., D.C. Rudolph, and R.E. Thill. 2009. Reptile and amphibian responses to restoration of fire-maintained pine woodlands. Restoration Ecology, 17(6): 917-927.

Puechmaille, S.J., G. Wibbelt, V. Korn, H. Fuller, F. Forget, K. Mühldorfer, A. Kurth, W. Bogdanowicz, C. Borel, T. Bosch, T. Cherezy, M. Drebet, T. Görföl, A. Haarrsma, F. Herhaus, G. Hallart, M. Hammer, C. Jungmann, Y. Le Bris, L. Lutsar, M. Masing, B. Mulkens, K. Passior, M. Starrach, A. Wojtaszewski, U. Zöphel, E. Teeling. 2011. Pan-European distribution of white-nose syndrome fungus (Geomyces destructans) not associated with mass mortality. PLoS ONE 6(4): e19167.

Reidy, J. L., F. R. Thompson III, and S. W. Kendrick. 2014. Breeding bird response to habitat and landscape factors across a gradient of savanna, woodland, and forest in the Missouri Ozarks. Forest Ecology and Management 313: 34-36.

Ross, A. 1967. Ecological aspects of the food habits of insectivorous bats. Western Foundation of Vertebrate Zoology 1(4): 205-263.

Royle, J.A. 2004a. Generalized estimators of avian abundance from count survey data. Animal Biodiversity and Conservation. 27(1): 375-386.

Royle, J.A. 2004b. N-mixture models for estimating population size from spatially replicated counts. Biometrics. 60(1): 108-115.

Saab, V.A. 1999. Importance of spatial scale to habitat use by breeding birds in riparian forests: a hierarchical analysis. Ecological Applications 9(1): 135-151. 
Seidman, V.M. and C.J. Zabel. 2001. Bat activity along intermittent streams in northwestern California. Journal of Mammalogy, 82(3): 738-747.

Schwartz, C.W., and E.R. Schwartz. 2001. The Wild Mammals of Missouri. University of Missouri Press. Columbia, MO. 368 pp.

Starbuck, C.A., S.K. Amelon, and F.R. Thompson. 2015. Relationships between bat occupancy and habitat and landscape structure along a savanna, woodland, forest gradient in the Missouri Ozarks. Wildlife Society Bulletin. 39(1): 20-30.

Taft, J.B. 1997. Savanna and open-woodland communities. Pg. 24-54 in Conservation in highly fragmented landscapes. (M.W. Schwartz, ed.). Springer, New York, NY. 436 pp.

Titchenell, M.A., R.A. Williams, and S.D. Gehrt. 2011. Bat response to shelterwood harvests and forest structure in oak-hickory forests. Forest Ecology and Management 262(6): 980-988.

Thogmartin, W.E., B.R. Gray, M. Gallagher, N. Young, J.J. Rohweder, and M.G. Knutson. 2007. Power to detect trend in short-term time series of bird abundance. The Condor 109(4): 943-948.

Turner, G.G., D.M. Reeder, J.T.H. Coleman. 2011. A five-year assessment of mortality and geographic spread of white-nose syndrome in North American bats and a look to the future. Bat Research News. 52(2):13-27.

U.S. Fish and Wildlife Service. 2012. North American bat death toll exceeds 5.5 million from white-nose syndrome. News Release.

U.S. Fish and Wildlife Service. 2015. Northern Long-eared bat (Myotis septentrionalis) status: threatened with 4(d) rule. News Release. 2 April 2015.

Walters, C.L., A. Collen, T. Lucas, K. Mroz, C.A. Sayer, and K.E. Jones. 2013. Challenges of using bioacoustics to globally monitor bats. In Bat Evolution, Ecology, and Conservation (pp. 479-499). Springer. New York, New York. 547 pgs.

Walters, B.L., C.M. Ritzi, D.W. Sparks, and J.O. Whitaker Jr. 2007. Foraging behavior of eastern red bats (Lasiurus borealis) at an urban-rural interface. The American midland naturalist 157(2): 365-373.

Wiens, J.A. 1989. Spatial scaling in ecology. Functional Ecology 3: 385-397.

Womack, K.M. 2008. Bat community dynamics and foraging activity patterns in young regenerating southern pine plantations and mixed hardwood forests. Senior Honor Thesis. Longwood University, Farmville, VA.vii+47 pp. 
Womack, K.M. 2011. Habitat and management effects on foraging activity of Indiana bats (Myotis sodalis) in Northeastern Missouri. Master's Thesis. University of Missouri, Columbia, MO. $x+83$ pp.

Womack, K.M., S.K. Amelon, and F.R. Thompson III. 2013. Summer home range size of female Indiana bats (Myotis sodalis) in Missouri, USA. Acta Chiroptera 15(2):423429.

Yates, M. D., and R. M. Muzika. 2006. Effect of forest structure and fragmentation on site occupancy of bat species in Missouri Ozark forests. Journal of Wildlife Management 70: 1238-1248.

Zebehazy, L.A. 2002. Avian and arthropod responses to fuel reduction treatments in the upper Piedmont of South Carolina. Masters Thesis. Clemson University, Clemson, SC, USA. 86 pp. 
Table 1. Habitat covariates at four spatial scales used in hierarchical abundance models for four bat species across a gradient of savanna, woodland, and forest in the Ozark Highlands of Missouri.

\begin{tabular}{|c|c|c|c|}
\hline Spatial Scale & Covariate & Covariate Description & Code \\
\hline \multirow[t]{7}{*}{ Site $(250 \mathrm{~m})$} & Canopy cover (\%) & $\begin{array}{l}\text { Mean percent of canopy cover } \\
\text { calculated at the insect/vegetation } \\
\text { plots within } 250 \mathrm{~m} \text { of a site. }\end{array}$ & Canopy \\
\hline & $\begin{array}{l}\text { Saw timber tree } \\
\text { density (trees/ha) }\end{array}$ & $\begin{array}{l}\text { Mean tree density (trees per } \\
\text { hectare; TPH) calculated for all } \\
\text { trees with DBH }<11 \text { in collected at } \\
\text { insect/vegetation plots within } 250 \\
\text { m of a site. }\end{array}$ & TPH11 \\
\hline & $\begin{array}{l}\text { Pole timber tree } \\
\text { density (trees/ha) }\end{array}$ & $\begin{array}{l}\text { Mean tree density }(\mathrm{TPH}) \\
\text { calculated for trees with } \mathrm{DBH}>5 \\
\text { in and } \mathrm{DBH}<11 \text { in collected at } \\
\text { insect/vegetation plots within } 250 \\
\mathrm{~m} \text { of a site. }\end{array}$ & TPH5 \\
\hline & $\begin{array}{l}\text { Sapling/seedling } \\
\text { tree density } \\
\text { (trees/ha) }\end{array}$ & $\begin{array}{l}\text { Mean tree density (TPH) } \\
\text { calculated for trees with DBH }<4.9 \\
\text { in collected at insect/vegetation } \\
\text { plots within } 250 \mathrm{~m} \text { of a site. }\end{array}$ & TPHs \\
\hline & Insect abundance & $\begin{array}{l}\text { Sum of nightly insect prey } \\
\text { abundance within a bat species } \\
\text { prey size class range collected } \\
\text { across insect traps within } 250 \mathrm{~m} \text { of } \\
\text { a site. PREY was calculated for } \\
\text { each bat species based on skull } \\
\text { morphology and literature review } \\
\text { of bat species diet. }\end{array}$ & PREY \\
\hline & Lunar light (hr) & $\begin{array}{l}\text { The number of lunar hours on a } \\
\text { survey night. }\end{array}$ & LUNAR \\
\hline & $\begin{array}{l}\text { Year since site } \\
\text { burned }\end{array}$ & $\begin{array}{l}\text { The years since the mist-net site } \\
\text { was burned within the last } 10 \\
\text { years. If the site has never been } \\
\text { burned } 11 \text { was assigned to the site } \\
\text { for this covariate. }\end{array}$ & YRburned \\
\hline
\end{tabular}




\begin{tabular}{|c|c|c|c|}
\hline Spatial Scale & Covariate & Covariate Description & Code \\
\hline \multirow[t]{5}{*}{ Patch (1km) } & Percent forest (\%) & $\begin{array}{l}\text { Percent forest calculated from } \\
2011 \text { NLCD canopy cover data } \\
\text { layer. Forest with canopy cover } \\
>71 \% \text {. }\end{array}$ & $\% \mathrm{FOR} 1 \mathrm{~km}$ \\
\hline & $\begin{array}{l}\text { Percent savanna } \\
\text { woodland }(\%)\end{array}$ & $\begin{array}{l}\text { Percent savanna-woodland was } \\
\text { calculated using } 2011 \text { NLCD } \\
\text { canopy cover data with savanna- } \\
\text { woodland = canopy cover }<70 \% \text {. }\end{array}$ & $\% \mathrm{SW} 1 \mathrm{~km}$ \\
\hline & $\begin{array}{l}\text { Percent non-forest } \\
(\%)\end{array}$ & $\begin{array}{l}\text { Percent non-forest calculated from } \\
2011 \text { NLCD canopy cover data } \\
\text { with non-forest when percent } \\
\text { canopy }=0 \% \text {. within } 1 \mathrm{~km} \text { of a } \\
\text { site. Reference covariate. }\end{array}$ & $\%$ NON1km \\
\hline & Fire frequency & $\begin{array}{l}\text { The number of fires within the last } \\
10 \text { years within } 1 \mathrm{~km} \text { of the mist- } \\
\text { net site. }\end{array}$ & FireFreq $1 \mathrm{~km}$ \\
\hline & Percent burned (\%) & $\begin{array}{l}\text { Percentage of area burned (in the } \\
\text { last } 10 \text { years) within } 1 \mathrm{~km} \text { of a } \\
\text { site. }\end{array}$ & \%burned \\
\hline \multirow[t]{4}{*}{$\begin{array}{l}\text { Landscape } \\
(16 \mathrm{~km})\end{array}$} & $\begin{array}{l}\text { Forest edge density } \\
(\mathrm{m} / \mathrm{ha})\end{array}$ & $\begin{array}{l}\text { Forest edge density is the amount } \\
\text { of edge calculated from } 2011 \\
\text { NLCD canopy cover data within } \\
16 \mathrm{~km} \text { of a site }\end{array}$ & Edge \\
\hline & Percent forest (\%) & $\begin{array}{l}\text { Percent forest landcover classes } \\
\text { reclassified from } 2011 \text { NLCD data } \\
\text { within } 16 \mathrm{~km} \text { of a mist-net site. }\end{array}$ & For $16 \mathrm{~km}$ \\
\hline & Percent urban (\%) & $\begin{array}{l}\text { Percent urban landcover classes } \\
\text { from } 2011 \text { NLCD data within } 16 \\
\mathrm{~km} \text { of a mist-net site. }\end{array}$ & Urban $16 \mathrm{~km}$ \\
\hline & Percent open $(\%)$ & $\begin{array}{l}\text { Percent other landcover classes } \\
\text { reclassified from } 2011 \text { NLCD data } \\
\text { (fields, pastures, water, etc.) } \\
\text { within } 16 \mathrm{~km} \text { of a mist-net site. } \\
\text { Reference covariate. }\end{array}$ & Other16km \\
\hline
\end{tabular}


Table 2. Covariates evaluated for relationships with detection probabilities of four bat species in hierarchical abundance models based on mist-net surveys s across a gradient of savanna, woodland, and forest in the Ozark Highlands of Missouri, 2014-2016.

\begin{tabular}{|c|c|c|c|}
\hline Classification & Covariate & Covariate Description & Code \\
\hline \multirow[t]{4}{*}{ Abiotic $^{1}$} & Lunar light (hr) & $\begin{array}{l}\text { The number of lunar hours on a } \\
\text { sampling night at a site. }\end{array}$ & LUNAR \\
\hline & $\begin{array}{l}\text { Barometric } \\
\text { pressure (inHg) }\end{array}$ & $\begin{array}{l}\text { Mean nightly barometric pressure } \\
\text { measured at each mist-net site. }\end{array}$ & PRESSURE \\
\hline & $\begin{array}{l}\text { Minimum nightly } \\
\text { temperature }\left({ }^{\circ} \mathrm{C}\right)\end{array}$ & $\begin{array}{l}\text { Minimum nightly temperature } \\
\text { collected at each mist-net site. }\end{array}$ & MnTemp \\
\hline & $\begin{array}{l}\text { Wind speed } \\
(\mathrm{m} / \mathrm{sec})\end{array}$ & $\begin{array}{l}\text { Average wind speed at mist-net } \\
\text { trapping site. Broken down into } 4 \\
\text { categories: } 0 \mathrm{mph}, 1-3 \mathrm{mph}, 4-6 \\
\text { mph, } 6-8 \mathrm{mph} \text {. Mist-netting bats } \\
\text { cannot occur at wind speeds greater } \\
\text { than } 8 \mathrm{mph} \text {. }\end{array}$ & WIND \\
\hline \multirow[t]{2}{*}{ Temporal $^{2}$} & Year & $\begin{array}{l}\text { Survey year. Summer } 2014 \text { was the } \\
\text { reference year for this categorical } \\
\text { covariate. }\end{array}$ & YR \\
\hline & Julian date & Julian date & JUL \\
\hline
\end{tabular}


Table 3. Candidate detection models used to estimate detection probabilities of four bat species in hierarchical abundance models based on mist-net surveys across a gradient of savanna, woodland, and forest in the Ozark Highlands of Missouri, 2014-2016.

\begin{tabular}{|c|c|}
\hline Detection Model & Model Structure \\
\hline Global & O(mnTEMP + LUNAR + WIND + PRESSURE + JUL + YR $)$ \\
\hline Climate & O̊(mnTEMP + LUNAR + WIND + PRESSURE) \\
\hline Temporal & Ơ(JUL + YR) \\
\hline Climate 1 & O̊(mnTEMP + PRESSURE) \\
\hline Climate 2 & Ơ(mnTEMP + WIND + PRESSURE) \\
\hline Climate 3 & O(mnTEMP + LUNAR + PRESSURE) \\
\hline Temperature & O̊(mnTEMP) \\
\hline Barometric pressure & O(PRESSURE) \\
\hline
\end{tabular}


Table 4. Candidate abundance models used for four bat species based on mist-net surveys across a gradient of savanna, woodland, and forest in the Ozark Highlands of Missouri, 2014-2016. We used the general multinomial-Poisson model for removal sampling in the UNMARKED package. Year was included as a fixed effect in all abundance models.

\begin{tabular}{|c|c|c|}
\hline Spatial Scale & Hypotheses & Model Structure \\
\hline \multirow[t]{6}{*}{ Local (250 m) } & 1 & $\chi(\mathrm{PREY}+\mathrm{YR})$ \\
\hline & 2 & $\chi(\mathrm{LUNAR}+\mathrm{YR})$ \\
\hline & 3 & $\chi(\mathrm{TPH} 11+\mathrm{TPH} 5+\mathrm{TPHs}+$ Canopy + YR $)$ \\
\hline & 3.1 & $\chi(\mathrm{TPH} 11+\mathrm{TPH} 5+\mathrm{TPHs}+\mathrm{YR})$ \\
\hline & 3.2 & $\chi($ Canopy + YR $)$ \\
\hline & 4 & $\chi($ YRsinceBurned + YR) \\
\hline \multirow[t]{4}{*}{ Patch (1 km) } & $5^{1}$ & $\chi\left(\right.$ For $\left.1 \mathrm{~km}^{1}+\mathrm{SW} 1 \mathrm{~km}^{1}+\mathrm{YR}\right)$ \\
\hline & 6 & $\chi($ FireFreq $1 \mathrm{~km}+\%$ burned $1 \mathrm{~km}+\mathrm{YR})$ \\
\hline & 6.1 & $\chi($ FireFreq1km + YR) \\
\hline & 6.2 & $\chi(\%$ burned $1 \mathrm{~km}+\mathrm{YR})$ \\
\hline \multirow[t]{2}{*}{ Landscape (16 km) } & 7 & $\chi($ Edge + YR $)$ \\
\hline & $8^{2}$ & $\chi\left(\right.$ For $16 \mathrm{~km}^{2}+$ Urban $\left.16 \mathrm{~km}^{2}+\mathrm{YR}\right)$ \\
\hline
\end{tabular}

${ }^{1}$ The reference class was the percent non-forest within $1 \mathrm{~km}$.

${ }^{2}$ The reference class was the percent of other land cover within $16 \mathrm{~km}$. 
Table 5. Descriptive statistics for detection and abundance covariates measured at mist net sites for a study of relationships between bat detection probability and abundance and savanna woodland restoration in the Ozarks of Missouri, 2014-2016.

\begin{tabular}{|c|c|c|c|c|c|}
\hline Covariate & Code & Mean & Min & Max & SD \\
\hline Lunar light (hr) & LUNAR & 4.78 & 0 & 10 & 2.50 \\
\hline Barometric pressure (inHg) & PRESSURE & 28.97 & 27.98 & 30.19 & 0.42 \\
\hline $\begin{array}{l}\text { Minimum nightly } \\
\text { temperature }\left({ }^{\circ} \mathrm{C}\right)\end{array}$ & MnTemp & 20.17 & 6.39 & 27.83 & 4.03 \\
\hline Wind speed $(\mathrm{m} / \mathrm{sec})$ & WIND & 0.59 & 0 & 3 & 0.91 \\
\hline Year & YR & 1.85 & 1 & 3 & 0.79 \\
\hline Julian date & JUL & 176.02 & 135 & 225 & 29.18 \\
\hline Canopy cover (\%) & Canopy & 56.43 & 7.5 & 97 & 16.86 \\
\hline $\begin{array}{l}\text { Saw timber tree density } \\
\text { (trees/ha) }\end{array}$ & TPH11 & 114.83 & 1.80 & 405.98 & 98.83 \\
\hline $\begin{array}{l}\text { Pole timber tree density } \\
\text { (trees/ha) }\end{array}$ & TPH5 & 7.24 & 1.34 & 26.73 & 4.55 \\
\hline $\begin{array}{l}\text { Sapling/seedling tree } \\
\text { density (trees/ha) }\end{array}$ & TPHs & 0.93 & 0 & 7.02 & 1.26 \\
\hline $\begin{array}{l}\text { Insect abundance for } \\
\text { northern long-eared bats }\end{array}$ & MYSEPREY & 99 & 0 & 905 & 150 \\
\hline $\begin{array}{l}\text { Insect abundance for tri- } \\
\text { colored bats }\end{array}$ & PESUPREY & 99 & 0 & 905 & 150 \\
\hline $\begin{array}{l}\text { Insect abundance for } \\
\text { evening bats }\end{array}$ & NYHUPREY & 113 & 0 & 950 & 161 \\
\hline $\begin{array}{l}\text { Insect abundance for } \\
\text { eastern red bats }\end{array}$ & LABOPREY & 120 & 0 & 964 & 166 \\
\hline Year since site burned & YRburned & 2.33 & 1 & 4 & 1.25 \\
\hline $\begin{array}{l}\text { Percent forest in } 1 \mathrm{~km} \\
\text { radius }(\%)\end{array}$ & $\%$ FOR $1 \mathrm{~km}$ & 29.71 & 0.20 & 87.40 & 25.68 \\
\hline
\end{tabular}




\begin{tabular}{|c|c|c|c|c|c|}
\hline Covariate & Code & Mean & Min & Max & SD \\
\hline $\begin{array}{l}\text { Percent savanna woodland } \\
\text { in } 1 \mathrm{~km} \text { radius }(\%)\end{array}$ & $\% \mathrm{SW} 1 \mathrm{~km}$ & 61.04 & 11.20 & 97.30 & 26.36 \\
\hline $\begin{array}{l}\text { Percent non-forest in } 1 \mathrm{~km} \\
\text { radius }(\%)\end{array}$ & $\%$ NON1km & 9.24 & 0 & 55.00 & 9.67 \\
\hline Fire frequency & FireFreq1km & 1.92 & 0 & 11 & 1.83 \\
\hline Percent Burned (\%) & \%burned & 43.02 & 0 & 100 & 34.51 \\
\hline Forest edge density (m/ha) & Edge & 48.70 & 25.27 & 66.61 & 9.34 \\
\hline $\begin{array}{l}\text { Percent forest in } 16 \mathrm{~km} \\
\text { radius }(\%)\end{array}$ & For16km & 74.43 & 21.80 & 92.10 & 12.36 \\
\hline $\begin{array}{l}\text { Percent urban in } 16 \mathrm{~km} \\
\text { radius }(\%)\end{array}$ & Urban $16 \mathrm{~km}$ & 4.63 & 2.20 & 9.40 & 1.56 \\
\hline $\begin{array}{l}\text { Percent open in } 16 \mathrm{~km} \\
\text { radius }(\%)\end{array}$ & Other16km & 20.95 & 5.70 & 68.90 & 11.32 \\
\hline
\end{tabular}


Table 6. Support for detection probability (O) models based on the number of model parameters (k), Akaike Information Criterion (AIC), delta AIC ( $\triangle \mathrm{AIC})$, and AIC weight $\left(w_{\mathrm{i}}\right)$ for four bat species based on mist-net surveys s across a gradient of savanna, woodland, and forest in the Ozark Highlands of Missouri, 2014-2016.

\begin{tabular}{|c|c|c|c|c|c|}
\hline Bat Species & Detection Models & $\mathrm{k}$ & AIC & $\Delta \mathrm{AIC}$ & $w_{i}$ \\
\hline \multirow{9}{*}{$\begin{array}{l}\text { Northern long- } \\
\text { eared bats } \\
\text { (Myotis } \\
\text { septentrionalis) }\end{array}$} & $\begin{array}{l}\text { O(mnTEMP + LUNAR + } \\
\text { WIND + PRESSURE + JUL } \\
+ \text { YR })\end{array}$ & 9 & 1085.2 & 0 & 1.00 \\
\hline & $\mathrm{O}(\mathrm{JUL}+\mathrm{YR})$ & 5 & 1101.0 & 15.83 & 3.7E-04 \\
\hline & $\begin{array}{l}\text { O̊(mnTEMP + LUNAR + } \\
\text { WIND + PRESSURE })\end{array}$ & 6 & 1138.1 & 52.91 & $3.2 \mathrm{E}-12$ \\
\hline & $\begin{array}{l}\text { O̊(mnTEMP + WIND + } \\
\text { PRESSURE })\end{array}$ & 5 & 1140.0 & 54.78 & $1.3 \mathrm{E}-12$ \\
\hline & $\begin{array}{l}\text { O̊(mnTEMP + LUNAR + } \\
\text { PRESSURE })\end{array}$ & 5 & 1140.5 & 55.34 & $9.6 \mathrm{E}-13$ \\
\hline & O(mnTEMP + PRESSURE) & 4 & 1140.5 & 55.36 & $9.5 \mathrm{E}-13$ \\
\hline & O(PRESSURE) & 3 & 1144.4 & 59.21 & $1.4 \mathrm{E}-13$ \\
\hline & O(mnTEMP) & 3 & 1150.7 & 65.55 & $5.8 \mathrm{E}-15$ \\
\hline & NULL & 2 & 1153.6 & 68.44 & $1.4 \mathrm{E}-15$ \\
\hline \multirow{6}{*}{$\begin{array}{l}\text { Tri-colored bats } \\
\text { (Perimyotis } \\
\text { subflavus) }\end{array}$} & Ơ(PRESSURE) & 3 & 461.4 & 0 & 0.45 \\
\hline & Ơ(mnTEMP + PRESSURE) & 4 & 463.4 & 2 & 0.166 \\
\hline & $\begin{array}{l}\text { O̊(mnTEMP + WIND + } \\
\text { PRESSURE })\end{array}$ & 5 & 464.3 & 2.94 & 0.103 \\
\hline & $\begin{array}{l}\text { O̊(mnTEMP + LUNAR + } \\
\text { PRESSURE })\end{array}$ & 5 & 465.1 & 3.7 & 0.071 \\
\hline & $\begin{array}{l}\text { O(mnTEMP + LUNAR + } \\
\text { WIND + PRESSURE + JUL } \\
+ \text { YR })\end{array}$ & 9 & 465.4 & 3.96 & 0.062 \\
\hline & $\begin{array}{l}\text { O(mnTEMP + LUNAR + } \\
\text { WIND + PRESSURE })\end{array}$ & 6 & 466.3 & 4.87 & 0.039 \\
\hline
\end{tabular}




\begin{tabular}{|c|c|c|c|c|c|}
\hline Bat Species & Detection Models & $\mathrm{k}$ & AIC & $\Delta \mathrm{AIC}$ & $w_{i}$ \\
\hline \multirow{6}{*}{$\begin{array}{l}\text { Evening bats } \\
\text { (Nycticeius } \\
\text { humeralis) }\end{array}$} & NULL & 2 & 466.3 & 4.9 & 0.039 \\
\hline & $\mathrm{O}(\mathrm{JUL}+\mathrm{YR})$ & 5 & 466.6 & 5.2 & 0.033 \\
\hline & Ơ(mnTEMP) & 3 & 468.3 & 6.89 & 0.014 \\
\hline & Ơ(PRESSURE) & 3 & 686.1 & 0 & 0.188 \\
\hline & $\begin{array}{l}\text { Ơ(mnTEMP + LUNAR + } \\
\text { WIND + PRESSURE + JUL } \\
+ \text { YR })\end{array}$ & 9 & 686.5 & 0.41 & 0.153 \\
\hline & $\begin{array}{l}\text { O(mnTEMP + LUNAR + } \\
\text { PRESSURE })\end{array}$ & 5 & 686.9 & 0.84 & 0.124 \\
\hline \multirow{15}{*}{$\begin{array}{l}\text { Eastern red bats } \\
\text { (Lasiurus } \\
\text { borealis) }\end{array}$} & NULL & 2 & 687.0 & 0.94 & 0.117 \\
\hline & Ơ(mnTEMP + PRESSURE) & 4 & 687.5 & 1.37 & 0.095 \\
\hline & Ơ(JUL + YR $)$ & 5 & 687.8 & 1.71 & 0.08 \\
\hline & Ö(mnTEMP) & 3 & 688.2 & 2.1 & 0.066 \\
\hline & $\begin{array}{l}\text { O̊(mnTEMP + LUNAR + } \\
\text { WIND + PRESSURE })\end{array}$ & 6 & 688.8 & 2.66 & 0.05 \\
\hline & $\begin{array}{l}\text { O(mnTEMP + WIND + } \\
\text { PRESSURE })\end{array}$ & 5 & 689.5 & 3.36 & 0.035 \\
\hline & $\begin{array}{l}\text { O(mnTEMP + LUNAR + } \\
\text { PRESSURE })\end{array}$ & 5 & 1586.0 & 0 & 0.2948 \\
\hline & Ơ(mnTEMP + PRESSURE) & 4 & 1586.9 & 0.9 & 0.1879 \\
\hline & $\begin{array}{l}\text { O(mnTEMP + LUNAR + } \\
\text { WIND + PRESSURE })\end{array}$ & 6 & 1586.9 & 0.91 & 0.1875 \\
\hline & $\begin{array}{l}\text { O(mnTEMP + WIND + } \\
\text { PRESSURE })\end{array}$ & 5 & 1587.1 & 1.07 & 0.173 \\
\hline & Ơ(PRESSURE) & 3 & 1589.2 & 3.21 & 0.0593 \\
\hline & Ơ(mnTEMP $)$ & 3 & 1589.4 & 3.4 & 0.0539 \\
\hline & $\begin{array}{l}\text { O(mnTEMP + LUNAR + } \\
\text { WIND + PRESSURE + JUL } \\
+ \text { YR })\end{array}$ & 9 & 1590.3 & 4.26 & 0.0349 \\
\hline & NULL & 2 & 1593.6 & 7.55 & 0.0068 \\
\hline & Ơ(JUL + YR) & 5 & 1596.2 & 10.19 & 0.0018 \\
\hline
\end{tabular}


Table 7. Parameter estimates ( $\beta$ ), standard errors (SE), and 95\% confidence limits (LCL, UCL) for parameters in our top detection models for four bat species based on hierarchical abundance models and mist-net surveys at 89 sites across a gradient of savanna, woodland, and forest in the Ozark Highlands of Missouri, 2014-2016.

\begin{tabular}{|c|c|c|c|c|c|}
\hline Bat Species & Model Parameter & $\beta$ & $\mathrm{SE}$ & LCL & UCL \\
\hline \multirow{8}{*}{$\begin{array}{l}\text { Northern long-eared bats } \\
\text { (Myotis septentrionalis) }\end{array}$} & Intercept & -1.33 & 0.39 & -2.10 & -0.55 \\
\hline & mnTEMP & -0.10 & 0.10 & -0.30 & 0.10 \\
\hline & WIND & 0.12 & 0.09 & -0.05 & 0.29 \\
\hline & JUL & -0.33 & 0.10 & -0.53 & -0.14 \\
\hline & PRESSURE & -0.46 & 0.14 & -0.72 & -0.19 \\
\hline & LUNAR & 0.00 & 0.08 & -0.16 & 0.17 \\
\hline & YR2 & 0.15 & 0.23 & -0.31 & 0.60 \\
\hline & YR3 & -0.58 & 0.38 & -1.33 & 0.17 \\
\hline \multirow{2}{*}{$\begin{array}{l}\text { Tri-colored bats } \\
\text { (Perimyotis subflavus) }\end{array}$} & Intercept & -0.16 & 0.261 & -0.68 & 0.35 \\
\hline & PRESSURE & -0.46 & 0.023 & -0.5 & -0.41 \\
\hline \multirow[t]{2}{*}{$\begin{array}{l}\text { Evening bats (Nycticeius } \\
\text { humeralis) }\end{array}$} & Intercept & -1 & 0.343 & -1.68 & -0.33 \\
\hline & PRESSURE & 0.094 & 0.117 & -0.14 & 0.32 \\
\hline \multirow[t]{4}{*}{$\begin{array}{l}\text { Eastern red bats } \\
\text { (Lasiurus borealis) }\end{array}$} & Intercept & -0.72 & 0.158 & -1.02 & -0.41 \\
\hline & mnTEMP & -0.1 & 0.06 & -0.22 & 0.01 \\
\hline & PRESSURE & 0.184 & 0.072 & 0.043 & 0.33 \\
\hline & LUNAR & 0.082 & 0.059 & -0.03 & 0.2 \\
\hline
\end{tabular}


Table 8. Support for abundance $(\chi)$ models for the northern long-eared bat (Myotis septentrionalis) including the number of model parameters (k), Akaike's Information Criterion (AIC), delta $\mathrm{AICc}(\triangle \mathrm{AICc})$, and AICc weight $\left(w_{\mathrm{i}}\right)$. Models were fit with the general multinomial Poisson model for removal sampling using the UNMARKED package and data from mist-net surveys at 89 sites across a gradient of savanna, woodland, and forest in the Ozark Highlands of Missouri, 2014-2016. All models include the top ranked detection model O(minTEMP + WIND + PRESSURE + LUNAR + JUL + YR).

\begin{tabular}{|c|c|c|c|c|c|}
\hline Spatial Scale & Model & $\mathrm{k}$ & AIC & $\Delta \mathrm{AIC}$ & $w_{i}$ \\
\hline Multi-scale & $\begin{array}{l}\text { TPH11 + TPH5 + TPHs + } \\
\text { SW1km + For1km + YR }\end{array}$ & 16 & 781.54 & 0 & 0.68 \\
\hline Multi-scale & $\begin{array}{l}\text { TPH11 + TPH5 + TPHs + } \\
\text { SW1km + For } 1 \mathrm{~km}+\text { Urban } 16 \mathrm{~km} \\
+ \text { For } 16 \mathrm{~km}+\text { YR }\end{array}$ & 18 & 783.08 & 1.54 & 0.32 \\
\hline Multi-scale & $\begin{array}{l}\text { TPH11 + TPH5 + TPHs + } \\
\text { Urban16km + For16km + YR }\end{array}$ & 16 & 895.85 & 114.31 & $1.0 \mathrm{E}-25$ \\
\hline Multi-scale & $\begin{array}{l}\text { SW } 1 \mathrm{~km}+\text { For } 1 \mathrm{~km}+\text { Urban } 16 \mathrm{~km} \\
+ \text { For } 16 \mathrm{~km}+\mathrm{YR}\end{array}$ & 15 & 905.05 & 123.51 & $1.0 \mathrm{E}-27$ \\
\hline Patch & $\mathrm{SW} 1 \mathrm{~km}+$ For $1 \mathrm{~km}+\mathrm{YR}$ & 13 & 907.52 & 125.97 & $3.0 \mathrm{E}-28$ \\
\hline Site & TPH11 + TPH5 + TPHs + YR & 14 & 932.74 & 151.2 & $1.0 \mathrm{E}-33$ \\
\hline Site & $\begin{array}{l}\text { TPH11 + TPH5 + TPHs + } \\
\text { canopy + YR }\end{array}$ & 15 & 934.7 & 153.16 & $3.8 \mathrm{E}-34$ \\
\hline Site & Lunar + YR & 14 & 964.9 & 183.35 & $1.0 \mathrm{E}-40$ \\
\hline Site & YrSinceBurned + YR & 14 & 1013.22 & 231.68 & $3.4 \mathrm{E}-51$ \\
\hline Landscape & Urban $16 \mathrm{~km}+$ For $16 \mathrm{~km}+\mathrm{YR}$ & 13 & 1018.77 & 237.23 & $2.1 \mathrm{E}-52$ \\
\hline Patch & $\begin{array}{l}\text { FireFreq } 1 \mathrm{~km}+\text { pBurned } 1 \mathrm{~km}+ \\
\text { YR }\end{array}$ & 13 & 1028.26 & 246.72 & $1.8 \mathrm{E}-54$ \\
\hline Patch & FireFreq1km + YR & 12 & 1028.62 & 247.08 & $1.5 \mathrm{E}-54$ \\
\hline
\end{tabular}




\begin{tabular}{llcccc}
\hline Spatial Scale & Model & $\mathrm{k}$ & AIC & $\Delta$ AIC & $w_{i}$ \\
\hline Patch & pBurned1km + YR & 12 & 1036.27 & 254.73 & $3.3 \mathrm{E}-56$ \\
Landscape & Edge + YR & 12 & 1037.71 & 256.16 & $1.6 \mathrm{E}-56$ \\
Site & canopy + YR & 12 & 1044.06 & 262.52 & $6.8 \mathrm{E}-58$ \\
Site & MysePrey + YR & 12 & 1048.71 & 267.16 & $6.6 \mathrm{E}-59$ \\
& NULL & 9 & 1085.18 & 303.63 & $8.0 \mathrm{E}-67$ \\
\hline
\end{tabular}


Table 9. Parameter estimates $(\beta)$, standard errors (SE), and 95\% confidence limits (LCL, UCL) for parameters in our top hierarchical abundance model for northern long-eared bat (Myotis septentrionalis) captured during mist-net surveys at 89 sites across a gradient of savanna, woodland, and forest in the Ozark Highlands of Missouri, 2014-2016.

Reference covariates are YR1 (2014) and \%NON1km.

\begin{tabular}{lcccc}
\hline Model Parameter & $\beta$ & SE & LCL & UCL \\
\hline Intercept & 2.095 & 0.150 & 1.800 & 2.390 \\
$\%$ SW1km & 0.642 & 0.252 & 0.149 & 1.135 \\
\%For1km & 1.267 & 0.237 & 0.803 & 1.731 \\
TPH11 & 0.641 & 0.098 & 0.450 & 0.832 \\
TPH5 & 0.541 & 0.063 & 0.417 & 0.665 \\
TPHs & -0.046 & 0.089 & -0.221 & 0.129 \\
YR2 & -2.011 & 0.242 & -2.485 & -1.536 \\
YR3 & -1.739 & 0.282 & -2.290 & -1.187 \\
\hline
\end{tabular}


Table 10. Support for abundance $(\chi)$ models for the tri-colored bat (Perimyotis subflavus) including the number of model parameters (k), Akaike's Information Criterion (AIC), delta AICc $(\triangle \mathrm{AICc})$, and AICc weight $\left(w_{\mathrm{i}}\right)$. Models were fit with the general multinomial Poisson model for removal sampling using the UNMARKED package and data from mist-net surveys at 89 sites across a gradient of savanna, woodland, and forest in the Ozark Highlands of Missouri, 2014-2016. All models include the top ranked detection model Ö(PRESSURE).

\begin{tabular}{|c|c|c|c|c|c|}
\hline Spatial Scale & Model & $\mathrm{k}$ & AIC & $\Delta \mathrm{AIC}$ & $w_{i}$ \\
\hline Multi-scale & $\begin{array}{l}\text { YrSinceBurned + SW1km + } \\
\text { For1km + YR }\end{array}$ & 10 & 400.96 & 0 & 0.82 \\
\hline Multi-scale & $\begin{array}{l}\text { YrSinceBurned + SW1km + } \\
\text { For } 1 \mathrm{~km}+\text { Urban } 16 \mathrm{~km}+\text { For } 16 \mathrm{~km} \\
+ \text { YR }\end{array}$ & 12 & 404.08 & 3.12 & 0.17 \\
\hline Patch & $\mathrm{SW} 1 \mathrm{~km}+$ For $1 \mathrm{~km}+\mathrm{YR}$ & 7 & 410.37 & 9.41 & $7.4 \mathrm{E}-03$ \\
\hline Multi-scale & $\begin{array}{l}\text { SW } 1 \mathrm{~km}+\text { For } 1 \mathrm{~km}+\text { Urban } 16 \mathrm{~km} \\
+ \text { For } 16 \mathrm{~km}+\mathrm{YR}\end{array}$ & 9 & 414.17 & 13.2 & $1.1 \mathrm{E}-03$ \\
\hline Multi-scale & $\begin{array}{l}\text { YrSinceBurned + Urban16km + } \\
\text { For16km + YR }\end{array}$ & 10 & 423.02 & 22.05 & $1.3 \mathrm{E}-05$ \\
\hline Site & YrSinceBurned + YR & 8 & 432.28 & 31.32 & $1.3 \mathrm{E}-07$ \\
\hline Site & Lunar + YR & 8 & 432.86 & 31.9 & 9.7E-08 \\
\hline Landscape & Urban $16 \mathrm{~km}+$ For $16 \mathrm{~km}+\mathrm{YR}$ & 7 & 440.66 & 39.7 & 2.0E-09 \\
\hline Site & PesuPrey + YR & 6 & 444.34 & 43.38 & $3.1 \mathrm{E}-10$ \\
\hline Site & TPH11 + TPH5 + TPHs + YR & 8 & 444.69 & 43.73 & $2.6 \mathrm{E}-10$ \\
\hline Site & $\begin{array}{l}\text { TPH11 + TPH5 + TPHs + Canopy } \\
+ \text { YR }\end{array}$ & 9 & 444.76 & 43.8 & $2.5 \mathrm{E}-10$ \\
\hline Landscape & Edge + YR & 6 & 445.3 & 44.34 & $1.9 \mathrm{E}-10$ \\
\hline Site & Canopy + YR & 6 & 445.61 & 44.64 & $1.7 \mathrm{E}-10$ \\
\hline Patch & $\%$ Burned $1 \mathrm{~km}+\mathrm{YR}$ & 6 & 445.84 & 44.88 & $1.5 \mathrm{E}-10$ \\
\hline
\end{tabular}




\begin{tabular}{llcccc}
\hline Spatial Scale & Model & $\mathrm{k}$ & AIC & $\Delta$ AIC & $w_{i}$ \\
\hline Patch & FireFreq1km + YR & 6 & 446.13 & 45.17 & $1.3 \mathrm{E}-10$ \\
\multirow{2}{*}{ Patch } & FireFreq1km + \%Burned1 $1 \mathrm{~km}+$ & 7 & 447.63 & 46.67 & $6.0 \mathrm{E}-11$ \\
& YR & & & & \\
& NULL & 3 & 461.39 & 60.43 & $6.2 \mathrm{E}-14$ \\
\hline
\end{tabular}


Table 11. Parameter estimates $(\beta)$, standard errors (SE), and $95 \%$ confidence limits (LCL, UCL) for parameters in our top hierarchical abundance model for tri-colored bats (Perimyotis subflavus) captured during mist-net surveys at 89 sites across a gradient of savanna, woodland, and forest in the Ozark Highlands of Missouri, 2014-2016. Reference covariates are YR1 (2014), YRburned $=0$ or non-managed and Non-Forest within $1 \mathrm{~km}$.

\begin{tabular}{lcccc}
\hline Model Parameter & $\beta$ & SE & LCL & UCL \\
\hline Intercept & 0.000 & 0.231 & -0.453 & 0.453 \\
$\%$ SW1km & 0.111 & 0.370 & -0.614 & 0.836 \\
\%For1km & 0.673 & 0.357 & -0.027 & 1.373 \\
YRburned2 & -0.392 & 0.733 & -1.829 & 1.045 \\
YRburned3 & -0.063 & 0.267 & -0.587 & 0.460 \\
YRburned4 & 0.739 & 0.230 & 0.288 & 1.190 \\
YR2 & 0.184 & 0.212 & -0.232 & 0.600 \\
YR3 & -0.917 & 0.369 & -1.640 & -0.194 \\
\hline
\end{tabular}


Table 12. Support for abundance $(\chi)$ models for evening bats (Nycticeius humeralis) including the number of model parameters (k), Akaike's Information Criterion (AIC), delta AICc $(\triangle \mathrm{AICc})$, and AICc weight $\left(w_{\mathrm{i}}\right)$. Models were fit with the general multinomial Poisson model for removal sampling using the UNMARKED package and data from mist-net surveys at 89 sites across a gradient of savanna, woodland, and forest in the Ozark Highlands of Missouri, 2014-2016. All models include the top ranked detection model Ö(PRESSURE).

\begin{tabular}{|c|c|c|c|c|c|}
\hline Spatial Scale & Model & $\mathrm{k}$ & AIC & $\Delta \mathrm{AIC}$ & $w_{i}$ \\
\hline Multi-scale & $\begin{array}{l}\text { YrSinceBurned + FireFreq1km + } \\
\text { YR }\end{array}$ & 9 & 659.39 & 0 & 0.29 \\
\hline Patch & FireFreq1km + YR & 6 & 659.9 & 0.51 & 0.22 \\
\hline Multi-scale & $\begin{array}{l}\text { YrSinceBurned + FireFreq } 1 \mathrm{~km}+ \\
\text { Edge + YR }\end{array}$ & 10 & 659.99 & 0.6 & 0.21 \\
\hline Multi-scale & FireFreq1km + Edge + YR & 7 & 660.4 & 1.01 & 0.17 \\
\hline Patch & $\begin{array}{l}\text { FireFreq1km + \%Burned } 1 \mathrm{~km}+ \\
\text { YR }\end{array}$ & 7 & 661.56 & 2.17 & 0.10 \\
\hline Patch & $\mathrm{SW} 1 \mathrm{~km}+$ For $1 \mathrm{~km}+\mathrm{YR}$ & 7 & 667.38 & 7.99 & 0.01 \\
\hline Multi-scale & YrSinceBurned + Edge + YR & 9 & 669.06 & 9.67 & $2.3 \mathrm{E}-03$ \\
\hline Site & YrSinceBurned + YR & 8 & 669.93 & 10.54 & $1.5 \mathrm{E}-03$ \\
\hline Patch & $\%$ Burned $1 \mathrm{~km}+\mathrm{YR}$ & 6 & 673.37 & 13.99 & $2.6 \mathrm{E}-04$ \\
\hline Site & NyhuPrey + YR & 6 & 673.56 & 14.17 & $2.4 \mathrm{E}-04$ \\
\hline Site & Lunar + YR & 8 & 674.89 & 15.5 & $1.2 \mathrm{E}-04$ \\
\hline Landscape & Edge + YR & 6 & 677.29 & 17.91 & $3.7 \mathrm{E}-05$ \\
\hline Site & TPH11 + TPH5 + TPHs + YR & 8 & 679.11 & 19.72 & $1.5 \mathrm{E}-05$ \\
\hline Site & Canopy + YR & 6 & 679.55 & 20.16 & $1.2 \mathrm{E}-05$ \\
\hline Landscape & Urban16km + For16km + YR & 7 & 679.87 & 20.48 & $1.0 \mathrm{E}-05$ \\
\hline
\end{tabular}




\begin{tabular}{llcccc}
\hline Spatial Scale & Model & $\mathrm{k}$ & AIC & $\Delta$ AIC & $w_{i}$ \\
\hline Site & TPH11 + TPH5 + TPHs + & 9 & 681.04 & 21.66 & $5.7 \mathrm{E}-06$ \\
& Canopy + YR & & & & \\
& NULL & 3 & 686.1 & 26.71 & $4.5 \mathrm{E}-07$ \\
\hline
\end{tabular}


Table 13. Parameter estimates $(\beta)$, standard errors (SE), and $95 \%$ confidence limits (LCL, UCL) for parameters in our top hierarchical abundance model for evening bats (Nycticeius humeralis) captured during mist-net surveys at 89 sites across a gradient of savanna, woodland, and forest in the Ozark Highlands of Missouri, 2014-2016. Reference covariates are YR1 (2014) and YRburned =0 or non-managed.

\begin{tabular}{lcccc}
\hline Model Parameter & $\beta$ & SE & LCL & UCL \\
\hline Intercept & 1.322 & 0.233 & 0.866 & 1.778 \\
FireFreq1km & 0.234 & 0.062 & 0.113 & 0.355 \\
YRburned2 & -0.250 & 0.402 & -1.037 & 0.537 \\
YRburned3 & 0.416 & 0.190 & 0.045 & 0.787 \\
YRburned4 & 0.125 & 0.208 & -0.283 & 0.533 \\
YR2 & -0.691 & 0.194 & -1.071 & -0.311 \\
YR3 & -0.399 & 0.194 & -0.780 & -0.018 \\
\hline
\end{tabular}


Table 14. Support for abundance $(\chi)$ models for eastern red bats (Lasiurus borealis) including the number of model parameters (k), Akaike's Information Criterion (AIC), delta AICc $(\triangle \mathrm{AICc})$, and AICc weight $\left(w_{\mathrm{i}}\right)$. Models were fit with the general multinomial Poisson model for removal sampling using the UNMARKED package and data from mist-net surveys at 89 sites across a gradient of savanna, woodland, and forest in the Ozark Highlands of Missouri, 2014-2016. All models include the top ranked detection model Ơ(mnTEMP + LUNAR + PRESSURE).

\begin{tabular}{|c|c|c|c|c|c|}
\hline Spatial Scale & Model & $\mathrm{k}$ & AIC & $\Delta \mathrm{AIC}$ & $w_{i}$ \\
\hline Multi-Scale & $\begin{array}{l}\text { TPH11 + TPH5 + TPHs + } \\
\text { Canopy + SW1km + For } 1 \mathrm{~km} \\
+ \text { Urban16km + For16km + } \\
\text { YR }\end{array}$ & 15 & 1499.51 & 0 & 1.00 \\
\hline Multi-Scale & $\begin{array}{l}\text { TPH11 + TPH5 + TPHs + } \\
\text { Canopy + SW1km + For } 1 \mathrm{~km} \\
+ \text { YR }\end{array}$ & 13 & 1523.42 & 23.91 & $6.4 \mathrm{E}-06$ \\
\hline Multi-Scale & $\begin{array}{l}\text { TPH11 + TPH5 + TPHs + } \\
\text { Canopy + Urban16km + } \\
\text { For16km + YR }\end{array}$ & 13 & 1529.09 & 29.58 & $3.8 \mathrm{E}-07$ \\
\hline Multi-Scale & $\begin{array}{l}\text { Urban16km + For16km + } \\
\text { SW1km + For1km + YR }\end{array}$ & 11 & 1542.17 & 42.66 & $5.4 \mathrm{E}-10$ \\
\hline Site & $\begin{array}{l}\text { TPH11 + TPH5 + TPHs + } \\
\text { Canopy + YR }\end{array}$ & 11 & 1551.3 & 51.79 & $5.7 \mathrm{E}-12$ \\
\hline Site & Canopy + YR & 8 & 1560.02 & 60.52 & 7.2E-14 \\
\hline Patch & $\mathrm{SW} 1 \mathrm{~km}+$ For $1 \mathrm{~km}+\mathrm{YR}$ & 9 & 1563.16 & 63.65 & $1.5 \mathrm{E}-14$ \\
\hline Landscape & Urban16km + For16km + YR & 9 & 1566.84 & 67.34 & $2.4 \mathrm{E}-15$ \\
\hline Patch & $\begin{array}{l}\text { FireFreq } 1 \mathrm{~km}+\% \text { Burned } 1 \mathrm{~km} \\
+ \text { YR }\end{array}$ & 9 & 1570.72 & 71.21 & $3.4 \mathrm{E}-16$ \\
\hline Site & TPH11 + TPH5 + TPHs + YR & 10 & 1572.68 & 73.17 & $1.3 \mathrm{E}-16$ \\
\hline Site & LaboPrey + YR & 8 & 1573.96 & 74.45 & $6.8 \mathrm{E}-17$ \\
\hline
\end{tabular}




\begin{tabular}{llcccc}
\hline Spatial Scale & Model & $\mathrm{k}$ & $\mathrm{AIC}$ & $\Delta \mathrm{AIC}$ & $w_{i}$ \\
\hline Patch & \%Burned1km + YR & 8 & 1580.2 & 80.69 & $3.0 \mathrm{E}-18$ \\
Site & Lunar + YR & 10 & 1580.44 & 80.94 & $2.7 \mathrm{E}-18$ \\
Landscape & Edge + YR & 8 & 1585.16 & 85.65 & $2.5 \mathrm{E}-19$ \\
Patch & FireFreq1km + YR & 8 & 1585.43 & 85.92 & $2.2 \mathrm{E}-19$ \\
& NULL & 5 & 1586.04 & 86.53 & $1.6 \mathrm{E}-19$ \\
& YrSinceBurned + YR & 10 & 1588.18 & 88.67 & $5.6 \mathrm{E}-20$ \\
\hline
\end{tabular}


Table 15. Parameter estimates $(\beta)$, standard errors (SE), and $95 \%$ confidence limits (LCL, UCL) for parameters in our top hierarchical abundance model for eastern red bats (Lasiurus borealis) captured during mist-net surveys at 89 sites across a gradient of savanna, woodland, and forest in the Ozark Highlands of Missouri, 2014-2016. Reference covariates are YR1 (2014), \%NON1km, and Other16km.

\begin{tabular}{lcccc}
\hline Model Parameter & $\beta$ & SE & LCL & UCL \\
\hline Intercept & 2.053 & 0.099 & 1.859 & 2.248 \\
Urban16km & 0.269 & 0.053 & 0.166 & 0.373 \\
For16km & 0.067 & 0.069 & -0.069 & 0.202 \\
\%SW1km & 0.529 & 0.157 & 0.222 & 0.836 \\
\%For1km & 0.209 & 0.145 & -0.076 & 0.493 \\
TPH11 & -0.184 & 0.064 & -0.308 & -0.059 \\
TPH5 & -0.116 & 0.054 & -0.222 & -0.009 \\
TPHs & -0.163 & 0.055 & -0.271 & -0.054 \\
Canopy & -0.178 & 0.041 & -0.259 & -0.097 \\
YR2 & 0.299 & 0.115 & 0.073 & 0.525 \\
YR3 & 0.313 & 0.136 & 0.046 & 0.580 \\
\hline
\end{tabular}




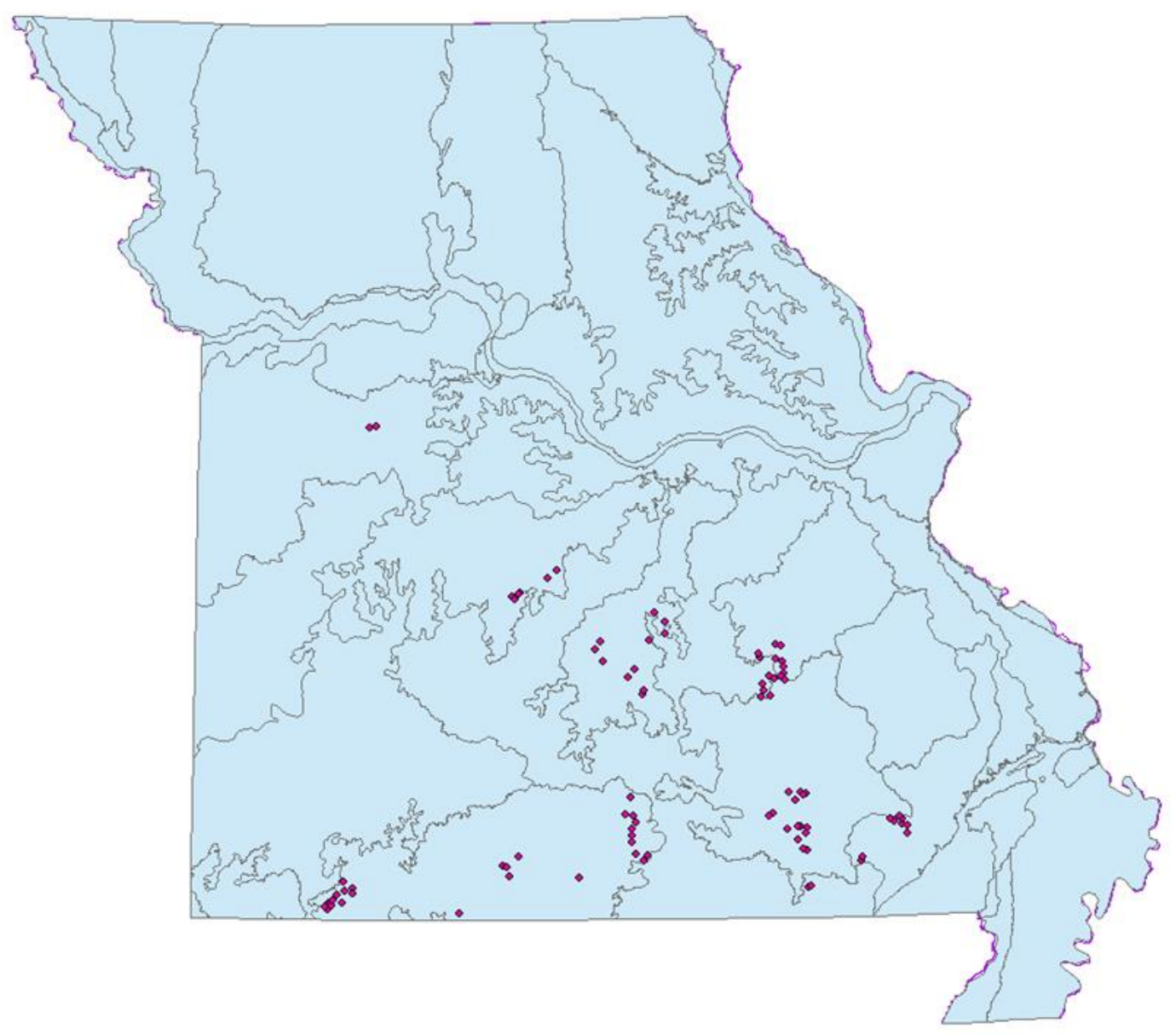

Figure 1. Bat mist-net capture site locations (dark magenta circles) surveyed across a gradient of savanna, woodlands, and non-managed forests on state and federal lands within the Ozarks of Missouri between May $15^{\text {th }}$-August $15^{\text {th }}, 2014-2016$. 

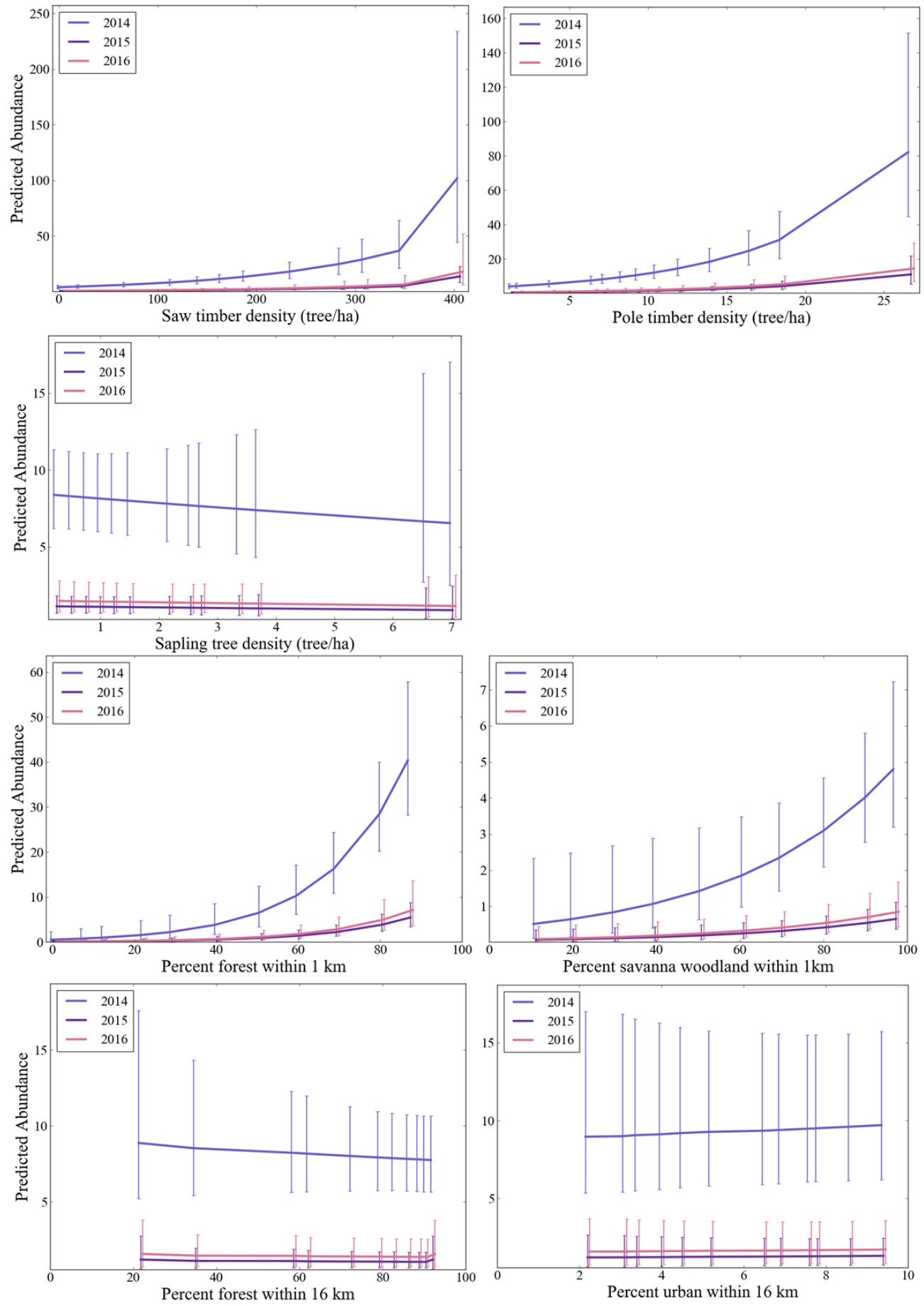

Figure 2. Predicted abundance and 95\% confidence limits for northern long-eared bats (Myotis septentrionalis) from model supported site, patch, and landscape factors in the Ozarks of Missouri, 2014-2016. 

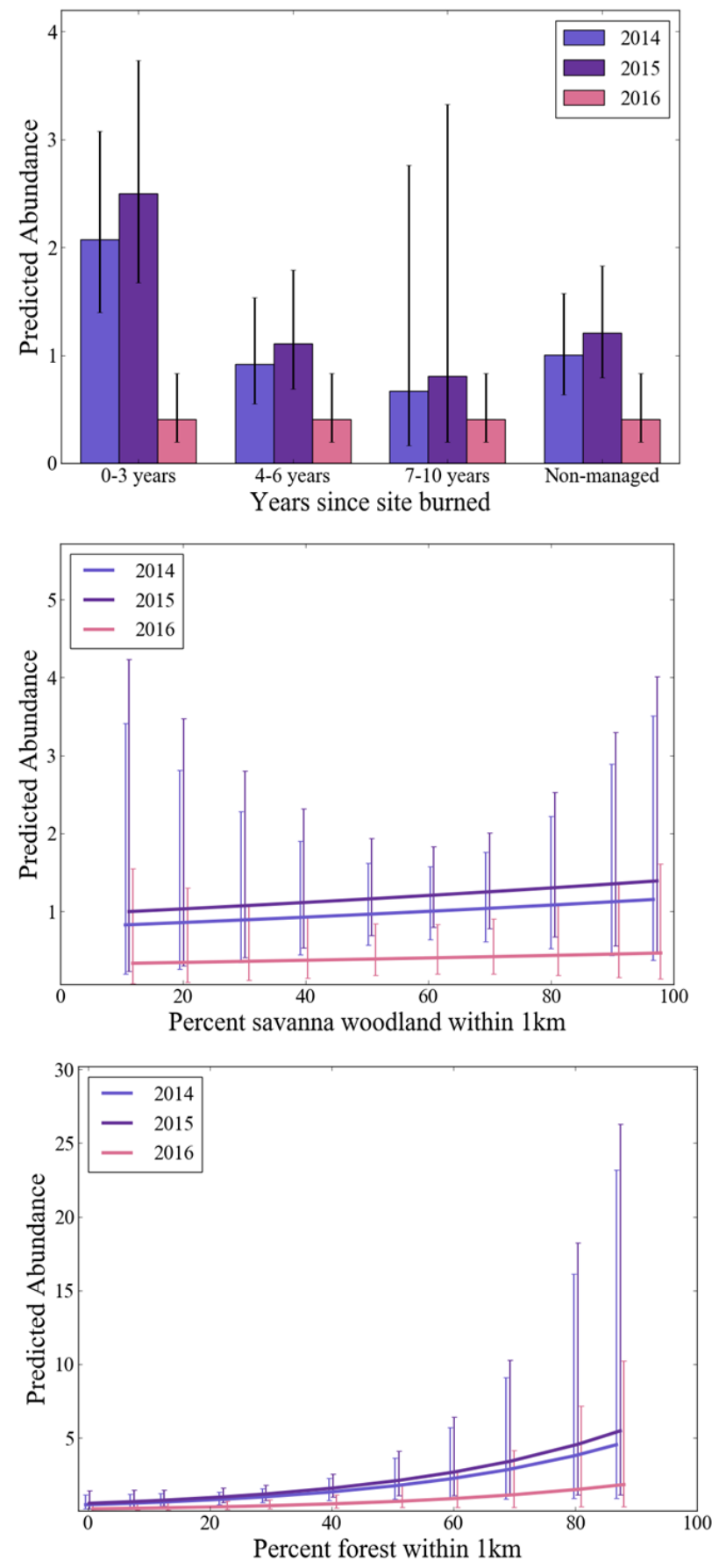

Figure 3. Predicted abundance and $95 \%$ confidence limits for tri-colored bats (Perimyotis subflavus) from model supported site, patch, and landscape factors in the Ozarks of Missouri, 2014-2016. Non-managed are sites either never burned or sites not burned within the last 10 years. 

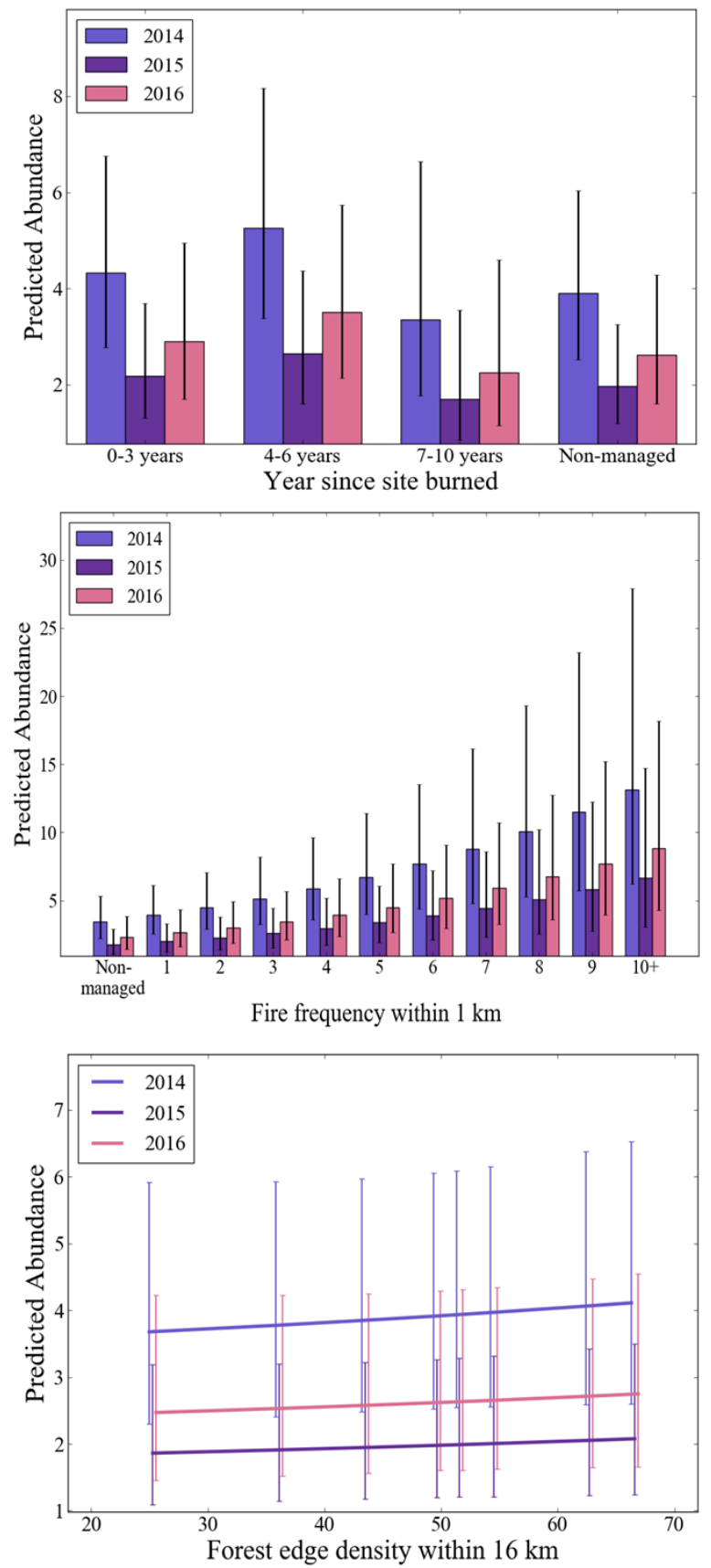

Figure 4. Predicted abundance and $95 \%$ confidence limits for evening bats (Nycticeius humeralis) from model supported site, patch, and landscape factors in the Ozarks of Missouri, 2014-2016. Non-managed are sites either never burned or sites not burned within the last 10 years. 

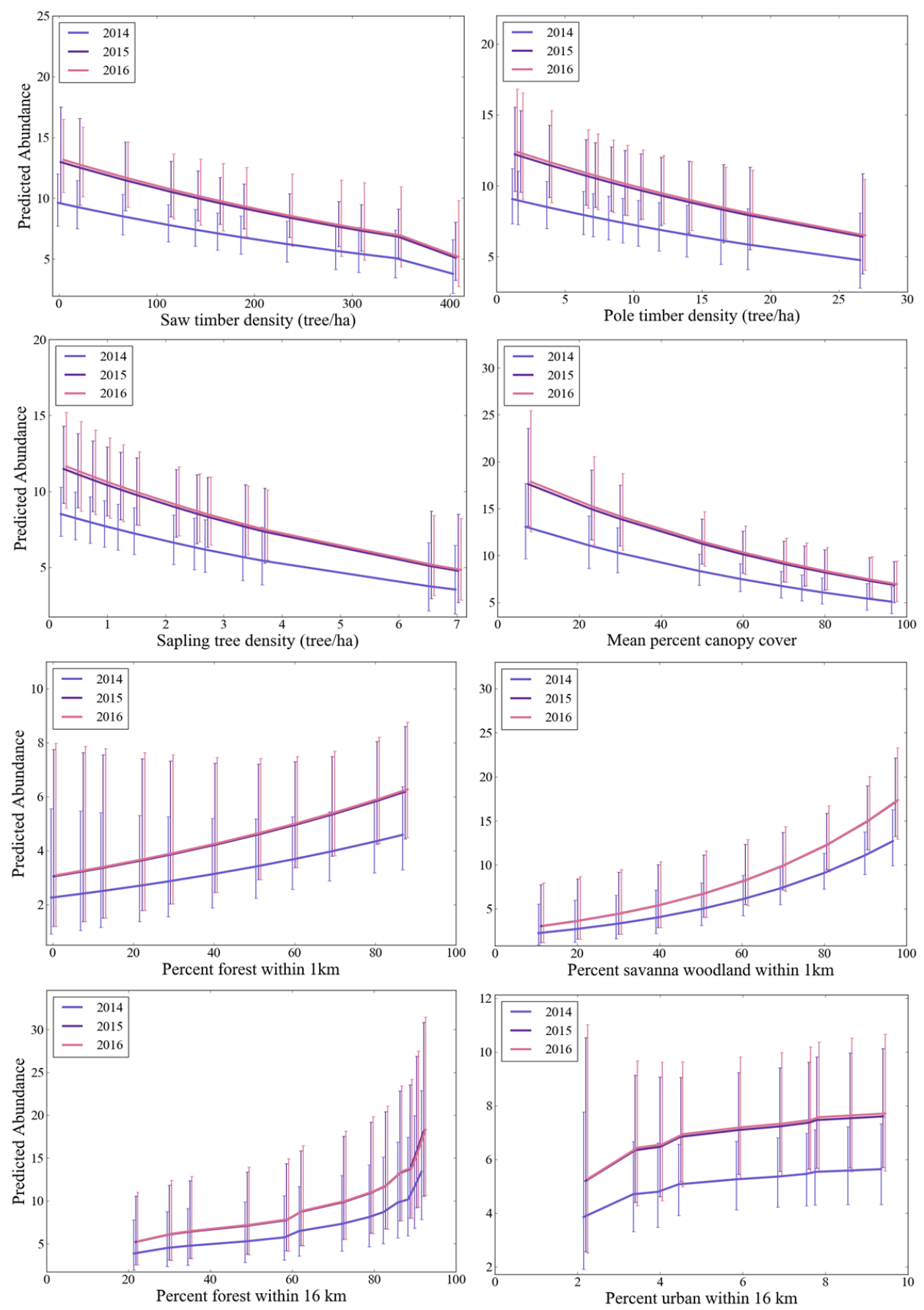

Figure 5. Predicted abundance and 95\% confidence limits for eastern red bats (Lasiurus borealis) from model supported site, patch, and landscape factors in the Ozarks of Missouri, 2014-2016. 


\section{CHAPTER 5: Conclusion}

Restoring savanna and woodland ecosystems is a priority for many state and federal agencies in the Midwest as these systems provide a critical habitat for many wildlife species, including species of conservation concern. Prescribed fire and mechanical tree thinning are the most common tools used to restore these disturbance dependent systems. Numerous studies have examined the effect of restoration on wildlife species; however, few studies have linked restoration management and potential prey abundances to wildlife abundances at restoration sites compared to non-managed forests. Due to recent population threats to bat populations - white nose syndrome (WNS), wind energy, and landscape conversion - there is a heightened need to quantify changes in population demographics during critical life stages. Abundance data can be used to determine if populations are stable, declining, or increasing over time. My dissertation focused on four bat species: northern long-eared bat (Myotis septentrionalis), tri-colored bat (Perimyotis subflavus), evening bat (Nycticeius humeralis), and eastern red bat (Lasiurus borealis), and their insect prey across a gradient of savannas, woodlands, and non-managed forests throughout the Ozark Highlands of Missouri. I estimated abundances during the maternity season during summers 2014-2016 - something that has not been done before in bat ecology.

My study has substantial management and conservation impacts. First, I evaluated abundance models using simulated datasets to determine their utility in bat ecological studies. I provided evidence that the general multinomial Poisson model with removal sampling can correctly estimate bat abundance from simulated repeated mist net surveys, and that the n-mixture model always produced less accurate and often very biased. The 
ability to correctly estimate abundance for a variety of bat species is increasingly important due to ever-present population threats. Accurate estimates of abundance will provide higher resolution estimates needed for population viability and trend assessments. The ability to have increased confidence in abundance estimates and factors that affect species abundances will enable improved conservation practices for species management.

Second, I determined how insect prey abundances were affected by restoration management practices, and habitat changes at sites. I evaluated the effect of savanna woodland restoration (i.e., prescribed fire), habitat, and environmental factors on insect abundances across a gradient of savannas, woodlands, and non-managed forests in my third dissertation chapter. Few studies have made the link from prescribed-fire effects on wildlife, and changes in potential insect prey availability. I found evidence that restoration directly (e.g. prescribed fire) and indirectly (e.g. tree densities by size class) affects insect abundances. Managers planning restoration activities can consider some of the relationships we report if they are concerned about effects on insects. For example, sites burned recently had the lowest Tricopteran abundances, and slowly increased overtime. However, sites with 1 or more fires had greater total insect abundances than those with no fires. Overall, restoration practices did not have lasting negative effects on insects as abundances were temporally dependent on when a site was last burned. Mangers should be mindful that abiotic factors and plot characteristics had more impact in predicting insect abundances at plots compared to a priori restoration hypotheses. 
Finally, I successfully fit abundance models for four bat species using repeated mist-net capture data which has never been done during the maternity season. My dissertation meaningfully contributes to bat conservation and management by providing a tested tool to successfully estimate bat abundances from repeated count data. Accurate estimates of abundance will provide higher resolution estimates needed for population viability and trend assessments. The ability to have increased confidence in abundance estimates and factors that affect species abundances will enable improved conservation practices for species management. In addition, I utilized a hierarchical multi-scale approach to identify factors affecting bat species abundances at sites that emphasizes the importance in understanding how species view the landscape, and the need to use multiple scales in ecological studies. Because bats are species of concern, knowledge of the spatial scales that species are using to select habitat is directly relevant, and ultimately crucial, to species management and conservation plans. My estimated abundances are ecologically reasonable for my geographical region, and highlight the effectiveness of the removal model in bat ecological studies. My supported model covariates for bat abundances can be used as expert knowledge in landscape abundance models, and in models trying to predict how bat species might respond to various climate change scenarios to further inform management and conservation of species. This is especially important for Federally listed species (i.e., the northern long-eared bat). Due to WNS and other threats to bat populations, I recommend studies use my bat capture methods and generate estimates of abundances for species to understand population changes over time, not just for WNS affected species, but for the entire bat community. 
Overall, we found that savanna woodland restoration to positively affect the abundances of eastern red, tri-color, and evening bats in the Ozark region. Eastern red bats had higher abundances at sites with reduced tree densities for all size classes and percent canopy cover, which is a result of savanna and woodland restoration. Evening and tri-colored bat abundances increased at sites burned within the last 6 years compared to non-managed sites or those not burned within 10 years - another management strategy used to restore savanna woodland ecosystems. However, northern long-eared bat abundances at sites was the greatest at sites with high pole and saw timber densities. At the $1 \mathrm{~km}$ spatial scale (patch scale), we found that eastern red and northern-long eared bat abundances were positively related to sites with highest percent forests and percent savanna woodlands compared to non-forest landscape types. Suggesting that managers wanting to maintain bat diversity should consider creating a forested matrix with a mix of non-managed forest stands with high tree densities of larger tree size classes among stands managed for savanna and woodland communities would likely result in a balance in creating habitat for all four focal species of our study. 


\section{VITA}

Kathryn M. Womack was born in Charlotte, North Carolina, and attended public school in Henrico County, VA from Kindergarten through $12^{\text {th }}$ grade. She graduated from Mills E. Godwin High School in 2004. In May 2008, she received her Bachelors in Arts degree in Biology with a minor in Chemistry from Longwood University. Kathryn graduated Magna Cum Laude and completed a 2-year honors thesis on the bat community dynamics in managed pine plantations in the piedmont region of Virginia. One day after graduating, Kathryn moved to Columbia, Missouri to start her fieldwork on her Master's thesis entitled: "Habitat and management effects on foraging activity of Indiana bats (Myotis sodalis) in Northern Missouri. Kathryn graduated with her MS from the Department of Fisheries and Wildlife Sciences at the University of Missouri. Between her masters and dissertation research, Kathryn worked in the Bat Ecology Lab at the University of Missouri under Sybill Amelon. She worked a summer field season in 2012 as a bat ecologist for Davey Tree Company in Ohio and West Virginia. Kathryn started her dissertation research in January 2013 on the effects of savanna woodland restoration on bat and insect abundances in the Ozarks of Missouri. In spring 2014, Kathryn received a certificate in the University of Missouri’s Mentoring Program. In May 2017, Kathryn received her Ph.D. from the School of Natural Resources at the University of Missouri. In June 2017, Kathryn will begin working for the Missouri Department of Conservation as bat ecologist for Missouri, and terrestrial wildlife ecologist for agriculturally dominated landscapes in the Kirksville office. 